Linköping Studies in Arts and Science No. 687

\title{
Sport as a Means of Responding to Social Problems \\ Rationales of Government, Welfare and Social Change
}

David Ekholm

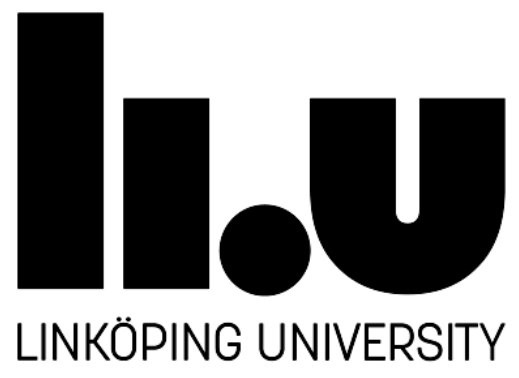

Department of Social and Welfare Studies

Faculty of Arts and Sciences

Linköping University, SE-581 83 Linköping, Sweden

Linköping/Norrköping 2016 
Linköping Studies in Arts and Science • No. 687

At the Faculty of Arts and Science at Linköping University, research and doctoral studies are carried out within broad problem areas. Research is organized in interdisciplinary research environments and doctoral studies mainly in graduate schools. Jointly, they publish the series Linköping Studies in Arts and Science. This thesis comes from the Division of Social Work at the Department of Social and Welfare Studies.

David Ekholm

Sport as a Means of Responding to Social Problems

Rationales of Government, Welfare and Social Change

Edition 1:1

ISBN 978-91-7685-725-0

ISSN 0282-9800

Distributed by:

Department of Social and Welfare Studies

Linköping University

SE-581 83, Linköping, Sweden

(C) David Ekholm

Department of Social and Welfare Studies, 2016

Printed in Sweden by LiU-Tryck, Linköping, 2016 


\section{ABSTRACT}

Sport has been increasingly recognized in social policy as a means of steering social change and as a method for responding to diverse social problems. The present study examines how rationales of social change are formed through 'sport as a means of responding to social problems'. Four research questions are posed: (1) How is it that sport can be thought of and articulated as a means of responding to social problems? (2) How are sport practices assumed to operate as a means of responding to social problems? (3) How are social problems represented when sport is promoted as a means of response? (4) What conduct, subjectivity and citizen competences are shaped within this regime of practice? The study focuses on the government of subjects' conduct, the formation of community and delineation of domains subjected to social change. The gradual shifts in the governmental rationality of the Swedish welfare state provide a framework for the study. Two kinds of empirical material are investigated. Initially, scientific knowledge is analysed; after this, a sport-based intervention, conducted in cooperation between a social entrepreneur, municipality and local sport clubs, is examined. In relation to scientific discourse, research on sport for social objectives would benefit from more theoretically driven constructionist perspectives related to welfare state transformations. In scientific discourse, rationales of social change in sport are conceived of as individual attainment of skills, competences and powers that are presumably transferable to other social spheres. Such discourse represents problems as individual problems. With respect to the sport-based intervention, individual change is promoted by representatives of the social entrepreneur in terms of providing subjects with motivational powers, which are shaped by role models and applied in 'choosing the right track'. By representing problems as risks, avoidance is formed as an individual opportunity. This positions subjects as being responsible for their own welfare and inclusion. Municipal policy makers view the intervention as a way to form community and social cohesion in response to tensions in society. They present sport (and the social entrepreneur) as a way to mobilize and activate civil society - which is associated with the potency of voluntarism, authentic leadership and personal relations based on common identity. Consequently, 
responsibility for responding to social problems is spread and elements of de-professionalized social work are imposed. To conclude, sport is conceptualized as a means of responding to social problems because sport practices are associated with individual agency and with an active civil society and moral community. The technologies and rationality of social change point out 'the self, 'the community' and 'the place' as locations where social change is possible, rather than the whole of society. For instance, the technologies of social change are based on activation and responsibilization of 'the self and of 'the community'. These rationales of social change are based on a critique of welfarist governmentality and of the idea of governing from 'the social' point of view. Arguably, such discourse obscures more profound social reform. The study provides some empirical explorations illustrating how a range of tendencies and mutations in the governmental rationality of the welfare state and of social work are manifested in 'sport as a means of responding to social problems'. 


\section{LIST OF INCLUDED ARTICLES}

\section{Article 1}

Ekholm, D. (2013). 'Research on Sport as a Means of Crime Prevention in a Swedish Welfare Context: A Literature Review'. Scandinavian Sport Studies Forum 4: 91-120.

\section{Article 2}

Ekholm, D. (2013). 'Sport and Crime Prevention: Individuality and Transferability in Research'. Journal of Sport for Development 1(2): 67-78.

\section{Article 3}

Ekholm, D. (in press). 'Sport-Based Risk Management: Shaping Motivated, Responsible and Self-Governing Citizen Subjects'. European Journal for Sport and Society.

\section{Article 4}

Ekholm, D. (forthcoming). 'Responding to Social Problems: Mobilizing the Sport-Based Community'. Submitted manuscript. 


\section{TABLE OF CONTENT}

PREFACE.................................................................................... ix

1 INTRODUCTION .................................................................. 3

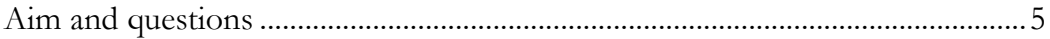

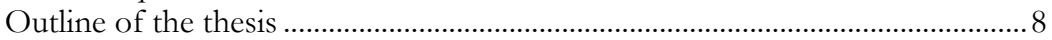

2 THEORETICAL FRAMEWORK ............................................... 11

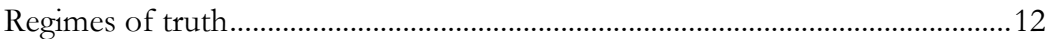

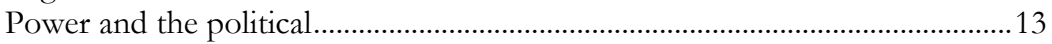

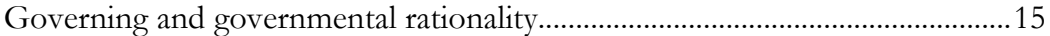

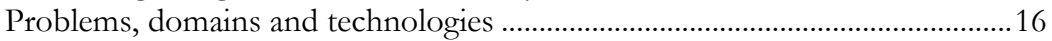

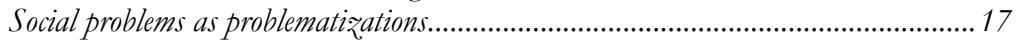

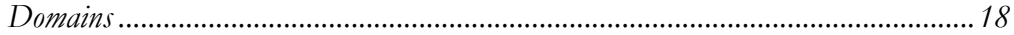

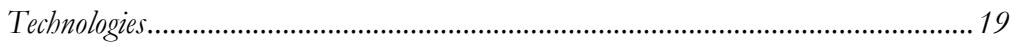

A governmental rationality of social work .........................................................20

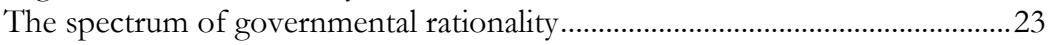

3 IN CONTEXT: WELFARE STATE TRANSFORMATIONS....... 25

Welfarism: governing from 'the social' point of view .......................................26

Social problems, the social domain, social technologies and social subjects ....................27

The social-democratic regime of welfare and governing...............................................29

Advanced liberalism: the possible 'death of the social' ........................................30

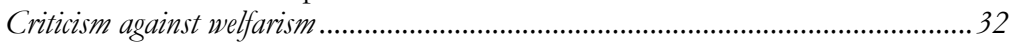

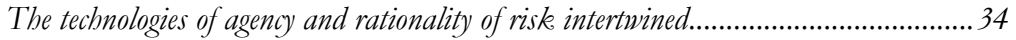

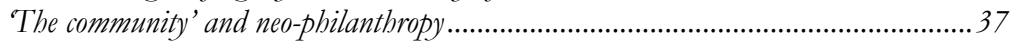

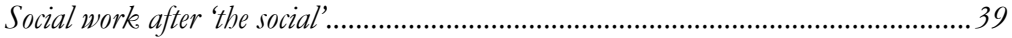

4 IN CONTEXT: SPORT AND WELFARE .............................41

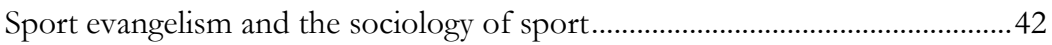

Critical perspectives in research.............................................................................42

An excursion: contemporary illustrations of sport evangelism....................................45

Sport for social objectives: institutionalized practices.......................................49

Youths, problems and a social kind of pedagogy ..............................................50

Intervention practices of social pedagogy ....................................................................50

Youth problems and youth inclusion ....................................................................5 52

Pedagogy and youth inclusion: the lens of governmental rationality ..............................53

De-statization of social work in practice ................................................................54

Situating the regime of practice ..............................................................................56

The rationales of sport for social objectives in Sweden.......................................57

A brief genealogy of sport and social objectives in Sweden ........................................5

Social goods as premise or effect: an analytical distinction .........................................60

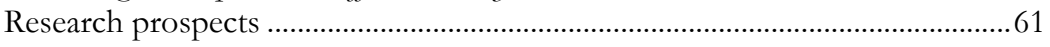




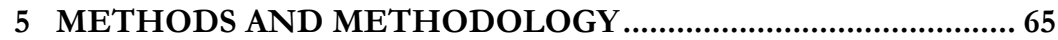

Methodological considerations: an 'analytics of governing' ..................................65

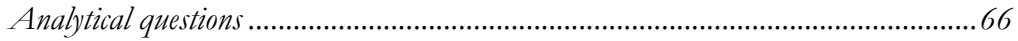

Interpretative strategies.....................................................................................69

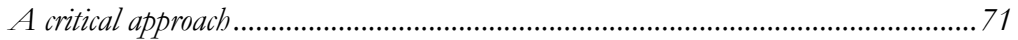

Empirical material examined.............................................................................. 71

The scientific discourse ............................................................................................ 72

Introducing the Sport Program ………………………………………………........ 73

The Sport Program discourse................................................................................... 75

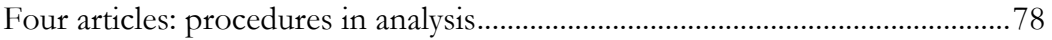

Discussion of methodology.................................................................................... 82

Selection and collection of empirical material ............................................................8

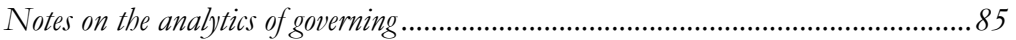

Reflections on the production of knowledge .............................................................. 88

Ethics ……........................................................................................... 90

6 RESULTS AND ANALYSIS: SUMMARY OF ARTICLES ............. 93

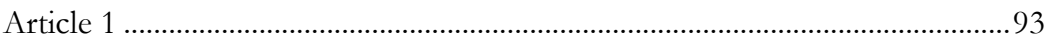

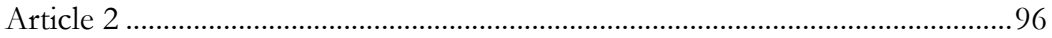

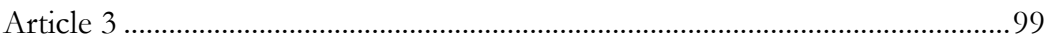

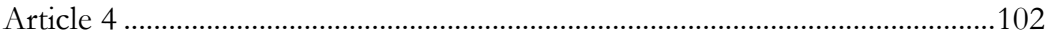

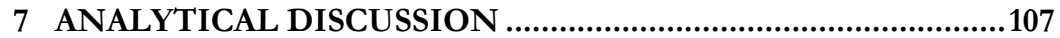

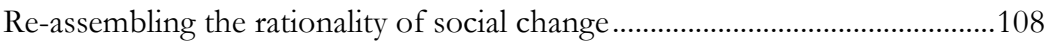

A regime of truth: 'Sport as a means of responding to social problems'.....................108

Fixing the discourse and knowledge of 'sport'.........................................................111

Governable domains: 'the self', 'the community' and 'the place'..................................112

Formation of the activated and responsibilized citizen subject.................................121

Ethical activation and the critique of welfarism.........................................................122

An activating and facilitating role for public welfare ………..................................127

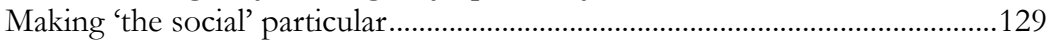

A rationality of social change beyond 'the social' ...................................................130

Questioning 'the social' of social problems and social work ......................................132

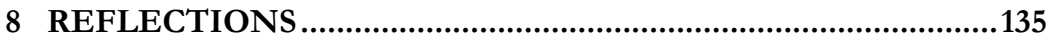

Re-assessing the critical perspective .................................................................135

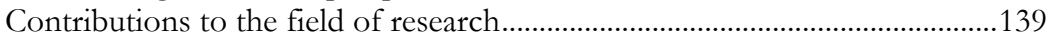

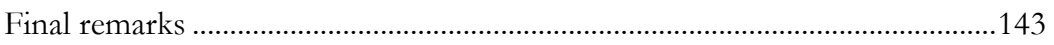

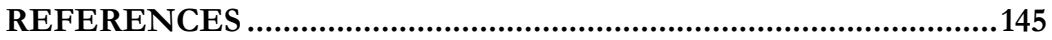

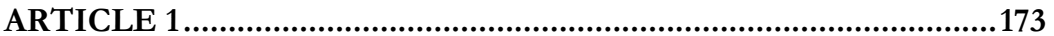

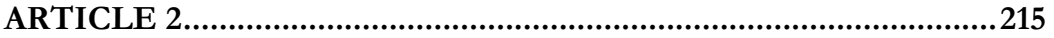

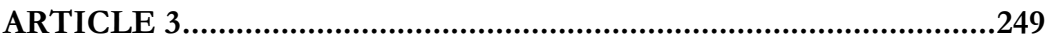

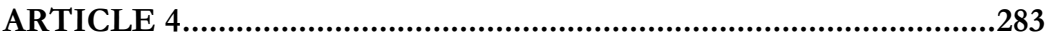




\section{PREFACE}

And I gave my heart to seek and search out by wisdom concerning all things that are done under heaven: this sore travail hath God given to the sons of man to be exercised therewith. I have seen all the works that are done under the sun; and, behold, all is vanity and vexation of spirit.

Ecclesiastes 1: 13-14

Pursuing truth and knowledge is hard travail. Yet one must persist in exploring, seeking and searching for the works that are done under the sun. This thesis explores how truth and knowledge are fixed. It deals with one instance of the formation of the morality and politics of welfare provision. The investigations target - rather than the practices of sport as such - the fixity of truths, the practices of conduct and the formation of moral subjectivity intertwined in the the machinery of welfare provision and social work. It is the means and ends of responding to social problems, the problematizations and rationales structuring these practices, that are subject to investigation. This is an ongoing and continual exploration - to problematize the ideas and truths, the practices and procedures; to trace the rationales and make visible the contingency of reality. However vain or futile, this is my modest contribution.

The thesis is a quest and an exploration. It is the result and a screenshot of learning processes. And learning and exploring are collective experiences. The subject and subjectivity are formed in social processes - facilitated by institutions, structures and conditions beyond comprehension; supported, guided and inspired by so many. Many people have participated in and contributed to the progressions of learning presented in this thesis. However, a few institutions and individuals need to be acknowledged in this joint venture - their participation and contributions have been crucial. I humbly express my great gratitude. And, in truth, this venture was more pleasure than sore travail. 


\section{Acknowledgements}

I am very grateful to the Faculty of Arts and Sciences for showing faith in me and for giving me the opportunity to engage in learning and dedicate this time to exploring the most fascinating dimensions of social life. It has been a real pleasure and a privilege to be involved not only in my own learning as a postgraduate student, but also in the learning processes of students, as a teacher, and in the learning processes of other researchers, as a colleague. Especially, my greatest thanks are addressed to the Department of Social and Welfare Studies (ISV) and the Division of Social Work, which have been my residence for the last few years and have provided the postgraduate education programme and courses.

I am thankful for being given the chance to engage in courses and conferences at Linköping University and beyond. I appreciate the support that has made the exchange of research and learning possible. Courses and conferences have taken me to a variety of places, ranging from Umeå, Malmö, Lund, Karlstad and Stockholm to Riga, Copenhagen, Prague, Oxford, Paris and Los Angeles. Going to these places has not only proven necessary for communicating with the research community, but even more for gaining on-the-spot insights into the social problems and challenges that are faced and the manifestations of social work and welfare interventions that are promoted. In this respect, I would also like to thank the Swedish Research Council for Health, Working Life and Welfare (FORTE) and the Erasmus mobility programme for travel grants. In relation to this, I wish to express gratitude for the chance to be part of the Swedish National Research School of Social Work (RSSW) and the Nordic-Baltic Doctoral Network in Social Work (NBSW).

However, research and learning did not start off at the postgraduate level. I am greatly indebted to teachers and fellow students who have facilitated learning and exploring from undergraduate courses in sociology, pedagogy, political science, history, moral philosophy, social anthropology and ethnology at Linköping University and Umeå University. I am thankful for the schooling I enjoyed as a research assistant at the Department of Public Health and Clinical Medicine at Umeå University. Moreover, I would like to express my gratitude to 
the welfare state in general for providing opportunities for higher education and for enabling postgraduate education as well as supporting my physical and mental well-being and for governing social security. I hope to further this reciprocal relation.

In addition, a diverse mix of people have contributed efforts that I gratefully recognize and appreciate. Most notably, the investigations would not have been possible without the helpful participation of respondents. Their contributions are vast. Their efforts and dedication contribute greatly to community and society. The support and encouragement from Bengt Ekholm, Ingalill Varverud, Matilda Ekholm, Astrid Ekholm and Nancy Varverud have been extraordinary. Additionally, Gunilla Ekholm's pathos and social ethos have stressed the importance of social work. Karin Linnea Matilda Ekholm (1912-2014) lived through a century of development, turmoil and transformation. She was an observer, explorer and teacher. Her quest in research and learning was characterized by curiosity, hard work and structure. I hope to have learned from her.

Per E Gustafsson's contribution has been outstanding. His friendship and generosity are widely recognized; his intellectual creativity, precision and critical thinking have served as guidance and constitute a landmark in research. Sofia Lindström has been a friend and ally for the past few years. I appreciate her presence, her curiosity and openmindedness. Anneli Silvén Hagström, Veronica Ekström, Jessica Sjögren, Nina Åkerlund, Elin Nilsson, Miriam Avorin, Christina Söderberg, Kamila Biszczanik, Maline Holmlund, Jenny Löf, Simon Härnbro and Magnus Wiberg in the $\mathrm{PhD}$ student group have provided terrific academic and social support. Their engagement in courses and seminars as well as at lunches and on coffee breaks is cherished. I am particularly delighted with our establishment of the $\mathrm{PhD}$ Student Association. Lars Wallner should also be acknowledged here for his tremendous contribution to the ISV Research Student Council. Furthermore, Viktor Vesterberg has inspired progression as a forerunner at ISV. I am also thankful to Johan Forsell for introducing me to sociology and hence saving me from political science. I would moreover like to thank the many friends who with 
joined (yet not coordinated) forces have sustained social life outside campus.

In addition, I would like to thank all the colleagues at the Division of Social Work and others involved in the social work programme. Teaching there has been not only a pleasure but also a vital dimension of learning and exploring. In particular, Marie Gustavsson and Anita Johansson have been important. The contributions of Lars Sörnsen, Marie Jansson, Martin Börjeson and Sabine Gruber to our course in Social Policy and the Welfare Society have been beneficial not only to the programme but also to the learning and understanding of social policy and welfare. I likewise owe a debt of gratitude to the students in the social work programme who have engaged in courses and been part of the development and learning experiences. I wish also to thank Anna Pettersson at Campus Norrköping Library for her helpful assistance. I am moreover thankful for the administrative and technical support at ISV and Campus Norrköping (including Karin Kylliäinen, Susana Högne, Ulrika Frisk, Bitte Palmqvist, Niclas Silfverhammar, Hamid Gharakhani and Slave Saveski). Therese Nilsson's support in particular has been altogether special - she is fantastic.

During the postgraduate education, drafts and manuscripts were reviewed and commented on in seminars. From the Division of Social Work, Kerstin Johansson and Gunilla Petersson were regular readers, and their comments and suggestions have had a vital impact on the thesis. Lucas Gottzén, Ingrid Söderlind and Karsten Åström also read and commented on manuscripts in formal seminars. Their efforts are highly cherished. Additionally, I am very grateful for the insightful comments and detailed reading of the manuscript at the final thesis seminar in February 2016. Håkan Johansson, Lund University, was the commentator while Marie Öhman, Örebro University, and Kenneth Petersson, ISV Institute for Research on Migration, Ethnicity and Society (REMESO) - together with Kerstin Johansson, mentioned above - were engaged readers. Their suggestions for clarifications and confirmation that the investigations were on the right track have been of great importance. Furthermore, the range of 
anonymous reviewers of the four papers helped to make arguments clearer and underscore the contributions of analyses.

I have been very fortunate to work with three supervisors during my postgraduate education. I would like to thank assistant supervisor Yvonne Sjöblom for our cooperation (even after she left for the University of Gävle) and for giving me access to her extensive knowledge on youths and social work interventions. Magnus Dahlstedt was the commentator at my mid-way seminar. I was subsequently fortunate to have him as assistant supervisor. His intellectual creativity and innovative approaches have inspired and facilitated learning and exploration. Finally, Dimitris Michailakis has been the supervisor, observing and steering the academic progress, and the tutor, guiding and shaping the learning processes. His careful intellectual craftsmanship, methodological precision and prowess have been an inspiration. He is one of a kind. 
[E]in paar Ideen sollen unauslöschlich, allgegenwärtig, unvergessbar, "fix" gemacht werden, zum Zweck der Hypnotisirung des ganzen nervösen und intellektuellen Systems durch diese "fixen Ideen" - und die asketischen Prozeduren und Lebensformen sind Mittel dazu, um jene Ideen aus der Concurrenz mit allen übrigen Ideen zu lösen, um sie "unvergesslich" zu machen.

Nietzsche, F. (1892), Zur Genealogie der Moral. Eine Streitschrift. Leipzig: Verlog von G. Nauman (p. 46). 


\section{INTRODUCTION}

This thesis deals with how sport is constructed as a means of responding to social problems in scientific discourse and in a particular sport-based social intervention (the Sport Program, onwards referred to as the SP). The study seeks to problematize the construction of the 'regime of practice and truth' - ways of doing things (cf. Dean 2010) and ways of establishing 'true knowledge' (cf. Foucault 1980) - of 'sport as a means of responding to social problems' and to analyse how rationales of social change are formed when sport is used for this purpose.

Over the past few decades, more and more attention has been paid in social policy to the presumed benefits of youth sport participation (Coalter 2007b, 2011b; Collins \& Kay 2014; Heinemann 2006; Houlihan, Bloyce \& Smith 2009; Silk \& Andrews 2012). A regime of practice utilizing sport as a means of responding to social problems is emerging globally (Coalter 2007b; Houlihan 1997, 2011) - and, with special relevance to this thesis, in Sweden (Fahlén \& Stenling 2015; Norberg 2011; Stenling 2015). Social problems such as segregation, exclusion, drugs, violence and crime have been highlighted as serious social policy challenges in times of austerity and social turmoil (Ferguson \& Lavalette 2013; Webb 2006), and responding to social problems in a welfare state context is generally considered to be a goal of modern social work and welfare provision (Parton 1996, Payne 2014; Webb 2006). When an adverse condition is constructed as a problem, something is due to change, and a key aspect of responding to social problems involves steering social change (cf. Rubington \& Weinberg 2011). Accordingly, the ways of producing social change formed and facilitated through sport practices and participation fall within the scope of investigation in this study. The kind of social change involved in social work practice generally concerns pedagogical dimensions that provide individuals with competences for citizenship and inclusion (Philp 1979; Villadsen 2004), and these are displayed in the promotion of sport practices. In considering means and strategies to deal with and even solve social problems and to promote social inclusion in a Swedish context, it is easy to assume (even take for granted) that this is first and foremost a task for social services. Such 
a conception would be highly indebted to notions of the Scandinavian and social-democratic regime of welfare and governing. However, this needs not to be the only and necessary order of social work. Social work may be, and is, conducted by a range of agencies using a variety of means and strategies (for instance involving pedagogy) to deal with and respond to social problems, facilitate social change and social inclusion (cf. Philp 1979).

In this study, the emergence of a formalized sport-based regime of practice in response to social problems is viewed in light of welfare state transformations in recent decades. This trend has been described as a gradual shift in welfare, from a welfarist governmental rationality to one of advanced liberalism (Donzelot 1979; Rose 1999); that has also been the case in Sweden (Dahlstedt 2009; Larsson, B., Letell \& Thörn 2012). The welfarist rationale has dominated - and may still dominate - social work in Sweden, with its emphasis on state-centred interventions conducted by professional social workers. Tendencies of an advanced liberal regime of welfare include less ambitious social risk protection, more selective outreach in welfare interventions, individualization and privatization of problems, an increase in private agencies and institutions involved in welfare provision and governing (Rose 1999; Webb 2006).

With respect to social work, unconventional means of responding to social problems and promoting social change have gained in prominence (Webb 2006) - among such unorthodox features of social work are sport practices (e.g. Lawson 2005). It is in this context of welfare state transformations and changing conditions of social work that expectations of sport practices have been formalized and made explicit by governing authorities (Coalter 2007b; Norberg 2011). Furthermore, the conditions for using sport as a means of responding to social problems have been thoroughly investigated (e.g. Fraser-Thomas, Côté \& Deakin 2005; Sugden \& Yiannakis 1982; Wicks et al. 2007), while the relation between sport and welfare and notions of the social utility of sport for such purposes have been critically assessed and disputed in research, and 
are considered to be based on vague assumptions that sport has an essential purity and goodness (Coakley 2002, 2011a, 2015; Coalter 2011a, 2011b, 2015; Hartmann \& Kwauk 2011; Houlihan, Bloyce \& Smith 2009; Morgan 2013).

The advent of sport as a formalized and explicit means of promoting social change and inclusion in targeting social problems, both as a way of practice and as an object of knowledge, commence curiosity and attention. If it is the case that there is no clear scientific support for using 'sport as a means of responding to social problems', it would then be important to scrutinize how such a regime of practice and truth has been enabled. Even so, when sport is promoted as a means of social objectives, the kind of interventions launched ought to involve specific rationales of social change; consequently, it would then be essential to understand the kind of social change produced and how this is thought to operate in practice. Moreover, since the kind of social change imbued in response to social problems (viewed as a task for the welfare state and social work) involves pedagogical dimensions of equipping subjects with competences needed for inclusion, it is critical to examine what kind of competences this may entail and what kind of citizen subjects are supposed to be shaped according to this regime of practice. In addition, the social problems explicitly highlighted in social policy and addressed by the welfare state and social work need to be represented in a way that aligns with the potential of the solution in response. It is thus crucial to consider the ways that problems may be interpreted and represented when sport is assumed to be a potential response.

\section{Aim and questions}

A certain regime of practice has been sketched out on the basis of 'sport as a means of responding to social problems'; this kind of practice is underpinned by and intertwined within a certain regime of truth about sport utilized for this purpose. In this study, it is both the kind of practice and various knowledges and truths articulated about it (and animating it) that fall within the scope of investigation. 'Sport', in this sense, refers to an object of knowledge and practice (or assembly of practices) enacted as a result of certain knowledge; 
i.e., in this thesis, 'sport' does not refer to specific actors such as clubs, associations or federations. With this in mind, the aim of this study is to examine how rationales of social change are formed through 'sport as a means of responding to social problems'. In order to consider this problem and achieve the above aim, four dimensions underpinning the issue are investigated:

(1) How is it that sport can be thought of and articulated as a means of responding to social problems?

(2) How are sport practices assumed to operate as a means of responding to social problems?

(3) How are social problems represented when sport is promoted as a means of response?

(4) What conduct, subjectivity and citizen competences are shaped within this regime of practice?

The aim and questions are further explored with respect to the theoretical framework and empirical material in the methodology section in chapter 5 as a point of departure for outlining an analytics of governing. There, it is demonstrated how these questions lay the ground for a certain analytical approach that is intertwined with the theoretical framework based on a constructionist epistemology and governmentality perspective. Such a perspective focuses on how ways of doing things are strategic and productive, bringing about social change and social inclusion, and moreover recognizes that this involves certain dimensions of power and politics. This perspective acknowledges power dimensions in forming representations of social problems, practical technologies of response, conditions of inclusion and for shaping the actions, behaviours and subjectivities of citizen subjects (cf. Bacchi 2009; Cruikshank 1999; Dean 2010; Foucault 1991; Rose 1999). The governmentality perspective provides a framework for interrogating the conditions of possibility in terms of discursive constructions as well as historical and political relations that enable the regimes of truth and practice at play. It provides tools for tracing the strategies, rationales, technologies and techniques assumed to be operating in practice to promote social 
change within 'sport as means of responding to social problems'. It also provides concepts for analysing the processes for shaping citizen subjects and for conceptualizing how problems are interpreted and how criteria of inclusion and exclusion are determined in relation (cf. Dean 2010). In addition, the perspective put forth enables a certain understanding of the transformations in the welfare state noted previously. This approach emphasizes the rationality of animating social problems and responding technologies of social change as well as the governing of the conduct of citizen subjects. Most notably, scholars from this tradition have outlined tendencies of how welfarist rationalities of governing are undergoing a gradual shift toward more advanced liberal modes of rule (cf. Rose 1999).

The aim and questions in this study are approached through investigations using two kinds of empirical material. First, the scientific regime of truth produced in research literature is reviewed and analysed. Following this, a specific case of the regime of practice outlined above, using 'sport as a means of responding to social problems' (the Sport Program or SP), is examined. The kind of knowledge produced in statements animating the frames for interpretation and for conducting social work and promoting social change within the intervention is viewed in relation to the scientific discourse produced. The empirical material, in that sense, comprises a complementary variety of statements analysed with one single aim.

Recognizing the formalized expectations that sport practices contribute to social objectives as an emerging regime of practice, approaching this phenomenon in an innovative way of conducting social work, investigating it in the context of welfare state transformation and approaching the means and ways of social change in terms of governing or governmental rationality together constitute an original approach in contemporary studies of social work. Moreover, this approach contributes to the formation of a research field that puts 'sport as a means of responding to social problems' at the centre. Referring to the explicit role of sport in achieving social objectives and spotlighting the Swedish model of welfare provision and the country's context of social work, this 
thesis strives to shed light on and gain further understanding of how new and unconventional forms of welfare provision and social work emerge in the contemporary, transforming welfare state. In this work, 'sport as a means of responding to social problems' can be viewed as an illustrative case containing a multitude of dimensions and tendencies at play. The regime of practice and truth introduced is constructed in this sense as a spectrum for the observation and the problematization of welfare, society and the shaping of citizen subjects.

The thesis contains four interrelated articles. Each article has specific aims and questions related to the general problem and aim of the thesis. Article 1 explores the research agenda of sport for social objectives in the case of crime prevention and seeks to outline problems and perspectives in need of further research. The article highlights the lack of and hence need for research on sport initiatives based on the premise of social goods in Sweden. Further conclusions are that such research would benefit from a theoretically driven constructionist perspective situated in relation to the general development of the welfare state. Article 2 takes such a constructionist approach as its point of departure and seeks to examine the assumptions underlying and facilitating the idea in the scientific discourse of sport as a means of responding to social problems in terms of crime prevention. Article 3 investigates how pedagogical and governing rationales and technologies operate in a specific sport-based social intervention (the SP). In line with this, the aim is to analyse how the youths targeted in the program are constructed as includable citizen subjects. The article also focuses on how problems are represented, made governable and intertwined with the responding solution. Article 4 examines how the inclusion of youths at risk of deviancy and exclusion is enabled through construction of 'the community'. The institutional arrangements and conditions of inclusion are scrutinized with respect to the SP.

\section{Outline of the thesis}

The thesis consists of a frame and four separate articles. The seven chapters in the frame contextualize the four articles and also advance the analysis. 
Chapter 1 introduces the subject, the aim and questions posed as well as declares a theoretical standpoint and provides a justification for this. In addition, the empirical material examined is introduced. All these dimensions are examined in greater detail further below.

Chapter 2 deals with the theoretical framework. Theoretical concepts of truth, power and governmental rationality as well as social problems, domains for intervention and governing technologies are developed in detail. Finally, governing in the sense of shaping the actions, behaviours and subjectivities of individuals and populations is considered in relation to the practice of social work. The strengths and opportunities identified from this perspective are then highlighted and summarized.

Chapter 3 employs a theoretical perspective to arrive at a specific understanding and contextualization of welfare state transformations. In that respect, this development is understood as a gradual shift in governmental rationality. The rationales of welfarism and advanced liberalism are presented.

Chapter 4 contextualizes sport in relation to welfare provision. The chapter seeks to contextualize the study with respect to research on the sociology of sport, social work and youth studies as well as relate these fields of interest to the study of governmental rationality. However, the specific concern is sport's role in achieving social objectives, and most attention is given to developments in Sweden.

Chapter 5 deals with the methodological considerations of the study, the empirical material analysed and the procedures of analysis. First, the analytics of governing are described and the questions posed in the introduction of the thesis are explored in detail in theoretical and methodological terms. In line with this, strategies of interpretation are considered. Second, the two sets of empirical material that constitute the basis of these examinations are presented. The scientific discourse produced in the research literature is explored in articles 1 and 2. Discourse produced in relation to the SP - statements from the social entrepreneur representatives and the representatives of the municipal policy making and administration side of operations - is examined in 
articles 3 and 4 . Here, the SP is also presented in detail as a case of a practice that conceives of social objectives as a premise for setting up the sport practice. Third, the analytical procedures used in the four investigations are outlined. A detailed description is given of how these separate studies relate to each other and align with the overarching theoretical and methodological framework. Fourth, the chapter concludes with discussions on ethics, strategies in the selection of empirical material and reflections on the knowledge produced in the study.

Chapter 6 summarizes the four articles, and important findings are highlighted. The sequence of articles provides crucial analyses and findings for this thesis. Each article contributes to the general aim of the thesis by pursuing various questions presented. In this sense, article 1 is primarily explorative, outlining the direction for the three subsequent articles. Articles 2, 3 and 4 then follow the direction laid out with respect to the two different types of empirical material.

Chapter 7 provides an analytical discussion, expanding on the analysis and findings presented in the preceding chapter. Here, strategies for producing social change within the context of 'sport as a means of responding to social problems' are highlighted. For instance, governable domains constructed are identified, a certain politics of activation and a seemingly shifting role for public welfare are examined at length as key features of the governmental rationality. There is also a discussion of how the advent of 'sport as a means of responding to social problems' raises some concerns about welfare provision and social work at a critical point for welfarist government.

Chapter 8 concludes the thesis with reflections on the critical underpinnings of the study and highlights important potential contributions to research. 


\section{THEORETICAL FRAMEWORK}

In the previous chapter, it was proposed that the advent of using sport as a means of responding to social problems has produced a regime of practice that involves a certain regime of truth. In this chapter, the regimes mentioned are elaborated on in terms of how ways of providing responses to social problems by means of steering social change and of how knowledge and truth about this can be theoretically assessed as governing. The presentation of this theoretical framework has a twofold purpose. It makes visible the theoretical underpinnings that have enabled the articulation of aim and questions posed. It also introduces the analytical framework that has guided the interpretations made of 'sport as a means of responding to social problems'. In addition, this theoretical framework facilitates the assessment of the description of welfare state transformations and the role of sport in welfare provision that is presented in the following two chapters. Based on a shared constructionist epistemology, theory and methods of analysis are intertwined in such an approach. However, in this presentation, they are separated from each other. Viewing social problems, means of social change and the people subjected as constructed in social processes of governing serves as a basis for de-construction and problematization as an approach to analysing ways of government. Methodological considerations and a delineation of an analytics of governing are given in chapter 5. The separation between theory and methods provides clarity in distinguishing between the theoretical basis and how such underpinnings are practically employed in analysing the distinct kinds of empirical material. Furthermore, this separation enables the presentation of a specific perspective on welfare state transformations (chapter 3) and on the role of sport in welfare provision (chapter 4) in close relation to the theoretical underpinnings, before the procedures of analysis are considered (chapter 5).

This chapter contains six sections, each developing key theoretical concepts. First, the concept of a regime of truth is discussed in relation to a specific epistemological approach to knowledge and discourse. Second, the production of truth is viewed as an act of power and thus reveals a political dimension. Here, the specific 
form of productive power in shaping knowledge and subjects is expanded on. Third, power is viewed in terms of governing, and forms of governmental rationality are outlined. Fourth, the concepts of problems, domains and technologies for promoting social change, which are vital for the analytics of governing, are described in detail. Fifth, concepts introduced above are further developed by exploring the process of subjectification (or of producing citizen subjects) in relation to social work. Sixth, in the concluding section, the most notable strengths and contributions of this theoretical approach are highlighted.

\section{Regimes of truth}

In the following investigations, statements made about 'sport as a means of responding to social problems' are scrutinized. From a constructionist perspective, statements are seen as productive, animating reality and its objects (such as problems, domains for intervention, means of change and individual subjects) (Bacchi 2009). According to Foucault (1980) and supported by Rose (1999), statements articulated with claims of truth constitute discourses about reality. When certain knowledge is given recognition, regimes of truth are constituted. The established ways of talking about things and objects that gain the status of truth make these objects manifest in a certain way and enable them to be thought about and acted upon. As a result, the objects animated are made governable. For them to acquire the status of truth, scientific production of knowledge has been found to be of particular importance. It is in scientific discourse that is demanded and incited by policy-making institutions, that truth takes shape (Foucault 1980). Consequently, regimes of truth are produced in social processes involving confrontation and struggle between agencies and authorities. Different forms of knowledge may compete in gaining the status of truth. Accordingly, truth is not stable or fixed but contingent, and should therefore not be taken for granted (Dean 2010; Foucault 1980; Rose 1999). In this respect, the regimes of truth and practice of 'sport as a means of responding to social problems' are historical, cultural and political constructs. Constructing truth, animating the world and its objects - such as social problems and citizen subjects - is an act of power in the sense that a certain representation is 
enforced in confrontation and competition with other representations and in the sense that it guides and enables forms of action (Foucault 1980). Constructing social problems and citizen subjects in certain ways is essential in steering processes of social change. Consequently, representations of the world and its objects need to be assessed as constructs underpinning governing and accordingly must be problematized and de-constructed in analysis. In this sense, the perspective promoted imbues a critical approach to power, knowledge and truth that is taken for granted (Dean 2010).

\section{Power and the political}

Truth and knowledge thus render the world and its objects visible in a certain way and facilitate certain ways of action that involve the exercise of power (Foucault 1980). In Foucault's lectures on governmentality (1991, 2009, 2010) and other works (1979), three prototypical ways of conceiving of and exercising power could be distinguished: 'sovereign law', 'discipline' and 'bio-politics/security' (Raffnsøe, Gudmand-Høyer \& Thaning 2014). This categorization, however, is not the central point here - slight variations in these categories may occur (cf. Hewitt 1983; O’Farrell 2005; Walters 2012). Yet the categorization is highlighted because it aids in comprehending and providing a perspective on the productive dimension of power: the power that is concerned with producing the future, knowledge, life and subjectivity. Sovereign law is characterized by prohibition, repression and restrictions from a sovereign and centralized body of power (i.e. the absolutist king), delimiting the freedom and action of subjects. This is a form a repressive power that says 'no' and that penalizes by taking away life and property. Discipline is characterized by prescriptive institutions that are set up in order to produce normalization. This could be done through threats of punishment and repression, but also via schemes of surveillance that construct individuals as subjects of observation and self-reflection (cf. Foucault 1979). Accordingly, discipline involves forms of repressive power, limiting the freedom and action of subjects, but also productive power, shaping the actions and behaviours of subjects. Bio-politics/security is a form of productive power, facilitating and steering the freedom and action of subjects. 
It is conductive of subjects' actions, guiding and shaping the subjects' conduct through productive technologies and forming subjectivities. It is the kind of power that says 'yes', that shapes and guides the will of the subject and governs by providing life and its necessities. These kinds of rationales of power not only react to what has happened but also take into account anything that can happen; they bring the future into the present and take security measures to avoid potential dangers; they produce life (bio) to steer populations and individuals toward future prosperity and safety. Such an exercise of power is conceived of as governing (cf. Foucault 1991). This form of power is a product of the Enlightenment and of modern as well as liberal society (Foucault 2009; Rose 1996a). Based on scientific knowledge about social and human life, modernity made it possible to control and govern human life - to produce actions, behaviour and conduct of individuals and populations (Rose 1996a). In that sense, bio-politics can be thought of as a modernist endeavour in planning and steering life and the future (Cruikshank 1999; Rose 1999). The distinct ways of exercising power outlined here should not be perceived as epochal characterizations, with one substituting for another in historical progression, but rather as shifts of emphasis in different times (Dean 2010). The distinctions between these forms of power are not clear-cut; they co-exist. However, the distinctions are analytically helpful.

The kind of productive power of modern society described above has been referred to as liberal rule (Barry, Osborne \& Rose 1996; Burchell 1996). In this sense, liberalism does not refer to a historical period or even an economic doctrine or an ideological set of philosophical ideas about rights and freedom, but rather to a way of regulating sovereign rule. Certain domains emerge that demarcate the outreach of direct political power - for instance, making 'the state' distinct from 'civil society' (Burchell 1991, 1996; Gordon 1991). Moreover, demarcations are made between what is conceived of as political and non-political domains of state power, for instance markets, families and civil society: liberalism enables the notion of a non-political civil society. Such demarcations are contingent and continually renegotiated. However, the theoretical perspective promoted here considers any such demarcations as contingent and 
questions any delineation between political and non-political domains (Barry, Osborne \& Rose 1996; Cruikshank 1999; Gordon 1991). Because power relations are assumed to be present within all spheres of human and social life, "it makes no sense to speak of 'the political', 'the social', 'the private', and 'the public' as separate domains" (Cruikshank 1999, p. 5). The political is not limited to the domains where power relations are explicit and visible; political conflict is as ubiquitous and productive in legislature as behind the bedroom door (Cruikshank 1999). Seemingly non-political domains are noted to be political and imbued with power relations in this sense.

\section{Governing and governmental rationality}

Governing is the concept of power that illustrates the productive side of bio-politics/security characteristic of liberalism and modern society. It refers to any rational and calculative activity performed by any agency that seeks to shape the conduct of populations or individual subjects, broadly defined as the "conduct of conduct" (Foucault 1982, 1991). Conduct, in the first instance, means "to lead, to direct or to guide" (Dean 2010, p. 17), and in the following instance it refers to "our behaviours, our actions and even our comportment" (Dean 2010, p. 17). This means that government does not refer to the administrative and legislative power of the state (or any other distinct institution or authority for that reason); instead, it refers to an "activity that consists in governing people's conduct" (Foucault 2010, p. 318) by shaping the subjects' actions and behaviour. Such governing targets the potential behaviour and actions of other people - "to govern, in this sense, is to structure the possible field of action of others" (Foucault 1982, p. 790). Moreover, it is noteworthy that such governing is viewed as rational, calculative and strategic - that it involves means and ends of social change (Dean 2010; Rose 1999).

Such an approach to power and governing presupposes a conception of freedom - it is the freedom of behaving and acting as individual subjects that is directed and regulated. In this sense, freedom is acted upon, regulated not primarily by means of repressive restrictions but through productive directions, guidance 
and incentives (Dean 2010, Foucault 1982, Rose 1999). Individuals are conceived of as subjects in a twofold sense: both subjected to power and yet self-conscious and active in exercising freedom (Foucault 1982). Productive power recognizes and acts upon the subject's identity and individuality and, in that sense, constructs the subject of power as an individual with action capacities and a certain kind of freedom (Foucault 1982). This perspective undermines the idea that "power can be perceived only as the antithesis of freedom" (Cruikshank 1999, p. 21); power is indeed productive of freedom.

Different ways to conceive of directing, guiding and shaping the behaviour and action of individuals and populations are referred to henceforth as governmental rationality (Gordon 1991), rationales of governing (Dean 2010), governmentality (Foucault 1991) or even political rationality (Miller \& Rose 1990). Identifying distinct ways of governing as rationales means that they are seen as containing ideas of means and ends (Gordon 1987; Miller \& Rose 1990) - governing "operate[s] according to a certain rationality" (Rose 1999, p. 25). Such a rationale may, however, not necessarily be visible or explicit to the governing agencies. No matter how liberal, totalitarian, subtle or barbaric they seem to be, governing practices are aimed at guiding and shaping the conduct of individual subjects and populations, and they do so according to a specific rationale. Such rationality is embedded in regimes of truth that define problems, means, ends and subjects of social change (Dean 2010; Rose 1999). Knowledge about problems, means, ends and subjects of social change constitute an epistemological form of the regimes of truth; moreover, it is important that governmental rationality contains a moral form concerning legitimacy and principles of authority, distinctions between right and wrong or desirable and undesirable (Rose \& Miller 1992; Rose 1999).

\section{Problems, domains and technologies}

The production of truth about problems, domains for intervention, means (technologies) of social change and individuals and populations underpins governing. Problems, domains, technologies and subjects should not be viewed as mutually exclusive categories; instead, they are overlapping and intertwined. They are concepts 
used to make visible different dimensions of governmental rationality.

\section{Social problems as problematizations}

'Social problems' are a key concept in the following studies because sport is considered a response to this kind of phenomena. There are a wide range of theories about and definitions of social problems. Different perspectives on what constitutes social problems vary in terms of what types of factors are assumed to cause social problems, under what conditions problems emerge and develop, how harmful the consequences are and, lastly, what types of responding solutions are promoted (Rubington \& Weinberg 2011). Among others, Rubington and Weinberg (2011) identify a range of perspectives on social problems, from pathological to critical and constructivist perspectives; Sullivan and Thompson (1994) highlight other major perspectives (functionalism, conflict theory and interactionism). Challenging the dominant objectivist, structuralist and functionalist perspectives, Spector and Kitsuse (1987), Loseke (2003) and Best (2013) promote a social constructionist perspective on social problems. They highlight the subjective claims-making activity of framing conditions as social problems, noting that there is no essential, objective quality in social conditions that constitutes a social problem. All these perspectives share the view that problems are defined in relation to some kind of external intervening and responding means or solution - something is bound to be changed: hence, social problems. Although this thesis adheres to a constructionist epistemology, it does not smoothly conform to the perspective of social construction of social problems. From a governmentality perspective, Bacchi (1999, 2009) notes that solutions are not only responses to social problems but merely constitutive of problem representations. This represents a thorough criticism of the constructionist approach to social problems, that social problems cannot be constructed through claims about certain conditions in society in the absence of social policy or social work interventions; instead, problems and solutions are intertwined, assembled and constitutive of each other. In this sense, social problems are represented and animated by performative acts and statements of social policy (Bacchi 1999, 2009). 
From this point of view, the process of constructing conditions as problems is called problematization (Bacchi 2009, 2012; Foucault 2004). The term emphasizes how problems are constructed in a social process, producing objects and conditions viewed as needing change, making them manifest in a certain way, accessible and ultimately governable. Social policy, means of response and rationales of governing are instead seen to be constitutive of problem representations (Bacchi 1999, 2009). In other words, problems are represented as depending in a certain way on how the means of response are promoted (Bacchi 2009; Foucault 2004). Statements concerning social policy and governing give shape to problematizations more than address them (Bacchi 1999, 2009). This also means that governing practices and technologies are intertwined with problematizations (Bacchi 2009) - "[g]overnment is a problematizing activity: it poses the obligations of rulers in terms of problems they seek to address" (Rose \& Miller 1992, p. 181). In the following studies, crime and segregation are problematized conditions in society that constitute two instances of social problems. They are, however, shaped and made visible in a range of ways and intertwined with (as well as animated by) conceptions of sport as a means of intervention and of social change.

\section{Domains}

Domains are considered platforms that interlink problematizations with technologies (or means) and subjects (or ends) of social change. Domains are the "abstract spaces" (Rose 1999, p. 31) that are constructed as hosts for certain problematizations and where technologies for governing social change can be performed (Dean 2010). These kind of spaces could also be referred to as territories of governing (cf. Rose \& Miller 1992; Rose 1996b). It is important here that domains are constituted by the problematizations and technologies of social change linked to them. Considered abstract spaces, they are discursive formations constructed through social processes in statements about problems and solutions. Constructing these formations, spaces, territories - domains - for intervention and social change, as containers of problematizations and responding technologies, involves animating certain aspects of society and human life and making them distinct from others. Rose 
(1999) compares the construction of governable domains with the work of a cartographer: making spaces and objects presentable, representative and visible with the aim of making the domain controllable as well as "docile and amenable" (Rose 1999, p. 36) for governing interventions. These discursive formations, called domains, can be presented, for instance, as geographic spatializations (i.e. 'the place' in article 3), institutionalized practices (i.e. the Sport Program in articles 3 and 4) or abstract platforms for organizing solidarity and inclusion (i.e. 'the social' and 'the community' in chapter 3). The fact that such domains are discursive formations that take the shape of a geographic place, institution or space for solidarity and inclusion does not make them any less real than anything else. They become real because they are acted upon and conceived of as real. To illustrate: 'the social', presented in chapter 3 , has had a profound significance for the emergence of the modern welfare state and for the notion of social work because it is a domain where problems are collectivized and technologies targeting the whole of a population could be performed. 'The place', considered at length in article 3 and in chapter 7 , is the scene of the Sport Program and a discursive domain animated as a geographical spatialization formed to host problematizations of risk and social exclusion as well as technologies of agency and empowerment schemes. In this sense, domains are integral parts of the regimes of truth that enable certain practices and ways of governing.

\section{Technologies}

The means for realizing social change and governing the conduct of subjects (in response to social problems) are called technologies (Rose 1999). A common sense understanding of technology would suggest that it is an assemblage of knowledge, technical mechanisms and techniques concerned with producing a certain outcome (Rose 1999). The "technologies of government" are the precise action tactics that seek to make political rationality a reality and produce real effects (Miller \& Rose 1990, p. 7). In line with this, technologies of governing are the knowledges and techniques concerned with producing and shaping (conducting) the conduct of individual subjects and populations (Rose \& Miller 1992; Rose 1999). Such 
technologies can find their form in social work, in sport practices or in any other kind of social activities. Because governing is the activity that aims to produce and shape the actions and behaviours of those subjected, in this sense, human beings are seen as being technologized (Barry, Osborne \& Rose 1996). Human beings, their actions, behaviours and subjectivities are the product and outcome of (bio) power (Rose 1999) and human capacities, competences and subjectivities are "inevitably and inescapably technologized" (Barry, Osborne \& Rose 1996, p. 13). This recognition, however, is not a point of departure for a normative critique of power which assumes that the technologized human is an inhuman construct or an antiethical production that deviates from nature and authenticity; instead, as Rose (1999: 54) argues, subjectivity and individual willpower are "the resultants of specific configurations of power, certain technological inventions" - productive power. In other words, it is not meaningful to speak of a human authenticity other than that constructed, produced or technologized. In this respect, the technologies of power and governing are inevitably intertwined with political rationales, regimes of truth and ways of posing problems and responding with means of social change (Barry, Osborne \& Rose 1996).

\section{A governmental rationality of social work}

As was noted in the introduction and demonstrated above, social work involves responding to social problems by steering social change and promoting social inclusion. The previous section dealt with the construction of problems, domains and technologies of governing. This section explores the process of subjectification that shapes (or technologizes) subjects and subjectivities (and, in turn, populations) as they are staged within the area of social work. In the following quote, Donzelot (1979) proposes that social work practice needs to be considered in relation to three interrelated dimensions: the judicial, the psychiatric and the educative. The most notable dimension (for this study) is the educative - the pedagogical - because it concerns the subtle processes of productive power in shaping and guiding the conduct of subjects and forming subjectivities. The social kind of pedagogy dealt with here concerns social change and social work practice that seek to provide presumably deviant, 
excluded or at-risk subjects with competences and subjectivities that enable social inclusion. Accordingly, this is the focal point of understanding the "socially decisive effect" of social work focusing on how it produces subjects and subjectivities.

We must cease asking, What is social work? [...] Instead, we should question social work regarding what it actually does, study the system of its transformations in relation to the designation of its effective targets. [...] In short, we must try to understand the socially decisive effect of social work from the standpoint of the strategical disposition of the three agencies that compose it: the judicial, the psychiatric, and the educative. (Donzelot 1979, p. 98-99)

In his seminal work on the genealogy of social work, Villadsen (2004) takes this proposition from Donzelot (1979) as a point of departure, but further draws on Philp (1979) and Cruikshank (1999) to highlight the pedagogical dimension of shaping included and integrated citizens as constitutive of social work practice. Villadsen (2004) elaborates on the three dimensions considered above: the judicial dimension represents citizens as subjects of judicial and formal rights; the psychiatric dimension represents citizens as psychological subjects and aims to explain behaviour, actions and problems through psychological diagnosis. But these dimension are not in the foreground of this study; instead, the focus is on the educative and pedagogical dimension of social work. This pedagogical dimension represents clients and citizens as social subjects and concerns the competences needed for inclusion in society; additionally, it concerns the pedagogical processes of social change through which citizens are equipped with or acquire these competences. To approach the pedagogical dimension, Villadsen (2004) draws on Philp's (1979) observation of constitutive discourses of social work. According to Philp (1979), social work aims to shape individuals that deviate from dominant norms of society into included, or includable, citizens. In that respect, social work needs to consider social change as a potential for individuals (and reject psycho-pathological problem representations). Accordingly, the conductor of social work (i.e. a social worker) is a mediator between the normal majority and the targeted groups and individuals subjected to welfare and social work interventions that 
facilitate social change. In line with Cruikshank (1999), Villadsen (2004) conceives of social work as technologies for shaping individual citizens made ready for inclusion. In this respect, Villadsen (2004) notes that social work practice is intimately intertwined with notions of free, autonomous individuals both as already existing and as something that needs to be shaped through various pedagogical technologies. With respect to the pedagogical dimension, social work deals with practices of subjectification shaping the actions and behaviour of subjects by producing subjectivity - and this is considered the strategy of producing subjects made ready for social inclusion. Setting up technologies for equipping individual clients and targeted groups and individuals with competences and constituting subjectivities is decisive for social work (Villadsen 2004). Here, subjectification is treated as the process of producing subjects, their subjectivities and modes of behaviour and action (cf. Cruikshank 1999; Rose 1999). It is a form of bio-politics "that promotes rather than represses subjectivity, power that produces and relies upon active subjects rather than absolute subjugation"; instead of repression, power "operates to invest the citizen with a set of goals and self-understandings, and gives the citizen subject an investment in participating voluntarily in programs, projects, and institutions set up to 'help' them" (Cruikshank 1999, p. 41). To reiterate, from this perspective the subject is considered both as subjected and as active, self-conscious and a subject of will-power (cf. Foucault 1982). To distinguish the process of subjectification (as a way of productive power) from subjection (as a way of subjugation and repressive power), it presumes that subjects are active and compliant in their own governing and conscious - and self-reflective - of their own behaviours and actions (Cruikshank 1999).

Following Cruikshank (1999), the term citizen subject is used to illustrate how included citizens are made and produced in a process of subjectification; the term is likewise used to illustrate that any delineation between subjects and citizens, deriving from normative democratic theory which signals that the former are passive and subjugated while the latter are active and deliberated, is rejected. The effect of technologization and subjectification - individual subjects, 
their subjectivities and by extension the population - in this sense becomes inseparable from power and governing: the subjects, their souls, subjectivities and selves, are the very product of power (Barry, Osborne \& Rose 1996; Rose 1990; Rose 1999). In that respect, the 'social citizen' stands out as an important concept. Becoming an included (or includable) citizen (citizen subject) would, in this sense, mean being empowered with capacities and competences needed to formally enjoy or to substantively be able to participate in democratic matters (Cruikshank 1999) as well as exercise the social rights that the state may guarantee (cf. Donzelot 1988; Marshall 1950). Consequently, being offered and enjoying formal rights of education or social insurance would not be enough for social inclusion; welfare provision and social work also need to provide subjects with powers to substantively be able to participate in society and actively exercise their rights, for instance, of freedom (Cruikshank 1999; Marshall 1950). In line with Donzelot (1979), governing by means of shaping actions, behaviours and subjectivities and making citizen subjects includable would be what social work actually does, and accordingly that would be the object of examination in studying social work. The next chapter further develops the different rationales for doing social work and providing welfare, called welfarism, and what is known as advanced liberalism.

\section{The spectrum of governmental rationality}

It was noted that the theoretical framework and the concepts presented in the introductory paragraphs of this chapter primarily facilitate three things. First, they enable the specific representation of the research problem articulated in the aim and questions posed. Second, they are considered to provide a toolbox of concepts for an analytical approach presented in a later chapter. Third, they allow access to a specific theoretical understanding of welfare state transformations in recent decades, with a focus specifically on the shifting rationalities of welfare provision and government, that is, the context and background for the regime of practice explored. With respect to these concerns, it is reasonable to highlight some of the benefits and contributions enabled by this approach. Most notably, the approach recognizes the contingency of power and 
makes manifest how power operates in the production of knowledge and in underpinning technologies that shape the conduct of citizen subjects. It makes visible how this kind of power and governing is ever present in the practices and institutions of social work aimed at social change and inclusion. In this sense, the perspective provides concepts for ensuring that the processes of social change are rational, with means and ends that can be steered and controlled. More explicitly, the approach enables an analysis of power specifically designated for the arenas and domains outside formal politics. Taking into account the idea of productive power, this perspective allows the observation of the operations of power and governing beyond the domains of sovereign law and of repressive operations of power; it allows observation of how power operates more subtly in the liberal, modern society through the production of life and by providing the freedom of subjects while at the same time steering their conduct. The approach also provides tools for examining how knowledge (and frames for interpretation) and subjects are produced as effects of power and thus conceptualizes all the arenas and domains in which the effects of power may be traced as part of the political field. In that sense, the demarcations between the fields of formal politics and non-political arenas are transcended - even eradicated. In turn, this allows for scrutiny of politics, political action and social policy in arenas that are not politically overt. Here, the focus is on how politics is made, acted out and conducted in the everyday practices of sport participation that form a governmental rationality of social change. Such an analysis would, in Cruikshank's words (1999, p. 5), "resist the temptation to locate the political only where there is contestation or overt relationships of power". Instead, she argues, analysis of power relations and acts of political needs to be traced specifically to wherever they do not seem to be clearly visible and where truths are not contested. 


\section{IN CONTEXT: WELFARE STATE TRANSFORMATIONS}

Welfare state transformations have been presented as a background and framework for examining the emerging practice and truth about 'sport as a means of responding to social problems'. In this chapter, welfare state transformations are presented from a specific theoretical perspective, in which changes are viewed as a gradual shift in governmental rationality (cf. Rose 1996a, 1996b, 1999, $2000 \mathrm{a}, 2000 \mathrm{~b}$ ). This means that ways of governing social change, of shaping the actions and behaviours of individual subjects and populations, and of providing welfare have been tuned according to two distinct rationales - welfarism and advanced liberalism - and that there is a shift in relative weight taking place from the former to the latter. Such a gradual shift entails modifications in how problems are represented, how the domains of interventions are formed, what technologies and techniques are used to promote social change and what subjects and subjectivities are shaped. However, the two rationales delineated should not primarily be conceived of as historical epochs, one succeeding the other; instead, they comprise two distinct rationales that coexist and overlap, but compete. These two overarching governmental rationalities are presented in this chapter. Roughly, welfarism can be distinguished by its emphasis on governing interventions that target the conduct of the wider social collectivity which are performed directly by state-centred agencies; advanced liberalism can be distinguished by its emphasis on governing interventions that target the conduct of individuals' actions and behaviours which are performed by a plethora of agencies at a distance from the state. In accordance with each distinct rationale of welfare provision and governing, social work as an instance of responding to social problems is performed and conceived of in different ways. As the welfare state is transmuting, so is social work.

In this chapter, the context for the analyses is presented. What follows are empirical findings made by scholars that have been developed in light of governmental rationality. It is important to provide a comprehensive account of the theoretical understanding of the emergence, sustainment and transformations of the welfare state in order to tackle the aim and questions as well as grasp the 
analysis, findings and discussions in this study. The thesis considers the gradual shift in balance of governmental rationality, with a specific focus on the mutation or particularization of 'the social', to enable the advent of 'sport as a means of responding to social problems' in the specific way that will be described later.

\section{Welfarism: governing from 'the social' point of view}

The welfare state has been described by Rose (1996b, p. 328) as a way of doing government "from the social point of view". By this he means that 'the social' domain gained recognition over competing forms of solidarity and inclusion based on, for instance, family relations, religious beliefs or regional belonging. In this section, the notion of 'the social', which has been so essential to understand social work, will be elaborated on and related to the governmental rationality of welfarism. To introduce this relation, the following quote from Parton (1996) characterizes welfarism and social work as a product of modernity.

The establishment of modern social work was a small, but significant, element of the 'welfarist' project as it developed in the twentieth century [...]. Social work, in its modern emergence in the context of welfarism, was imbued with a considerable optimism, and it was believed that measured and significant improvements could be made in the lives of individuals and families by judicious professional interventions. (Parton 1996, p. 7-8)

Social problems, social change and social work presuppose a certain conception of 'the social'; accordingly, such a conception seems to be instilled in welfarism and modernism. Social problems and responding means of interventions, methods or solutions involving social change are generally noted to be the mission of social work practice and, accordingly, acknowledged as being at the core of social work research (cf. Brante 2010; Gredig \& Marsh 2010; Johnsson \& Svensson, K. 2005; Meeuwisse \& Swärd 2007; Parton \& Kirk 2010; Payne 2014; Shaw et al. 2010; Soydan 2012). Guided by modern notions of reason and progress, welfarism is associated with the view that "social problems could be overcome via state intervention by professional experts with social-scientific knowledge 
and technical skills" (Parton 1996, p. 8). The ambition in this section is to outline some important features of welfarism and highlight the importance of 'the social' in relation. This section takes a conceptualization of 'the social' as a point of departure. First, a description is given of how the notion of 'the social' is decisive in determining problems, domains, technologies and subjects of welfarism. In relation to this, the concepts of risk and security are explored. Second, a presentation is given of the specific way of governing and providing welfare in Sweden from the social point of view. This presentation focuses on the social-democratic welfare regime and the concept of social engineering.

\section{Social problems, the social domain, social technologies and social subjects}

The emergence of welfarism - or "government from the social point of view" (Rose 1996b, p. 328) - has been interpreted as a reaction to a set of shortcomings of the laissez-faire liberalism of the late 1800s (Donzelot 1988, 1991). Modern, industrial capitalism allegedly gave rise to social problems, risks and fragmentation which entailed, above all, poverty, uncertainties of employment and social security (Donzelot 1988, 1991). These were problems that philanthropy and moral disciplining (of the urban labouring class) could not address (Rose 1996a). The welfare state, based on modern ideals of reason and progress (and of bio-politics/security), was assumed to offer a solution to the problems and risks imbued in capitalism (Donzelot 1991).

In his genealogy of the welfare state, Donzelot (1988) depicts 'the social' as a domain of collective solidarity and security (beyond the family and religious or regional community). Problems and risks were conceived of as consequences of growing labour division and advanced capitalism. As a result, the emphasis was not just on individual responsibility but also on the notion that people were interdependent in their exposure to problems. Welfarism thus involves conceiving of problems of poverty, insecurity, exclusion and crime as more than problems of individual morality (or lack thereof), instead focusing on how such problems can be grasped as consequences of social structures (Dean 2010). Consequently, 
problems and risks are recoded in name of 'the social' (Donzelot 1979, 1988; Rose 1996b, 1999).

Risk is a term used to describe potential dangers and events. This means that risks are not real in the sense that they constitute objective conditions in society, they are representations of (ways of describing) reality as problems and potential dangers in order to make them calculable and governable (Castel 1991; Dean 1998; Ewald 1991). In this sense, risk targets the uncertain future and attributes potential dangers and hazards to it (Ewald 1991; Rose 1999). In Rose's (1999, p. 118) words, the notion of the "'social' implied a kind of anti-individualism: the need to conceive of human beings as citizens of a wider collectivity" beyond direct personal relations. In line with this, social citizens are protected from risk and provided economic security through collective insurance schemes, which spread risk and create a sense of social solidarity and social cohesion. Consequently, individual subjects are conceptualized as part of an interrelated and interdependent collectivity (Donzelot 1988, 1991). Social security - alongside, for instance, education - is viewed as a social right under welfarism (Esping-Andersen 1990; Marshall 1950).

Accordingly, technologies of social change would be aimed not directly at the conduct of individuals; rather, the conduct of "society as a whole" could be addressed (and redressed) through social reform (Cruikshank 1999, p. 6; Donzelot 1991, p. 173), producing the fitness of a population (Rose 1999). Moreover, because social insurance, social solidarity and social work are viewed as different types of protection from risk and from problems attributed to the capitalist market economy, 'the social' domain represents a domain separate from 'the market' (or the economic domain), where instead the freedom of individual choice, contracts and responsibility are core rationales (Donzelot 1988). To conclude, the governmental rationality of welfarism involves socialization of problems and technologies that target the whole collective population and form a social citizen subject imbued with social solidarity and cohesion. 


\section{The social-democratic regime of welfare and governing}

Three regimes of governing and welfare provision were distinguished by Esping-Andersen (1990, 1999). It is important to mention them here because of the specific characteristics of the Swedish social-democratic model that provides the context for the following studies. A liberal regime was characterized by a moderate state power, individual responsibility for risk insurance provided in the market and selective, residual and limited social interventions targeting those with special needs (those at risk). This constitutes a relatively low level of socialization of problems and risks, instead emphasizing individual responsibility and market solutions (EspingAndersen 1990). A conservative regime was characterized by a subsidiary state power, where the state's role was to support the family, church or civil society in providing welfare and managing risk. This involves relatively poor socialization of problems and risk (Esping-Andersen 1990).

Welfarism and governing from the social point of view perhaps find their clearest form in the Scandinavian (and Swedish) socialdemocratic regime (Esping-Andersen 1990). The context of this regime, of course, serves as a focus in the thesis because the mutations and tendencies in the governing rationales of this particular regime are subject to observation, with respect to sport emerging as a means of responding to social problems in Sweden. Welfare provision is considered to be universal; it covers the broad population (is not limited to those with special needs) and emphasizes equality and generally high standards of living (instead of basic protection). This is thought to contribute to universal solidarity and social cohesion between citizens and between classes. In essence, the state takes on responsibility to protect citizens from dependence on the labour market, the family or community, guaranteeing individual emancipation (Trägårdh 1990). Important aspects that highlight modernism and concerns about the future are a focus on prevention and on social engineering. They include organizing society in a way that prevents problems from arising for instance, by providing youths with meaningful leisure activities, promoting good behaviour and eliminating bad conduct or passive lifestyles (cf. Petersson, K. 1997) or through institutions and 
prevention programmes formed under the Swedish Social Services Act (cf. Sahlin 2000). In addition, social engineering - based on scientific knowledge and conducted by experts who hold such knowledge - connotes the technological production (the technologization) of social relations, individuals and populations, which leads to a presumed improvement of the people (Larsson, B., Letell \& Thörn 2012). This is one of the most significant features of the social-democratic regime and its ways of carrying out social work. Hirdman (2000) spotlights the utopian ambition of the Swedish welfare state to engineer people's lives, which aims to control and plan not just the labour market and social policy, but the whole of society and to protect people from risk and problems of commodification (Hirdman 2000). In that sense, political steering and planning are not aimed directly at the conduct of individual subjects; however, steering and planning society, forming institutions, would result in engineering a certain kind of social citizen. Relative to the statist notion of governing that characterizes welfarism and the social-democratic regime, it is worth mentioning Sweden's strong consensus culture, of involving social movements, civil society and even market-based agencies in central government bodies and administration. Such corporatism highlights a strong governance tradition of involving non-state actors (Larsson, B., Letell \& Thörn 2012). Notwithstanding, the social-democratic regime of welfare are seen to be undergoing serious transformations shifting balance from welfarism to advanced liberalism (Dahlstedt 2009; Larsson, B., Letell \& Thörn 2012). Importantly, the socialdemocratic regime of welfare is changing through and by the actual practices of provision and intervention undertaken and conducted (rather than shifts on the policy level) (cf. Johansson, H., Arvidsson \& Johansson, S. 2015).

\section{Advanced liberalism: the possible 'death of the social'}

Welfarism and governing from the social point of view are not an "inevitable horizon for our thought" (Rose 1996b, p. 329) but instead a political and historical construct that has been seriously contested since the last few decades of the twentieth century. This social kind of governing was challenged across Western societies as well as in Sweden (Larsson, B., Letell \& Thörn 2012). In the 
hyperbolic words of Baudrillard (1983) and Rose (1996b), the gradual shift in governing rationales occurred through "the death of the social". Among others, Garland (2014) and Dean (2010) have questioned the alleged death of the social. According to Garland (2014, p. 327), the welfare state and governing from 'the social' point of view constitutes a "fundamental dimension of modern government" even in contemporary advanced industrial societies. In Dean's (2010, p. 202) words, the gradual shift or displacement in balance could be understood as a mutation rendering "a postwelfarist regime of the social". Though, however much government is placed under pressure or undergoes reconfiguration, empirically "there are still social workers, systems of social security, and even proliferation of social policy experts" testifying to government in 'the social' domain - albeit undergoing certain mutations in governmental rationality (Dean 2010, p. 178). This section recognizes a range of mutations of 'the social' and seeks to identify some common features of an advanced liberal rationality of governing.

Contemporary social policy involves a de-centralization of state power. Governing is based on ambitions of increased freedom and autonomy for markets, families, communities and individuals (Rose 1999). Accordingly, governing entails promoting self-governing citizen subjects and institutions that are responsible for themselves (Mik-Meyer \& Villadsen 2013). Under welfarist rule, individuals were governed through society, that is, through broad interventions targeting the whole population (top-down); under advanced liberal rule, society are governed "through the regulated choices of individual citizens" (Rose 1996a, p. 41), that is, by inducing a specific subjectivity within citizen subjects who through their actions and behaviours form society (bottom-up) (cf. Petersson, K. 2000). Producing de-centred, autonomous and self-governing individuals and institutions also means that the state governs more indirectly or "at a distance" (Miller \& Rose 1990, p. 1; Rose 1996a, p. 43; Rose \& Miller 1992, p. 173); the state takes on the role of activating self-regulating markets, institutions and individuals. As a result, political power is exercised by a variety of agencies with more or less loose connections to "the formal organs of the state" (Miller 
\& Rose 1990, p. 1). Yet the state remains active in governing but develops new subtle and effective strategies in activating a multitude of authorities and agencies in performing social and welfare interventions (Rose 1996a).

This section takes the mutations in governmental rationality, the notions of governing interventions that target individual conduct and decentralization of the exercise of power as its point of departure. The presentation of advanced liberal governmental rationality mainly focuses on how individuals and communities are made autonomous and responsibilized. First, key features of an ideological critique of welfarism are presented. Second, characteristic kinds of problematizations and technologies aimed in response to problems are outlined. Third, the emergence of 'the community' in welfare provision is presented, and a dual rationale of ethical activation is outlined. Fourth, some observations on social work in relation to an ongoing mutation of 'the social' are highlighted.

\section{Criticism against welfarism}

In the final decades of the 1900 s, welfarist governing was criticized on (at least) two interrelated grounds. The economic critique asserted that the state had grown too large and that extensive public spending was economically unsustainable and ineffective, thwarting wealth, creating inflation and damaging capitalism and growth (Rose 1996a; 1999). This critique also gained in strength in Sweden starting in the 1980s (Boréus 1994; Dahlstedt 2009; Lindvall 2004; Sunesson et al. 1998). From this point of view, government needed to be more effective; more effective government needed another population - an active population utilizing their freedom and autonomy to take care of themselves, be self-governing and responsible (Rose 1999). This was likewise mirrored in Swedish social policy (Boréus 1994; Dahlstedt 2009; Johansson, K. 2007; Larsson, B, Letell \& Thörn 2012). In line with this, ideological critiques emerged (from both the political right and left) concerning the alleged passivation of citizens; the expansion of welfare state intervention, statist authoritarianism and bureaucratization; and anti- 
human technologization and engineering (cf. Bergh 2009; Hirdman 2000; Trägårdh 1990).

This kind of critique maintained that welfarist social insurance schemes, economic compensation and redistribution were too generous and served to passivize citizens (Rose 1999). Consequently, social work and welfare interventions engineering people's lives were seen to intrude on and violate personal autonomy (cf. Hirdman 2000) and deprive individual citizens of agency and responsibility. According to Dahlstedt (2009), the latter dimension underpins the government inquiry on power and democracy in Sweden, SOU 1990:44, from the early 1990s, that had great importance for Swedish social policy in the following decades. From a range of perspectives, it has been claimed that the nature of welfare and intrusive social planning made citizen subjects dependent upon the state to manage their lives, instilling a client mentality (Larsson, B, Letell \& Thörn 2012; Lessenich 2011; Rose 1999) and undermining the moral fabric and activity of individuals and collectives (Villadsen 2007). It was further claimed that the extension and expansion of the welfare state not only deprived individuals of agency and responsibility, but that welfarism "destroyed other forms of social support such as church, community and family" (Rose 1996a, p. 51-52). With respect to Swedish conditions in particular, there has been an emphasis on a strong governance tradition of public-private partnerships (cf. Larsson, B., Letell and Thörn 2012) with civil society seen as a space of democratic and citizenship formation (cf. Dahlstedt 2009) Here, situations of the state taking over and controlling civil society based welfare provision have also been noted (Trägårdh 2013a, 2013b). In addition, welfarism - as instanced by professional social work - was criticized for being patronizing, authoritarian and bureaucratic. It was claimed that this deviated from the naturalness and authenticity in social relations and in social support, which were believed to have been present in community work, Christian aid or philanthropy (Rose 1999; Villadsen 2009). Trägårdh (2013a), for instance, notes that the Swedish statist welfare system suppressed charitable and philanthropic human initiatives. This kind of critique aligns with a sceptical attitude towards the technologization and engineering of 
individuals and populations, which presumably would deviate from authentic humanism (cf. Larsson, B., Letell \& Thörn 2012).

The critique gained in magnitude starting in the 1970s and influenced social policy in the West from at least the 1980s and on. In light of this critique, a new advanced liberal way of governing took shape in a Thatcherite UK and Reaganite US in the 1980s. It was refined in the Clinton and New Labour eras the following decade, and continued to guide government in the 2000s and 2010s, including in Sweden. This kind of politics has been considered to be a politics of activation (Dahlstedt 2008, 2009; Lessenich 2011; Rose 1999), aimed at re-activating people allegedly passivized under welfarism. According to Lessenich (2011), the politics of activation evolves around re-distributing responsibility for welfare from the state to individuals themselves and making them active, responsible risk-takers. Such a development has been termed "a displacement in the balance" (Larsson, B., Letell \& Thörn 2012: 17) in governmental rationality in Sweden and Scandinavia as well - and constitutes a transformation in the social-democratic regime of welfare.

\section{The technologies of agency and rationality of risk intertwined}

Whereas welfarism spreads and reduces risk on the scale of population, making risk less visible in the daily lives of citizens, advanced liberal governing imposes active responsibility for managing risk, making it visible and present. Contemporary society has been characterized as a society inflated with risk (Dean 2010, Rose 1999, 2000b; Webb 2006). Here, risk is seen as an inevitable fact of society, though still calculable, manageable and avertable for the individual (Hughes 1998; O’Malley 1996; Webb 2006). Moreover, risk rationality produces a division between active and passive citizens: active citizens are seen as competent in managing their own risk, while passive ones become dependent on welfare support and social work. Groups that are targeted as being at-risk marginalized and excluded - become the targets of intervention for selective welfare interventions (Rose 2000b; Webb 2006) and "case management" programs (Dean 1998, p. 33). They are attributed to lack powers, competences and capabilities necessary to manage risk and gain inclusion (Cruikshank 1999; Rose 1999; Webb 2006); they 
are represented as being dependent upon welfare support. Accordingly, they are the problematized targets of a social policy aimed at producing citizenship "from dependency to activity" (Rose 1999 , p. 263). Such a way of problematization moreover construes individual citizens - the poor and the excluded, those to whom such problems are attributed - as risky and potentially dangerous individuals (Rose 1999, 2000b).

In this context, risk becomes not a means to promote insurance technologies for protection in response to problems (as with welfarism), but instead a means to introduce chance and opportunities; it opens up space for individual action (Ewald 1991). In this sense, risk rationality is intertwined with and enables technologies that promote individual agency (Dean 2010) and activity (Rose 1999). Governing rationales of advanced liberalism constitute technologies that enhance, promote and deploy individual agency through active and free choices - "technologies of agency" (Dean 2010, p. 196). They address the subjects and construe them as active citizens who act upon their freedom of choice; activity and agency become an imperative of citizenship (Cruikshank 1999; Dean 2010; Rose 1999). This notion is crucial in a politics aimed at activating those who are allegedly passive, powerless or at risk.

Technologies of agency have been presented as programs for "empowerment" of the powerless and excluded (Cruikshank 1999; Rose 1999). In essence, empowerment entails providing subjects with the skills, powers, competences and capabilities necessary for their freedom, inclusion and risk management (Cruikshank 1999). Governing through empowerment techniques operates by providing powers of individual agency such as self-esteem and self-confidence (Cruikshank 1996), reforming the subjectivities of citizen subjects by shaping their motivations and interests - their ways of thinking (Cruikshank 1999). Rose (1999, p. 268) adds that the "beauty of empowerment is that it appears to reject the logics of patronizing dependency that infused earlier welfare modes of expertise", because "[s]ubjects are to do the work on themselves, not in the name of conformity, but to make them free". Empowerment strategies are both coercive and voluntary (Cruikshank 1999): they 
are imposed on the powerless and the excluded yet also assume the voluntary participation of those subjected to exercising various forms of freedom, transcending simple dichotomies between freedom and subjugation (what is termed a strategy of subjectification) (Cruikshank 1999; Dean 2010). Empowerment emerges as a set of strategies to help people help themselves, to become agents of their own lives and welfare (Cruikshank 1999, Dean 2010, Webb 2006) - such strategies are a constitutive feature in the genealogy of social work (Villadsen 2004).

This means that the citizen subject must be technologized; such individuals must become agents of their own lives and be active in taking care of themselves, pursuing their own interests. This kind of advanced liberalism, delineated by Rose (1996a, 1999), is not a return to a notion of laissez faire liberalism based on individual autonomy and freedom; instead freedom and autonomy need to be produced, engineered and governed. One dimension of this involves an economic logic of enterprise and competition. Subjects are induced to make rational choices based on cost-benefit analyses; governing is aimed at providing subjects with such powers and at shaping the use of these powers. In this sense, state power do not refrain from governing; instead state power intervenes and creates conditions for entrepreneurial subjects of economic rationality and engineers citizen subjects who conceive of themselves as active entrepreneurs of self-interest (Rose 1999) - to govern, but at a distance. Citizen subjects are therefore made - shaped and guided through economic incentives - to be the homo oeconomicus of freedom, autonomy, self-interest and self-management: an artefact (Dean 2010) and product of "advanced liberal engineering" (Thörn \& Larsson, B. 2012, p. 264). Accordingly, subjects need to be shaped to accept and use their freedom in making active choices. According to such a governmental rationality, "individuals are not merely 'free to choose' but obliged to be free, to understand and enact their lives in terms of choice" (Rose 1999, p. 87). The aim then is to produce subjectivity: to make subjects think in a specific way, to induce subjects to look after themselves, govern themselves. Crucially, this is a way of exercising power and executing government (not a way of liberation or emancipation) by means of 
constructing a free subject that is, as Haahr (2004, p. 215-216) has put it, "a potential technical instrument in the achievement of governmental purposes and objectives", as the subject is "shaped, guided and moulded into one capable of responsibility" and one who therefore can be used as a tool for governing.

\section{'The community' and neo-philanthropy}

The kinds of problematizations, technologies and subjects considered to be characteristic of advanced liberalism have focused on the individualization of responsibility for managing problems and risk. In another dimension, this governmental rationality entails some collectivist influences - however, not operating on 'the social' domain. According to Rose (1996b, 1999), the death of the social is adjacent to the rise of the community. Even if the reconfiguration of 'the social' is not considered a death, 'the community' has been highlighted in social policy as a domain for social intervention. The rise - and rejuvenation - of 'the community' aligns with traditional perceptions of the community as a space for moral bonds, personal relations and solidarity between individuals tied to the local neighbourhood, which was presumably fragmented by the division of labour, capitalism and, later, welfarism. 'The community' in this sense is a domain of morally active - and activated - subjects. This formation of 'the community' as a domain for intervention (and for solidarity and inclusion) draws on the critique of state-centred welfare provision and social work as being authoritarian, patriarchal and bureaucratic; instead, the naturalness of personal relations and moral bonds between individuals assumed within 'the community' is highlighted. Efforts made to form this domain are called "technologies of community" (Rose 1999, p. 188). Notions of 'the community' distinguish this domain from 'the economic' as well as from 'the social' domains and rationales; this entails the formation of a third space (Rose 2000a) of welfare provision, distinct from totalitarian and patriarchal rule of the state as well as from commodification of the market. Accordingly, privatization of risk not only entails individualization, but also a collectivizing (though not socializing) dimension: 'the community' evolves as a domain for managing risk and providing security. Risk is not distributed (socialized) over the whole population, but instead attributed to 
communities of geographical or interpersonal zones based on personal relations and moral bonds. Risk becomes a responsibility for 'the community' to manage (Rose 1999, 2000b). Under welfarism, security was provided by the state through socialized techniques ranging from universal old age pensions and insurance schemes to socially funded law-enforcing police; under advanced liberalism, "each community is to take responsibility for preserving the security of its own members [...] within a variety of discrete spatio-ethical zones" (Rose 2000b, p. 328).

In a number of articles, Villadsen (2007, 2008, 2009, 2011a, 2011b, 2011c) has analysed a related feature of government - the emergence of neo-philanthropy. This is related to a renewal of the belief in charitable and voluntary activities based on the community, church or other civil society formations in social policy - the view that such formations can provide a "human touch" (Villadsen 2009, p. 217) of morality and authenticity in social work and welfare provision that supersedes the capacities of state-centred welfarism. The neo-philanthropic approach, like the formation of 'the community', can be viewed as a way to re-innovate a welfare society that is believed to be in a state of crisis and retrenchment. Villadsen (2004, 2007, 2011a) traces core principles of social work from philanthropic and religious societies of the late 1800s in today's welfare provision, stressing, for instance, that "help must be selfhelp" and "poverty is spiritual rather than material" (Villadsen 2007, p. 309). The aim of philanthropy was to "establish a moral community, i.e. a community where a set of collective moral standards and community obligations knitted individuals together", and thus for social change and governing interventions to target individual and "spiritual nourishment" of citizen subjects - features that are rejuvenated today (Villadsen 2007, p. 314). In this way of doing social work, "[f]reedom becomes a question of transgressing the rigidity of the mind; the restraints on the client's freedom appear to be set by the client's own self-perception, not by various exterior social conditions" (Villadsen 2007, p. 320). The philanthropic belp to self-help techniques moreover operated as a way of disciplining client subjects. Diligence, tidiness and hard work were seen as core imperatives for individuals that would assumedly give subjects 
future rewards (Petersson, K. 1997). This shift towards 'the community' and neo-philanthropy highlights an ethical dimension in advanced liberal governmental rationality.

To conclude, starting from the assumption that welfarism produced passive subjects and a kind of de-moralizing client mentality, the dominant advanced liberal governmental rationality can be described as a politics of activation that seeks to re-moralize those in need of social support (Lessenich 2011; Rose 1999). First, the ethical dimension consists of shaping empowered subjects who, based on an economic logic, pursue their own interest through cost and benefit calculations manifested in freedom of choice and acceptance of agency, responsibility and accountability - so that they do not become a burden to society. Second, it consists of shaping subjects who involve themselves in personal and moral relations and form solidarity within 'the community'. This kind of politics of ethical activation involves the autonomization and de-centralization of governing agencies (markets, communities, individuals) as well as their responsibilization. In a world of de-politicization (where seemingly more and more domains are represented as being nonpolitical), politics, according to Rose (1999, p. 174-175) is shaped "no longer in a social form [but] in the form of individual morality, organizational responsibility and ethical community".

\section{Social work after 'the social'}

Under the heading 'After social work?', Clarke (1996) elaborates on the transforming conditions for social work. In addition to principles of marketization of social welfare, he notes, first, that welfarist social work is undergoing fragmentation and disintegration and is now conducted in a range of inconsistent forms; second, that we may be witnessing a "transfer of responsibilities from formal to informal provision" (Clarke 1996, p. 46) that involves civil society agencies and community work; and, third, a managerialization of social work. When welfarist administrative professional bureaucracy does not necessarily run social work, managers from informal providers of welfare gain in prominence. Clarke (1996) notes that this development is in reaction to the bureaucratic and professionalized way of doing social work under a social-democratic 
consensus, and constitutes a supposedly more effective, flexible way of providing welfare. These observations raise questions about the forms and conditions of social work with respect to the mutations of 'the social' mentioned above. With the gradual shift in governmental rationality, social work practices are required to be more cost-effective and not burden public sector finances (Reisch 2013). As a result, social work practices are decentralized (from public authority) and may be conducted following market-based and contractual principles featuring a split between purchasers (public authorities) and providers (other agencies and authorities) (Parton 1996; Webb 2006). Actors from civil society and market-based agencies have gained in prominence as providers of welfare and social work (Webb 2006). In one aspect, privatization and marketization of social services have become more prominent in welfare states in general (Webb 2006) and in Sweden in particular (Larsson, B., Letell \& Thörn 2012). In another aspect, non-profit actors of civil society have been increasingly involved in welfare provision, both internationally (Clarke 1996) and in Sweden (Johansson, H., Nordfeldt \& Johansson, S. 2015). Both are organizational instances of a reconfiguration of 'the social' of social work. Sport associations and the sport movement in general seem to be common representatives of civil society (Coalter 2007b; Norberg 2010; Seippel, Ibsen \& Norberg 2010) and congregate a kind of managerial social entrepreneurialism (Cohen \& Peachey 2015; Sherry, Schulenkorf \& Chalip 2015). In Sweden too, they challenge competitive sport with new institutional logics of social entrepreneurialism (Linde 2013). It is in the context of this kind of fragmentation and reorientation of welfarist social work - and in the overall shift in governmental rationalities from welfarism to advanced liberalism - that the role of sport in welfare provision may be viewed. In the next chapter, the context and a background on sport in relation to welfare are presented, and some findings from research about the organization of sport, social pedagogy and welfare-providing institutions are noted. 


\section{IN CONTEXT: SPORT AND WELFARE}

The question of how rationales of social change are formed within 'sport as a means of responding to social problems' that is to be examined in this thesis is articulated in the intersection of the sociologies of social problems, social work, social policy and the sociology of sport. This chapter focuses on the practice of and knowledge about sport in relation to welfare provision and provides a context, situating the emergence of 'sport as a means of responding to social problems' within relevant research fields with respect to shaping social policy. This is important in investigating the governmental rationalities imbued within these regimes of practice and truth. The argument pursued in this chapter is that a widespread favourable notion of sport's potential for achieving social objectives (a notion nonetheless disputed in empirical research) has influenced social policy. Expectations that sport provides welfare have also been made increasingly explicit, resulting in the emergence of sport practices based on such expectations. This situation provides scope for an investigation of sport practices premised by social objectives. Five sections make up this chapter. First, some central concerns in sport sociology are highlighted. Critical perspectives on the notion of sport's essential goodness and expectations for sport in policymaking are presented. Some contemporary illustrations of such sport evangelism are offered from a range of contexts. In the second section, examples of institutionalized practices using sport as a means of responding to social problems are given. The kinds of practices presented here necessitate a mapping of 'sport as a means of responding to social problems' that takes into consideration research on the institutions of social work, youth inclusion and social pedagogy practices, which is outlined in the third section. In the fourth section, the history and role of sport (and sport policy) in relation to welfare provision (and social policy) are examined in detail. Here, the focus is on the distinction between social objectives as a premise or effect of sport practices. Finally, key challenges and prospects in research concerning sport as a means of responding to social problems are explored in the fifth section based on the context provided. 


\section{Sport evangelism and the sociology of sport}

It was noted in the introductory chapter that there are strong beliefs attached to sport as presumably contributing to social objectives. In this section, this kind of sport evangelism will be further examined: first, with respect to critical perspectives in the sociology of sport and, second, with respect to some illustrative statements from sport advocates in social work, social policy, international development, research institutes and the media.

\section{Critical perspectives in research}

Coakley (2002, 2011a, 2011b, 2015) and Coalter (2011b, 2015) has considered from different angles what they have called "sport evangelism" or "the great sport myth", that is, dreams about the social utility of sport. Perhaps this is most succinctly articulated in the following quote.

There is a widespread belief that sport participation inevitably contributes to youth development because sport's assumed essential goodness and purity is passed on to those who partake in it. Promoted and perpetuated by sport evangelists and kindred spirits, this belief inspires the strategy of using sports to create among young people the attributes needed to achieve personal success [...] Worldwide, few people disagree with or qualify this statement [that sport contributes to development], whether it is said in reference to individual, community, or society-wide development. The seldom questioned link between sport and development is grounded in the dual assumption that sport, unlike other activities, has a fundamentally positive and pure essence that transcends time and place so that positive changes befall individuals and groups that engage in or consume sport. The implications of this dual assumption are significant. It often leads decision makers at all levels of power to allocate public and private resources to sports and sport programs. Coakley (2011a, p. 306-307)

This quote demonstrates the strong belief attached to sport that it could contribute to social goods in a wide range of dimensions. Sport advocates have highlighted such potential in developing a sense of community and building bridges between people, 
developing individual character and the social life skills needed in society, promoting social mobility for individuals in order to leave poor living conditions for better ones, and averting from destructive behaviour (Coakley 2002, 2011a). The idea that sport is a means of fostering and socializing youths as a way to solve problems in society has a long tradition (Coalter 2015; Patriksson 1973). However, it has often been noted that such faith in sport's potential to solve social problems are based on "deeply entrenched storylines" (Houlihan, Bloyce \& Smith 2009, p. 5) or "sport evangelism" (Coakley 2011a, p. 307), that it has been "uncritically determined" (Morgan 2013, p. 831) rather than scientifically supported and that it "tend[s] to be vague, ill-defined and lack [of] clarity and intellectual coherence" (Coalter 2015, p. 20). As will be developed in the first two articles, relations between sport and social outcomes are difficult to evaluate because possible correlations are complex, indirect, poorly theorized and thus difficult to confirm. However, it is apparent that there is no inherent essence in sport that makes it suitable for achieving social objectives and providing welfare; that all depends on how it is performed. Smith and Waddington (2004) have noted that beliefs in sport's potential as a means of responding to social problems are not necessarily unfounded; however, they are most often one-sided and reductive of the complex relationships between sport (as a means) and social objectives (as ends). In establishing a background and context, it is important to acknowledge the strong faith in sport's potential because this has been shown to be influential in organizing sport practices for social objectives and for allocating public resources (Coakley 2011a; Houlihan 1997). In a US context, Coakley (2002, p. 15-18) has shown that the notion of sport for social objectives takes shape in naïve dreams about "social control and deficit-reduction" (normalization and integration) and "social opportunity and privilege promotion" (empowerment and emancipation). Additionally, Riess (1980) has critically examined how sport is used to promote "the American dream" of social mobility, demonstrating that it is more a case of dreams than anything else. Instead, observers who take such a critical position argue that these notions serve to "reproduce neoliberal ideas and beliefs" (Coakley 2011b, p. 67) “aimed at governing the 'conduct of conduct' of 'unskilled' 
youth by equipping them with the tools for self-improvement and self-management" (Hartmann \& Kwauk 2011, p. 288). Crucial to this study, it has been argued that this notion leads to a kind of "social problems industry" (Pitter \& Andrews 1997, p. 86), which is "organized minimally by the state and operated primarily by philanthropic [and] nongovernmental agencies" (Hartmann \& Kwauk 2011, p. 288). This could be viewed in light of broader tendencies in organizing welfare provision under advanced liberalism (cf. Coakley 2011b; Collins \& Haudenhuyse 2015; Spaaij 2013), which were considered in the previous chapter and will also be addressed in another section of this chapter. In relation, scholars have highlighted the potential of and argued for adopting more critical and emancipatory education rationales, targeting dialogue, collective problem-solving, transformative action and making visible underlying causes of segregation, marginalization and injustice, within sport-based interventions (Coakley 2011a; Giulianotti 2011; Hartmann \& Kwauk 2011; Spaaij \& Jeanes 2013; Spaaij, Oxford \& Jeanes 2016).

To situate these notions about purity and goodness, a wide range of critiques questioning the firm belief in the potency of sport have been recognized in research. Such criticism is presented in the first two articles; it is displayed that sport practices cannot change social structures or reduce the poverty and unemployment that arguably create social problems (e.g Coakley 2002, 2011a; Collins \& Kay 2014; Kelly 2011, 2012; Pitter \& Andrews 1997), that sport associations are primarily interested in sport for competition and not social work (Coalter 2007b), that sport practices contribute to selection and stratification (Hartmann \& Kwauk 2011) and that skills and competences attained in a sport setting are rarely transferable to other social settings (Wagnsson 2009). In addition, sport has even been described in research as a generator of social problems (Anderson 2010; Eitzen 2012). It has been noted that sport practices in some cases legitimize and ritualize violence and confrontation (Fraser-Thomas, Côté \& Deakin 2005; Messner 1990) and promote aggressive violations on the field (Eitzen 2012; Young 2002), that it may lead to violence and aggression outside sport practices because of the assumed appropriation of violent skills used 
in other social settings (Eitzen 2012; Endresen \& Olweus 2005; Messner \& Sabo 1994), that sport practices involve relatively higher levels of sexual violence and rapes among athletes than comparable groups (Messner \& Sabo 1994), that sport involves immorality in terms of cheating and the normalized violation of rules (Eitzen 2012; Preston \& Szymanski 2003; Sefiha 2012), that sport practices involve hazing rites (Groves, Griggs \& Leflay 2012; Waldron \& Kowalski 2009) and, lastly, that doping and performance-enhancing drugs are a consequence of the emphasis on competition and the importance of winning (Eitzen 2012; Preston \& Szymanski 2003). Violence and crime in sports are strongly linked to ideals of masculinity (Eitzen 2012; Fraser-Thomas, Côté \& Deakin, 2005; Messner 1990; Messner \& Sabo 1994; Young 2002) and are considered an effect of competitiveness and a full-scale emphasis on winning (Eitzen 2012). Furthermore, problems generated by sport involving spectators or in relation to organizing sport events, such as hooliganism and crowd violence (Armstrong 1998), match-fixing and illegal gambling (Preston \& Szymanski 2003) and corruption (Eitzen 2012), have also been considered in research. Although sport has been observed as being a potential generator of such problems, this aspect is not given explicit focus in the thesis.

\section{An excursion: contemporary illustrations of sport evangelism}

Globally, a wide range of agencies and authorities express faith in the power and potential of sport. To give a brief illustration, some examples from global and national policy and from narratives in the media are provided. The following statements are not subject to analysis: they are only presented to make visible some features of sport evangelism and how this is expressed in contemporary society. For instance, the United Nations (UN) argues that sport can be used to achieve the agency's Millennium goals (cf. Beutler 2008) of combatting poverty, promoting education and gender equality, improving health and sustainability, increasing employability and employment, and promoting peace and development in general terms (SDP IWG 2008) - and, specifically, preventing crime and drug abuse (UNODCCP 2002). The UN Office on Drugs and Crime highlights the potency of sport, concisely summarized in an e-lecture by special adviser Wilfried Lemke, who argues that: 
Through sport you learn life values and social skills that can help you resist or escape the pitfall of drugs and crime [and that] sport can fill a void and prevent young people becoming involved in criminal activity. (UNODC 2014).

Throughout Western societies, a tremendous number of statements of this nature from national and international agencies in social and sport policy can be found. In Sweden, the centre-left government and Social Democratic Minister for Health Care, Public Health and Sport specifically granted substantial additional funds in 2015 for sport initiatives that contribute to social objectives based on integration, in this case, on the grounds that:

The sport movement offers a fantastic platform for integration [and] the sport movement has potential and is itself prepared to assume this responsibility. (Government Offices of Sweden 2015) [my own translation from Swedish].

With even greater emphasis on sport and social objectives, the rightwing Moderate Party, which governed Sweden from 2006 to 2014, noted that:

Sport fosters and forms character, [and] for groups of young people in the risk zone of ending up in permanent exclusion, sport and individual sport leaders can be the outright difference between a life in abuse and crime and an orderly social life. (New Moderates 2010) [my own translation from Swedish].

No political party in Swedish parliament deviates from such an orientation. Moreover, the discussion within social work practice and public welfare provision has recognized sport's presumed potential before. In a report from Stockholm Municipal Crime Prevention from as early as 1993, it was noted that:

Most social workers see sport as a means of support in preventive social work. Social workers look to sport and place ever greater demands on the sport movement taking a social responsibility. In what way can sport be used in social work and what function can sport fulfil? [...] To the extent sport 
succeeds in integrating social activity with training and competing, sport can be a kind of 'vaccination' against the destructive formation of gangs, against crime and substance abuse. (Holmberg \& Liljegren 1993: 14-15) [my own translation from Swedish].

In an article from the Swedish Research Council for Sport Science (CIF), sport is again highlighted as an alternative route to such social problems as homelessness, drug abuse and mental illness, based on assumptions about inherent qualities in sport that would provide moral and social goods:

Homelessness is a growing social problem in Sweden. Life without a home of one's own is often connected to substance abuse and psychological problems. In order to change their lives, the players on the Street team get help from football and their dream of a World Cup. [...] The idea is that sport should be a means of support on the road to another life. Regular football training will help motivate the players to get a hold of their housing situation, stay sober, drug-free and renounce crime. To help them, they have the intrinsic qualities of team sport: community, team spirit, routines, discipline and tolerance of failure. (CIF 2014) [my own translation from Swedish].

This kind of narrative is also a recurring feature in the media. One example is an anecdote about the American basketball player Allen Iverson in a Swedish newspaper:

[It] may sound silly but I love people like Allen Iverson [...]. As a 17-year-old, he was put in prison [but] basketball saved him from mortal decline and a life as an original gangster. (Helsingborgs Dagblad, 2004-08-14) [my own translation from Swedish].

Again, these statements do not constitute part of the empirical material analysed; nor do they provide a thorough or consistent background on sport evangelism - they are simply a few examples selected to illustrate a widespread notion of sport that emphasizes its potential for social objectives. They are statements that cover 
themes such as individual development, social change, diversion, community development, civil society, risk, exclusion, inclusion, social work and more. These are themes that were already introduced, and - as will be shown - many of the themes touched upon in the above statements resurface in the empirical material analysed with respect to the scientific discourse and the SP. Statements like these can be found almost wherever sport and welfare are talked about. The examples provided represent a way of producing truth about sport's potential in achieving social objectives. Many more examples can be found - these are just a handful. It is worth noting here that many of these actors and other agencies seem to be very aware of the difficulties and conditions involved in using sport as a tool in this sense; however, the emphasis is on its potential, and potential difficulties are downplayed.

Evidently, there are discrepancies between evangelist notions and critical perspectives in research. However, there is scientific discourse that affirms sport's potential as a means of responding to social problems, which is examined in the first two articles. It is reasonable that such a discourse influences the common sense notions described above, which are not quite distinct (but rather intertwined), forming regimes of truth that underpin institutionalized practices. However, it is important to note that, based on a comprehensive review of research, sport practices have potential to contribute to social objectives when, for instance, they are used rationally with a clear idea of means and ends, combined with education and performed by trained professionals in noncompetitive settings; such findings are further scrutinized in article 2. In this respect, certain common sense notions about sport seem to be, if not wrong, at least fairly one-sided. The notion of the assumed goodness of sport and its presumed potential contribution to social objectives is widespread, despite being vaguely supported by research. Problematizing this regime of practice and truth, which is a key aim of the thesis, takes this as one point of departure. Notably, what is important for the aim and scope is not really whether claims made about sport in relation to social objectives are true or false in a traditional sense, but instead what kind of effects 
these regimes of truth make possible - what kind of frames for interpreting social problems, what kind of technologies and citizen subjects they may produce.

\section{Sport for social objectives: institutionalized practices}

The kinds of sport-based interventions outlined above and underpinned by the affirmative regimes of truth established have attracted international interest for decades. For instance, sport has been used in social policy to promote a wide range of objectives: public health (e.g. Österlind 2016; Österlind \& Wright 2014), democracy (e.g. Coalter 2007b), active citizenship (e.g. Coalter 2007a, Green, M. 2007), drug prevention (e.g. Crabbe 2000), crime prevention (e.g. Nichols 2007), integration (e.g. Hylton 2011), social inclusion (e.g. Kelly 2011, 2012; Verdot \& Schut 2012), social cohesion (e.g. Spaaij 2009), peace (e.g. Svensson, P.G., Hancock \& Hums 2016), human rights (e.g. Kidd 2008), HIV/AIDS prevention (e.g. Banda 2011) and more. Perhaps the most famous of such practices is the US Midnight Basketball program from the late 1980s and 1990s. Briefly, the program offered youths ages 17-21 in urban areas of exclusion the opportunity to play in basketball tournaments, in the presence of the police, from 22.00 to 02.00 during the summer. The idea was to provide youths with safe, healthy activities during the hours when crime rates were high. The program gained a great deal of attention because of what was claimed to be a reduction in crime rates. These claims were later criticized and noted to be scientifically unsupported (Hartmann \& Depro 2006). Assumed to regenerate and activate citizenship and a sense of community, such sport programs were promoted in the US under the Reagan administration (Hartmann \& Depro 2006) and in the UK under New Labour (Coalter 2007b), and are still gaining prominence. A range of programs in this vein have been promoted since then, including a small sample that have been subject to research: Positive Futures (Crabbe 2005, 2007; Kelly 2011, 2012; Nichols 2007) and Closing the Gap (Heaward, Ryan \& Suckling 2008) in the UK, the Sport Steward Program in the Netherlands (Spaaij 2009), Boxing Upwards in Belgium (Haudenhuyse, Theebom \& Coalter 2012), DGI Playground in Denmark (Agergaard, Michelsen la Cour \& Treumer Gregersen 2015), the Vencer 
program in Brazil (Spaaij 2013), and Drive-in Sports in Sweden (Fahlén 2015; Elvhage \& Linde 2012; Linde 2013; Stenling 2015). Such sport-based interventions follow a disparate set of rationales, some emphasizing diversion (Midnight Basketball) and others social change (for instance, Positive Futures). Nonetheless, others seem to develop their means and ends more or less ad hoc in practice (Smith $\&$ Waddington 2004) with vague theoretical underpinnings (Coalter 2011a, 2011b). These kinds of practices, with a focus on sport as a means to promote social objectives, are also emerging in Sweden. Their objectives serve as the premise of practice, and their practice is conceived of as a way of responding to social problems.

\section{Youths, problems and a social kind of pedagogy}

The regime of practice described above and the examples presented for investigation in this study, particularly with regard to the SP, concern a range of issues that intersect at the point of 'sport as a means of responding to social problems'. In this section, some remarks will be made on social pedagogy, youth inclusion - in relation to governmental rationality - and transforming conditions of social work institutions in Sweden. This section helps to map out the context and contours of the study at hand. Previous research on the more specific regime of practice presented is reviewed in depth and scrutinized in articles 1 and 2 .

\section{Intervention practices of social pedagogy}

In terms of the pedagogical dimension, explored in chapter 2 with respect to the shaping of includable citizen subjects as a governmental rationality of social work, social pedagogy stands out as a particular field of practice (and research) with respect to welfare provision. Interventions of social pedagogy can deal with preventive case work that targets deviant or delinquent youths, marginalized and socially excluded youth, or youths who carry out violent and criminal acts, creating social problems. These interventions aim to promote social change through the learning and socialization of personal and social skills and competences necessary for inclusion (Madsen 2005). Consequently, social pedagogy can be considered a form of social work aimed at fostering integration and social cohesion by means of providing deviant or excluded individuals 
with skills and competences needed for inclusion. It should be noted that these are basically the same rationales that have been considered the pedagogical dimension of social work, and such practices take place in a wide range of arenas. The literature focused on Sweden covers, for instance, school environments (Winman \& Hermansson 2008), institutional child care (Markström \& Münger 2004), family therapy (Eriksson \& Markström 2000), summer camps (Münger 2000), special residential homes for young people (Severinsson 2010). Even, sport based pedagogy is emerging in youth detention homes in Sweden as a correctional strategy and for development of pro-social skills and knowledge (cf. Roe 2015). Special attention could be paid to social pedagogy programs that target stigmatized areas of exclusion and migrant populations as a way to promote social inclusion and integration in general (Sernhede 2008). This includes even leisure activities such as the Swedish youth centre Fryshuset and Lugna Gatan ['Quiet Street']. Fryshuset is a program set up by a voluntary organization during the 1990s that offered sport and music activities with social agendas (Öhlund, Gundel \& Klaus 2009). Interestingly, one key dimension of the social and pedagogical intervention concerned here, highlighted by, among others, Eriksson (2004), Berglund (2000) and Petersson (2000), is the close relation between the social pedagogy discourse and inclusion within 'the community', understood as a sphere of personal bonds and moral relations. This theme was touched upon in chapter 3 and will be further explored (also with respect to community work). Petersson, K. et al. (2007) see governing in the form of pedagogy as a key feature of social and educational policy in the early 2000s in Sweden. Over a range of the welfare state's fields of interest - for instance, public health, teacher training and crime prevention - governing is shaped in the form of educative interventions aimed at producing autonomous and responsibilized citizen subjects. In this sense, the formation of responsible, selfmanaging subjects becomes a way to construct the future as a target of social change and to govern the future conduct of subjects - in "the name of pedagogy" (Petersson, K. et al. 2007, p. 239 [my own translation from Swedish]). 


\section{Youth problems and youth inclusion}

Most obviously, the conduct of youths is the target of social and pedagogical interventions. Youth and adolescence have been viewed in various ways throughout history; delinquency, deviancy and social problems have been attributed to and associated with this period of life (Börjesson \& Palmblad 2003; Gillis 1984). Ohlsson and Swärd (1999) note three kinds of problem characteristics attributed to representations of youths: youths are viewed as violent and destructive, they are considered to lack norms or have bad morals, and they are assumed to lack the resources and competences needed to participate substantively in society. In various ways and through various differentiations, youths who exhibit normal behaviour are distinguished from youths who are deviant and problematic, in school, other institutions and leisure activities (Börjesson \& Palmblad 2003); some deviant conduct is identified as making youths governable targets (Palmblad 2007). The characteristics attributed to problem youths are often territorialized into areas of exclusion or risk, involving gangs or other informal, delinquent, social networks (Petersson, K. 1990; Sernhede 2007). This may be viewed in relation to how urban life is, and has been, segregated along social, economic, cultural and ethnic lines. These kinds of segregations put youths in exposed and vulnerable situations with respect to social inequalities, not least in terms of education (Bunar \& Sernhede 2013). Consequently, social pedagogical interventions may target the local community with ambitions to promote inclusion, where subjects are viewed as active participants in the community and responsible for dealing with problems (Petersson, K. 2000). Youth subjects may adapt to structural segregations and develop strategies and activities to deal with the conditions they are subjected to (Hertzberg 2007). In this sense, youths have been viewed as individualized deviants in an otherwise well-functioning and adapted society (Mørch 1997).

An important feature of the problems associated with youths involves their uncontrolled leisure time, which is believed to enable misconduct (Ohlsson \& Swärd 1999; Olson, H-E. 1995). Because of youths' bad morals, it is thought that their freedom and leisure time need regulation; the conduct of youths thus needs to be controlled 
and cultivated (Ohlsson \& Swärd 1999; Olson, H-E. 1995). As a result, prevention should be seen as a key rationale in responding to youth problems. Leisure activities have been used to promote good behaviour and eliminate bad conduct or passive lifestyles as a way of preventing social problems (Petersson, K. 1997). Emphasis on the prevention rationale in Swedish welfare provision illustrates the modernist notion of producing future conduct and order. Interventions that impose control and target youths' misconduct have varied from restricting the freedom of youths through detention homes and institutions to providing freedom through pedagogical programs based on voluntary participation that promote a certain kind of conduct and shape a desirable subjectivity. As for problems attributed to youths, differences in viewing them as victims or as perpetrators have resulted in a variety of regimes of governing and control (Sjöblom 2012). Accordingly, interventions that target youths - and animate their targets - vary in their rationales between care, control and punishment. It is worth mentioning, with respect to social pedagogical interventions, that voluntary associations have long held a role in performing such intervention practices (Ohlsson \& Swärd 1999).

\section{Pedagogy and youth inclusion: the lens of governmental rationality}

Interest for pedagogy as a means of government, subject formation and inclusion is spread across a multitude of disciplines that seek to examine the sustainment and tendencies of transformation in society (Peterson et al. 2007). It is neither possible nor necessary to give an overview of the numerous empirical studies focused on the governmental rationality of subject formation and inclusion or even the institutional setting for these kinds of interventions. Nevertheless, a few examples can be given to illustrate the range of disciplines concerned and the different ways they have influenced this study. For instance, disciplines such as pedagogy (e.g. Olson, M. et al. 2015), social work (e.g. Besley 2010; Green, D. 2007; Kemshall 2002; Pollack 2010), ethnic and migration studies (e.g. Dahlstedt 2008, Vesterberg 2016), criminology (e.g. Gray 2009; Muncie 2006; Stenson 2005), public health (e.g. Crawshaw 2012) and political science (e.g. Haahr 2004) ought to be mentioned here. In different ways, the construction and formation of an educable subject as the 
locus of social change are developed and situated within the frames of government. Studies from these disciplines concretely concern themes that are recognized and examined in this study, such as individual responsibilization, risk management, control and freedom, normalization, active citizenship, re-moralization of social work, a new kind of philanthropy in social work, reconfiguration of social policy agendas, educational dimensions in the process of subjectification etc. All of these were introduced in chapters 2 and 3 . Studies from this range of disciplines and with a range of varying empirical objectives illustrate how the tendencies analysed through and within 'sport as a means of responding to social problems' are present in many social policy contexts. This insight aids in situating the aim, approach and results of this study. Some examples from sport studies are provided in the next section.

\section{De-statization of social work in practice}

The recent changes in the welfare state concern the institutions of social work that respond to social problems (with respect to the conduct of youths). Social work in Sweden has relied on statecentred institutions, most often embodied in the municipal social services under welfarist government. However, social work in Sweden has tended to be transformed in two noteworthy dimensions. On one hand, privatization and marketization of social services, for instance in individual and family care as well as in interventions for children and adolescents, have recently been subject to debate in Swedish social policy (Hartman 2011a; Sallnäs \& Wiklund 2015; Wiklund 2011). A steady increase in private and market-based providers has been legitimized as an innovative way to secure more effective production of services and a way to involve client subjects in choosing between different providers (Sallnäs \& Wiklund 2015). The claimed benefits from such marketization, however, lack empirical support (Hartman 2011b), and a range of problems have been highlighted (Sallnäs \& Wiklund 2015). In any case, this involves a kind of entrepreneur model, where public welfare institutions purchase services on contract from private agencies (Hartman 2011a). On the other hand, Sweden has witnessed an increase in the involvement of non-profit actors from civil society in welfare service provision (Johansson, H., Arvidsson 
\& Johansson, S. 2015; Johansson, H., Nordfeldt \& Johansson, S. 2015). Although recognized for its state-centred welfare provision, Sweden has a large voluntary sector and civil society relative to other countries (Svedberg \& Olsson 2010; Svedberg \& Vamstad 2006). Still, the importance and influence of such actors in social policy have been downplayed until recently. But, looking back at the history of the welfare state, civil society has played an important role in philanthropy and in advocating social reforms (Johansson, H., Nordfeldt \& Johansson, S. 2015; Lundström \& Wijkström 1997). In some ways, the development involves new roles for non-profit and voluntary organisations, moving from political agents and advocates of social reform and justice into service providers (Johansson, H., Arvidsson \& Johansson, S. 2015; Kings 2011). The development aligns with a "renewed interest for community work in Scandinavia" (Turunen 2009, p. 51) and in Sweden - with an emphasis on casebased interventions that target groups and individuals limited to a geographical area or social unit sharing relations and identity (Turunen 2009). Here, locally based associations, most notably in areas suffering from marginalization and exclusion, have come to play an important role in terms of local service provision (Kings 2011). This kind of civil society and social entrepreneurial sector consists of a wide range of non-profit agencies and authorities (Lundström \& Wijkström 1997). Wijkström (2012) has observed the emergence of organizational hybridities growing in welfare service provision, based on a mix of market-based economic rationales and charitable philanthropic rationales. With respect to Sweden's archetypically statist welfare model, the introduction of new welfare mixes has been debated and conflict laden; especially, the right-wing government of 2006 advocated and endorsed this development (Johansson, H., Arvidsson \& Johansson, S. 2015). The re-emergence of civil society and community work in contemporary social policy and social service provision is an interesting feature of welfare recalibration that has been viewed in relation to sport (Norberg 2010) and could be further elaborated on in relation to 'sport as a means of responding to social problems'.

Both these dimensions are examples of de-statization, in other words, the increasing reliance on non-state agencies in welfare 
provision. Still, entrepreneurialism and its close relations with civil society agencies (Hallström 2015) are a recent and growing feature of Swedish welfare provision (Levander 2011; Palmås 2008). Social entrepreneurialism has emerged as an innovative way of tackling social exclusion through empowerment schemes in recent Swedish social policy (Levander 2011). However, the statist social-democratic regime in Sweden has also historically featured partnerships between social movements (for instance, the sport movement), civil society, and even market-based agencies in central government bodies and administration in certain spheres (Larsson, B., Letell \& Thörn 2012) - although not to the same extent in the performance of social services. As noted in the preceding chapter, sport is often associated with civil society and entrepreneurialism. The sport movement, clubs and associations represent civil society because they organize their practices to at least some degree in a way that is autonomous of state involvement (Seippel, Ibsen \& Norberg 2010), out of reach of the sovereign power of the state. In addition, social entrepreneurs seem to progress in sport organizations or through sport practices (Cohen \& Peachey 2015).

\section{Situating the regime of practice}

It is in light of pedagogical rationales of social change and of institutional frames concerning marketization, privatization, civil society involvement and informal kinds of welfare provision and social work that the institutionalized regime of practice utilizing sport as a means of responding social problems is viewed in this study. The issues highlighted concerning pedagogical interventions, youths viewed and constructed as problems and the changing institutional conditions of social work and welfare provision congregate and merge into each other through the regime of practice of 'sport as a means of responding to social problems'. In order to situate the study within Swedish research, it is beneficial to at least be familiar with the kinds of practices and target representations that have been observed in related fields of research. Clearly, more in-depth reviews of research could be provided on these issues, framing the object of this study in various ways; however, for this end and purpose, the brief insights provided help to map out the field of interest for this study. 


\section{The rationales of sport for social objectives in Sweden}

In light of the different social and pedagogical interventions provided by the welfare state that target youths and their conduct as well as the state's provision and control of leisure time and activities in relation to this, sport practices have long been included on the social policy agenda in various ways. In this section, the rationales of sport for social objectives in Sweden are outlined, with a focus on the difference between seeing social goods as an effect of or a premise for sport practices.

\section{A brief genealogy of sport and social objectives in Sweden}

Early modern sport in Sweden is seen to take its influences from the British educational system, which highlights fair-play ideals and considers sport as a way of fostering youths to ensure compliance, loyalty, courage and discipline (Patriksson 1973). These ideas were then embraced by the military, and sport was organized in order to shape a strong, unified national population (Schelin 1985). However, in Sweden sport - more so than military aims - was seen to instil great will-power, steadfast fearlessness, self-confidence and good morals; sport was also considered to have an impact on sobriety and general discipline since competences gained from taking part in sport were presumably transferred to broader social spheres (Lindroth 1988). In 1913, the sport movement, consolidated through the Swedish Sports Confederation, received its first annual government grants, which were seen as confirmation of the social utility of sport (Eichberg \& Loland 2010; Norberg 2010, 2011). However, sport was often criticized for being competitive and brutalizing, and government support was called into question (Norberg 2004). During the first half of the 1900s the sport movement concentrated its focus on youth sports and the positive contributions sport made to society by fostering participants (Wijk 2001), and increased funding for the sport movement was part of welfare policies from the 1930s on (Norberg 2010). The labour movement played a prominent role here, embracing sport as a means of promoting democratic ideals beyond class boundaries (Norberg 2004). The ideal of good character promoted in the sport movement was expressed, for instance, through the restrictive attitude towards alcohol (Andersson 2002). Such ideals moreover 
spurred social work initiatives with sport-based supervisors for adolescents who were sentenced, on probation or discharged (Andersson 2002). In its self-representation, the sport movement could draw on notions of youth culture and youth problems to promote sport as a solution, highlight specific social utility and motivate public financial support (Wijk 2001). In a broader sense, this has been the case in the post-war period; the sport movement has organized practices with public support in a corporatist partnership model (Bergsgard \& Norberg 2010; Fahlén \& Stenling 2015) based on implicit expectations that sport has positive effects on public health, democratic socialization and social integration (Bergsgard \& Norberg 2010). In many ways, the sport movement can be seen as intertwined with the Scandinavian and socialdemocratic way of doing welfare, with aspirations of universal outreach and far-reaching ambitions to reduce risk and combat social inequalities (Bergsgard \& Norberg 2010). One key ambition of the welfare state was to provide youths with recreational and meaningful leisure time that would benefit both individuals and wider society by producing healthy, democratic citizens (Fahlén \& Stenling 2015). Formally, the sport movement (organized through the Swedish Sports Confederation) has been autonomous of state and public authorities yet still dependent on public funding. As a result, public authorities cannot easily place conditions on such support for sport practices without destabilizing the autonomy that is presumably the foundation and precondition for democratic socialization in the sport movement (Bergsgard \& Norberg 2010). Crucially, the level of member participation in Swedish sports has been exceptionally high, an indication that civil society makes an important contribution, measured both in financial terms and, with respect to voluntary work, to welfare objectives (Norberg 2010). Confidence in sport with social benefits and as an arena for positive socialization is fairly well established in contemporary Sweden, according to Wagnsson (2009). The social goods anticipated from sport resemble many of the themes previously mentioned in this chapter; moreover, the corporatist organization of sport aligns with the rationales of the Swedish social-democratic model of welfare provision and governing presented in chapter 3 . 
However, this model is in some instances being renegotiated since public authorities have formalized and specified their expectations for the social utility of sport (Norberg 2011). In the past decade, popular movements in general, sport associations and other forms of doing sport practices have increasingly been seen as tools for achieving social objectives, and demands have been raised by public authorities in such a direction (Norberg 2011). Governmental programs like The Handshake from 2004 and The Sports Lift, which replaced it in 2007, are worth mentioning here. They allocated funding for sport-based projects on the premise of public health, equal opportunities and social integration (Fahlén \& Stenling 2015) and increased government funding dramatically (Norberg 2010). According to Österlind (2016, p. 13-14), participating in organized sport for social objectives is "regarded as 'cost-effective' solutions to problems that are caused by social and economic disadvantages and inequalities" by policy makers. Sport's role as a means of achieving social objectives has thus been defined and explained, with the result being that demands on the sport movement, sport initiatives and sport practices have been clarified (Norberg 2011; Österlind 2016). In line with this, Fahlén and Stenling (2015, p. 9) add that "more instrumental goals have been accompanied by increased resources to aid their attainment". In relation, a range of publically financed and supported programs and social interventions have emerged nationally which conceive of sport as means of achieving social objectives, for instance crime prevention (e.g. Kilborn Arvérus 2009; Kolfjord 2007), normbreaking behaviour (e.g. Stenling 2015) and integration (e.g. Carlson 2007; Ellefsen Hansen \& Törnros 2015; Elvhage \& Linde 2012; Sparr 2015). Such initiatives reflect a new institutionalized logic in sport organization in Sweden (Linde 2013; Stenling 2014a), where the sport movement and voluntary sport clubs are positioned as intended implementers of social and welfare programs (Stenling 2014b). Crucially, Norberg (2011, p. 312) notes that the Swedish sport model has been characterized by an "implicit contract" that recognizes the social benefits of sport but that this contract is currently being renegotiated and transformed into a more explicit form. This includes demands, monitoring and auditing for support (Norberg 2011; Österlind 2016). To sum up, such an explicit 
contract highlights a development whereby sport is increasingly conceived of and used as an explicit means to achieve social objectives. In view of the development identified above, the potential role of sport in contributing to social work has been examined in a number of articles by Östnäs (1990, 1991, 2005), highlighting prospects and difficulties in using sport as a means of responding to social problems.

\section{Social goods as premise or effect: an analytical distinction}

In the first article of this thesis, an analytical distinction is identified between sport practices with potential socially beneficial effects and sport practices with social objectives as premise. Traditional Swedish competitive sport practices in voluntary clubs and associations organize sport with the potential effect of social benefits, and it is with respect to such practices that the implicit contract took shape. For instance, Brännberg (1998) has researched socialization and social goods with respect to social work within the context of Swedish voluntary sport organizations. In this thesis, however, the focus is on the emerging regime of practices constituted by social objectives as the premise, performed under a more explicit contract, more or less distinct from traditional voluntary sport practices in clubs or associations. The distinction identified is one analytical finding of this thesis and is developed in article 1; at the same time, it is used as a point of departure for the thesis's overall aim and questions. Other such distinctions have been explored in research - though with different emphases - on SportPlus and PlusSport (Coalter 2007b) or implicit and explicit expectations (Norberg 2011), which share similar rationales and have inspired this interpretation. The distinction between premise and effect helps to situate what kinds of practices are concerned in the following examination of the scientific discourse and the SP discourse; however, this distinction does not quite capture the continuum between the ideal types present in how sport is organized today. In line with the more explicit contract, many sport associations concerned with traditional competitive sport practices are affected by expectations of contributing social goods, not least because of demands placed on public funding. Sport associations and clubs become involved in partnerships with municipal authorities and entrepreneurs in carrying out sport-for-all 
projects which can be described as somewhere on the continuum of ways of doing sport for social outcomes outlined here (cf. Linde 2013; Stenling 2015). Accordingly, this distinction reduces the complexity of reality, in order to make some aspects clearly visible. However, the distinction could use some nuances and may well be problematized. The SP, investigated in the last two articles of the thesis, constitutes a typical case of a sport-based social and welfare intervention with social objectives as premise. That intervention provides the principal object of investigation, reflecting some instances of the policy context introduced here.

\section{Research prospects}

The steady growth in sport for social objectives has not been matched by an equal intensification in studies of this development in sport and social policy (Houlihan, Bloyce \& Smith 2009). One empirically based finding in the thesis, presented in article 1 , is that this is specifically the case in Swedish research. In addition, Wirén Akesson (2014) notes that only a small share of Swedish sport studies with social concerns are produced in disciplines such as sociology or social work; instead, the focus is on pedagogical perspectives focusing on voluntary sport in associations. However, in just the past few years, there has been a substantial increase in international studies on the subject, and this increase may soon start to be apparent in Sweden as well (e.g. Österlind 2016; Stenling 2015). Most specifically, there seems to be a want for critical perspectives on the role that sport has come to play in providing welfare and achieving social objectives. In a note on the current sociology of sport, Coakley (2015) warns that "the great sport myth" undermines critical thinking in research on sport for social objectives. He suggests that the notion that "sport inevitably leads to individual and community development" (Coakley 2015, p. 404) has become so established even among researchers of sport's role in society that there seems to be "NO need to study and analyse sport critically, because it is already as it should be". In accordance, Coalter (2015, p. 22) argues that the "need for scepticism is nowhere more relevant than in the area of sport-for-change" and that research needs to be "theorising [sport's] limitations as well as outlining its 'potential"', Most notably, critical approaches are 
sought after (Black 2010; Coakley 2011a, 2015; Coalter 2015; Collins \& Haudenhuyse 2015). Furthermore, there have been calls for theoretically informed analysis (Houlihan, Bloyce \& Smith 2009) and for evidence-based empirical research (Coalter 2011a; Houlihan, Bloyce \& Smith 2009; Richards et al. 2013) on the seemingly new role of sport in welfare provision. Heinemann (2006) in particular has declared that we must examine the ideological underpinnings and foundations of sport and welfare initiatives that form interventions. Consequently, the sociology of sport with relevance for welfare provision and social work calls for a revitalized analysis of sport's emerging role in social and governmental policy, highlighting the significance of governing and welfare interventions that operate through sports (Houlihan, Bloyce \& Smith 2009). Studies on governmental rationality focused on sport for social objectives have provided and continue to provide valuable insights and perspectives (e.g. Agergaard \& Michelsen LaCour 2012; Agergaard, Michelsen La Cour \& Treumer Gregersen 2015; Green, M. 2007; Green, M. 2012; Green, M. \& Houlihan 2006; Österlind 2016; Österlind \& Wright 2014; Piggin, Jackson \& Lewis 2009). Specifically, Österlind and Fahlén (2015) have argued for the benefits of such an approach and of focusing on governmental rationality in studying the organization of sport in Sweden. They spotlight how such an approach may provide with insights on how problems are conceptualized in relation to the promotion of sport as a solution, on how the relations between state and civil society in Swedish sport policy are arranged and on how social change are governed with respect to sport policy in times of advanced liberalism.

'Sport as a means of responding to social problems' constitutes a regime of practice that needs more attention in research. This study helps to fill a gap in the research on the emerging regime of practice described. It contributes to the general level of knowledge on the subject and highlights the pedagogical dimensions operating within sport-based interventions. By critically scrutinizing the truths and practices of 'sport as a means of responding to social problems' that are taken for granted, the study is not undermined by the great sport myth; rather, the study investigates how such a myth operates within 
the regimes of practice and truth that emerge in the statements analysed. This study adheres to calls for research that contextualizes the emergent regime of sport-based interventions within a broader development of welfare provision. 


\section{METHODS AND METHODOLOGY}

In this chapter, the methods used in the thesis are presented. The chapter focuses on how theoretical and methodological approaches have been assessed and conveyed in empirical analysis. The purpose of presenting the methodological considerations is to aid in assessing and understanding the empirical analyses that constitutes the substantial contribution of this thesis. First, based on the theoretical framework presented in chapter 2, an analytics of governing is methodologically explored at length. In this section, a clear and detailed description is given of how the theoretical underpinnings take shape in articulating the aim and questions of this thesis. Consequently, important concepts and themes investigated are explained and developed. The section also demonstrates how the frameworks underpinning this constitute an interpretative as well as critical strategy for analysis. Second, two distinct kinds of empirical material are examined in the study. The scientific discourse conveyed in the research literature and the Sport Program (SP) discourse produced in representatives' statements are presented. The SP, viewed as a case of the regime of practice examined, is presented in detail. Third, an account is given of how the methodological approaches in the four articles constituting the thesis are aligned. Examples of how the analysis in each article was conducted in practice are provided and explained. Fourth, some reflections and discussions on the theoretical and methodological approach are elaborated concerning ethics, the selection of empirical material, the specific analytical approach and the assessment of the findings produced in the thesis.

\section{Methodological considerations: an 'analytics of governing'}

An analytics of governing (cf. Dean 2010) seeks to examine in particular how regimes of practices and truth have been enabled, how power and governing operate and are exercised, and what potential effects are made possible from a certain way of governing (Bacchi 2009; Bröckling, Krasmann \& Lemke 2011; Dean 2010; Rose 1999). With its special focus, this analytics provides a theoretical framework for making visible how social problems are constructed and how the knowledge about problems is intertwined with means and technologies used in response. It thus facilitates 
investigation of how problematizations and technologies produce a certain kind of social change, social life and citizen subjects (cf. Dean 2010; Rose 1999; Rose 2000b). From this point of view, the contingency of power, manifested in established truths and in practices, can be highlighted and problematized. By focusing on the governmental rationality, the particular and local governing practices can be studied to see how they form certain rationales that are part of, and constitute, the "exercise of power at the scale of whole societies and populations" (Gordon 1987, p. 296) and ultimately the politics of social work. The approach presented acknowledges activities such as sport and leisure activities that are performed for the promotion of youths' wellbeing, seemingly beyond the scope of formal politics, as important sites where governing ought to be scrutinized. Because such practices involve social change and promotion of social inclusion, and because social change is strategically conducted (imbued with a certain governmental rationality), producing frames for interpretation and a certain kind of citizen subject, these are political practices and constructs - and ought to be analysed as such. As was noted in chapter 2, it is important to scrutinize power and politics where such dimensions of social life are not overt or visible and where truths are not contested. The analytics provides a toolbox of concepts and perspectives that enable interpretation of patterns and regularities in statements on problems, means and ends of social change (cf. Rose 1999). This section deals, first, with the questions raised and, second, with the use of the toolbox in interpretation strategies. Some examples of how these questions have been approached in the articles are provided. It then concludes with a brief remark on how this analytics constitutes a critical approach.

\section{Analytical questions}

The aim of the thesis is to examine how rationales of social change are formed through 'sport as a means of responding to social problems'. Accordingly, four questions have been articulated with the help of the theoretical framework. These questions are elaborated on in detail here, and some examples of how they have been approached in the empirical examinations are provided for illustration. 
How is it that sport can be thought of and articulated as a means of responding to social problems? This question focuses on the circumstances and conditions around which the regimes of practice and truth that constitute governmental rationality have been enabled. Because governmental rationality is contingent and the result of social processes and ideological confrontation, the analytics investigates the discursive premises and even takes into consideration the historical, political and institutional conditions that enable the specific ways of governing. In the first instance, discursive premises concern the assumptions that are taken for granted and that underpin governmental rationality (Bacchi 2009). This concerns the notions of problems, domains for intervention, means and technologies to promote social change as well as the kind of citizenship that is implied in the statements examined. In the second instance, truth, practices and rationality emerge within a context of historical and institutional conditions, which need to be delineated and analysed (Bacchi 2009). This concerns, in a general sense, certain dimensions of welfare state transformations and sport in welfare, which were introduced in previous chapters. For instance, the discursive premises supporting 'sport as a means of responding to social problems' are investigated in article 2. Attention is paid to notions of individuality and transferability and how they enable a certain type of knowledge about sport as a means for individuals to attain skills that may be transferred to other social spheres. As for historical and political conditions, they are concerned, for instance, in relation to de-statization of government, discussed in article 4.

How are sport practices assumed to operate as a means of responding to social problems? This question focuses on the activities and processes of power - what power and governing do, how they operate (not on who presumably possesses power). The approach targets the precise technologies and techniques employed to promote social change and governing. It aims to explore what conducting the actions and behaviours of subjects really means, how the production of citizen subjects, subjectivities, is carried out. The approach does not focus on state power or any other agency that presumably possesses power; instead, the state is one of a variety of agencies and authorities involved in governing (Bacchi 2009; Rose 1999). 
However, this should not entail reluctance to analyse the technologies of governing promoted by the state, since the state is inevitably a form and authority in doing government (cf. Villadsen \& Dean 2012). Certain technologies that operate in practice may be exemplified by role-modelling techniques scrutinized in articles 3 and 4. They make visible how governing is exercised in practice through sport.

How are social problems represented when sport is promoted as a means of response? This question is underpinned by the view that problems and solutions are intertwined, indeed, that statements about means of social change in response to problems are constitutive of problem representations and give shape to problems. By focusing on the regime of practice (sport) promoted in response to social problems, it becomes apparent how the problems are represented and become constituted in a specific way. The question posed aligns with Bacchi's (2009) well-reputed question, "What's the problem represented to be?" Problem representations, or problematizations, could be viewed as one of two kinds of fundamental effects of power studied in this thesis. Discursive effects are the frames for interpreting problems (and solutions) that are produced, which enable or limit the ways problems and solutions in general could be thought about (Bacchi 2009). For instance, very briefly, article 2 concludes that, although problems are explicitly viewed in research as having structural causes, the responding solution targets individual change, which represents the problems at hand as individual problems. Hence, the problem is represented as an individual lack, for instance, of pro-social skills - and such knowledge can be acted upon through a certain set of technologies. The other kinds of effect examined, subjectification effects, are the ways in which citizen subjects and subjectivities are shaped as a result of governing (cf. Bacchi 2009, Cruikshank 1999; Rose 1999). This is further developed with respect to the next question.

What conduct, subjectivity and citizen competences are shaped within this regime of practice? As was shown, the ends of governing and social change promoted could be described as producing and shaping the actions and behaviours of citizen subjects and their kind of subjectivities. 
Effectively, the question concerns the end product of this kind of social work: it questions what competences and capabilities, what subjectivities, are considered desirable or even necessary for social inclusion, for managing risk or for averting social problems. For instance, in article 3, it is noted how such governing practices aim to shape a self-governing citizen subject empowered with the selfconfidence and self-esteem necessary for choosing the right track in life.

All in all, the aim proposed and questions explored provide an entry to investigating the regimes of practice and truth sketched out in terms of 'sport as a means of responding to social problems'. Alongside the theoretical framework and toolbox of concepts highlighted, the questions give rise to an interpretative strategy for finding the implicit and untrodden rationales embedded in truths about problems, domains, technologies and subjects - finding a certain kind of rationality for (the politics of) social work in the context of welfare recalibration.

\section{Interpretative strategies}

The analytics of governing laid out above entails an interpretative strategy. The strategy could be viewed in two sequences: first, disassembling the truths and experiences that are taken for granted as articulated in statements; second, re-assembling them to make visible governmental rationality.

Keeping in mind that truth and practices (the governmental rationality) studied are constructions, this analytics is aimed, at least in a very rudimentary sense, at deconstructing and problematizing them. Problematizing, in a methodological sense, means "putting into question of accepted "truths" (Bacchi 2012, p. 1). Deconstructing, in this sense, means dis-assembling the truths that are taken for granted which underpin any way of governing and making clear the contingency of thinking, talking and doing government. This kind of discursive analysis aims to clarify how, on what grounds, truths and rationales are formed and how they become coherent sets of meaningful statements (cf. Howarth 2000; Winther Jørgensen 2002; Winther Jørgensen \& Phillips 2000). 
However, it is not a matter of finding hidden agendas, intentions or ideologies behind the statements (Rose 1999). The approach acknowledges that the truths and experiences related to problems, domains, technologies and subjects, which are articulated in statements are effectively the interpretations of articulating subjects of the world and its objects (Bacchi 2009, Rose 1999). To analyse them is to "interpret interpretations" (Derrida 2003, p. 354), which calls for a certain reflexivity and perspectivism: to establish a critical distance to the seemingly timeless and natural truths of one's own time (Rose 1999). In line with Flyvbjerg (1991), the analytics of governing described above does not seek to access an assumed inherent essence in the objects observed; instead, it seeks to understand how the interpretations that gain status as truth have been formed and how the objects experienced are constructed and made intelligible in a specific way. Here, the interpretative strategy deviates from hermeneutic interpretation and phenomenology (Dreyfus \& Rabinow 1983). In the sense that deconstruction involves interpretation of interpretation, it could be viewed as a form of second-order observation (Luhmann 1993). Analysis is focused on how respondents (subjects of articulation) conceive of, interpret and describe 'sport as a means of responding to social problems'. Their interpretations are first-order observations. The analytical move is then to trace (interpret) the rationales structuring the subjects' interpretations - to analyse the interpretations and articulations made, second-order (cf. Luhmann 1993).

More than dis-assembling knowledge, the analytics seeks to elaborate refined understandings, concepts and perspectives of how regimes of truth and practice are formed (cf. Howarth 2000). This means re-assembling knowledge in a way that makes visible how it constitutes governmental rationalities. Accordingly, the concepts and perspectives presented are used as a toolbox, enabling interpretation, for seeing patterns and regularities, for providing context and for re-assembling the dis-assembled statements, the result of which is refined perspectives and understanding of the truth and practices promoted in the statements analysed (Rose 1999). The toolbox presented guides the interpretations made. This means that it is not a way to deductively test the observations of 
general lines of government, for instance in advanced liberalism, or to theoretically derive conclusions about how any way of governing is neo-liberal, neo-conservative or any other label. For instance, Mik-Meyer and Villadsen (2013, p. 3-4) note that highlighting a diagnosis of a gradual shift in governing welfare rationales means taking inspiration from a particular way of interpretation, not settling by pointing out certain political programs or historical epochs - they urge investigations to "avoid an abstract, a priori and too hasty critique ('this is simply neo-liberal domination') and to give priority to the careful study of practices". The purpose is thus to examine and problematize how governing is exercised, not to confirm that a given kind of governing has a certain label.

\section{A critical approach}

Deconstructing and problematizing the taken-for-granted truths and highlighting the contingency of truth and practice make the analytics a critical approach (Dean 2010). In short, the critical approach seeks to make visible the historical and political contingency of the rationales analysed as well as demonstrate the potential effects enabled for individual youths, society, the welfare state and, not least, social work. The analytics is diagnostic in the sense that it identifies the regimes of truth underpinning action, diagnoses how domains of governing are demarcated and formed, how technologies operate and how subjects and populations are produced in effect (Rose 1999); it demonstrates the contingency of governing rationales but does not prescribe alternatives (Dean 2010). This means that such an analytics is not an emancipatory project of liberating citizen subjects from governing. The analytics of governing does not seek to reform the conduct of conduct or install new technologies or forms of subjectification (Dean 2010).

\section{Empirical material examined}

To conduct the analytics of governing, a variety of statements in two distinct sets of empirical material are examined. The first consists of statements produced in the scientific discourse about sport as a means of responding to social problems with respect to the specific case of crime prevention (articles 1 and 2). The knowledge produced in research has a special significance in giving 
shape to the regimes of truth about 'sport as a means of responding to social problems' and is therefore highlighted in the studies. The second comprises statements articulated by social entrepreneur representatives and sport coaches (article 3) as well as municipal policy makers and administration (article 4) with respect to the Sport Program. Such statements make accessible how knowledge about 'sport as a means of responding to social problems' is employed in practice. This empirical material provides two contexts where knowledge about sport's potential for welfare provision is articulated. The material included was selected because one set represents a context with special importance in producing the regimes of truth investigated and because the other enables an investigation of how knowledge is employed in emerging regimes of practice. This section contains three parts. First, the scientific discourse is presented. Second, the Sport Program is introduced. Third, the statements constituting the SP discourse are outlined.

\section{The scientific discourse}

The kinds of statements analysed in articles 1 and 2 constitute scientific knowledge; this consists of Swedish and international research literature on sport as a means of responding to social problems in the case of crime prevention. Such research literature is accessed in the form of dissertation theses, scientific articles in peerreviewed journals, popular scientific articles, research reports, books and designated book chapters. The literature was selected after thorough database searches, manual searches of publications and publication series and systematic review of references in the literature identified. Databases included, keywords used and selection criteria are presented in each article.

Statements in the scientific discourse focusing on Swedish research literature are reviewed in article 1, with international research providing a contextualizing background. In the study presented in article 1, 38 scientific pieces examining the situation in Sweden (including mostly research reports and project evaluations) were included. In addition, 53 international research publications provided a context in this study (mainly scientific articles in peerreviewed journals). In article 2 , the international body of research 
constitutes the scope of investigation. Some 55 research publications were included in the material. Scientific articles in peerreviewed journals constitute the bulk of the material, but research reports, book chapters and monographs are also represented. Publications from a wide range of disciplines such as sociology, sport studies, pedagogy and education, social work, criminology, psychology, history and political science are included.

Most importantly, articles 1 and 2 are distinguished by different scopes of interest, not by different empirical material. The different scopes are presented in the next section. Many of the publications reviewed are included in both articles 1 and 2, but they are approached from different points of view. With respect to examining social change in relation to 'sport as a means of responding to social problems', crime prevention is noted here to be a necessary delimitation of such efforts. Without this emphasis and limit, the empirical material and body of scientific discourse would be unmanageable.

\section{Introducing the Sport Program}

Articles 3 and 4 of this thesis examine statements made in relation to and about the Sport Program. The SP is viewed in this study as typical of the kind of institutionalized practices that use sport as a means of responding to social problems that were examined in chapter 4. The program was chosen as a typical case because it thematically concerns central features of the regime of practice noted in research. The program was selected and included in the study because it provides a case of the development in sport policy and social policy described in chapter 4. Articles 1 and 2 also schematically demonstrate some lines of development of the regime of practice concerned. Underpinned by the findings in these articles, the SP could then be assessed as an object of investigation. The kind of sport-based social and welfare intervention that the SP constitutes is typical in a range of instances of the kind of practice that is premised by social objectives and that enjoys some formal expectations from governing bodies in public welfare. A number of features were recognized from the scientific discourse; social objectives were seen as a premise of the sport practices, the notions 
expressed about the program contained ideas about social change and pedagogy (beyond ideas limited to diversion from deviancy), and the kind of social change promoted was related to both individual development and the building of social capital and relations as well as community development.

Another important feature was that policy makers acknowledged the program as an innovative way of providing welfare. The program had attracted attention in the media and was assessed as a potential research object. After initial contact with the social entrepreneur manager and with municipal government administrators, the program background and rationale were outlined. Shortly after, initial and informal meetings were held, in which respondents agreed to participate in the study.

The SP is conducted in cooperation between a social entrepreneur, the municipal political administration (municipal schools) and local sport clubs. The program was originally conveyed as a political response to needs and special requests for backing from sport clubs in an urban area (hereinafter 'the place') in a large Swedish municipality. Local politicians also acknowledged the needs and problems attributed to 'the place' in municipal debates and statements in mass media. The program was initiated by municipal policy makers in the governing Social Democratic party (in consensus with the other parties in the municipal council) and by municipal administrators, and managed by the social entrepreneur in partnership with local sport clubs. The aim was to respond to social problems such as crime, segregation and social exclusion. In short, the political administration responded to the request by involving a sport coach (hereinafter the social entrepreneur manager) from a local sport club for the project who then re-organized the project into a social entrepreneur corporation, performing the Sport Program on behalf of the political administration.

The program is carried out as sporting and outdoor activities during school, after school and during school holidays. Several sports are performed in the program, among them football, basketball, boxing and dancing. The SP involves traditional sport associations that are involved in competitive sports with implicit prospects of potential 
social benefits in their everyday practices. The clubs are enrolled in this intervention to contribute to social and welfare objectives based on more explicit expectations within the SP. Social entrepreneur coaches and local sport club coaches lead the sport activities. The manager and the coaches implementing the affiliated practice have articulated the statements analysed in articles 3 and 4.

Notably, the manager and coaches are men in their twenties with a background in sport. They are not professionally trained in social work or education but have experience growing up in areas like 'the place' and experienced social problems in their youth. Details about the participants articulating the variety of statements examined, both the manager and coaches as well as the policy makers and the civil servant, are presented in the next section. Since its launch, the SP has attracted considerable local and national media coverage. It has expanded and spread to other Swedish cities. In 2016, the SP is still operating in the original city and in four other Swedish municipalities. Clearly, this makes it even more relevant and urgent to examine the program. Since it started, the program has received a number of awards. To conclude, the SP constitutes a case of sport practice where the social objectives are considered a premise. In other words, sport is used as a tool and a means that incorporate technologies to promote social change in response to social problems and is assumed to drive social change according to a certain governmental rationality.

\section{The Sport Program discourse}

Articles 3 and 4 examine the discourse articulated with respect to the local sport-based social and welfare intervention presented. In article 3, statements made by the social entrepreneur managing the program and the sport coaches leading the activities are analysed. The manager and the two affiliated coaches who have implemented the practice and articulated the statements analysed share a common background: they have practiced sport continuously in life; they are men between 20 and 30 years of age (the manager is in his late twenties; the coaches are in their early twenties); they were either born abroad or have immigrant parents; they grew up in 'the place' or in similar urban areas in Sweden; they lack formal social work or 
pedagogical training or other higher education; they describe themselves as not being involved in drugs or crime but they allegedly saw and were around such problems in their childhood and youth.

The statements examined were accessed in four ways. First, interviews with the respondents were conducted on site at the Sport Program (and in one case on the university campus) and transcribed verbatim. The manager was interviewed, twice and the coaches were each interviewed once. Each interview took between 45 and 120 minutes. Interviews were guided by the respondents' own descriptions and presentations of the program and did not follow a predefined schema. Unquestionably, statements made during the interview are shaped by and dependent upon the situation in which they are articulated (Bech Dyrberg, Dreyer Hansen \& Torfing 2001; Potter \& Wetherell 1987) and in dialogue with the interviewer. The specific nature of such context-specific articulations need to be taken into consideration when analysing interview statements from a discourse analytical point of view (Cruickshank 2012; Potter \& Wetherell 1987). In order to investigate the discourse and the kind of truth articulated by the representatives themselves, little steering by the interviewer was desired (cf. Cruickshank 2012). Serious efforts were made to minimize the interviewer's influence. For instance, the interviewer initiated various subjects, asking the respondents to describe aspects of the practice. This could be assessed in interview transcripts that generally contain long narratives rarely interrupted by the interviewer. This empirical source provides prompt articulation of the discourse and direct access to the notions and assumptions underpinning the regimes of truth and practice analysed. The empirical material analysed relies to a high extent on interviews. Second, statements were taken from a public PowerPoint presentation normally used to present the program to an audience of potential partners and sponsors. The presentation contains 25 slides and is a major component of the empirical material since the rationales of governing and providing welfare are articulated in great detail. As a complement to the interviews, the presentation provides a more permanent form of articulation. Third, explicit quotations made by the representatives 
in 22 local newspaper articles between the years 2008 and 2015 were collected. The statements included provide insight into how the intervention is presented to the public. The newspaper material contains a lot of text that is not statements made by the manager or the coaches - such text is not included in the analysis. Fourth, the SP's official Articles of Association were obtained from the Swedish Companies Registration Office. This constitutes a relatively short statement - only about half a page of text are up for qualitative analysis. However, the statement concisely summarizes the purpose and scope of the cooperation and practice. The statement provides access to the official raison d'être. Further details concerning the statements accessed and analysed are provided in article 3.

In article 4, statements made by municipal policy makers and the civil servant in charge of the administration are analysed. Municipal Councillor 1 chairs the Municipal Executive Committee and previously chaired the Childcare and Education Committee. Municipal Councillor 2 chairs the Childcare and Education Committee and is a member of the Municipal Executive Committee. Both councillors represent the ruling Social Democratic Party in the municipal council. The councillors were actively involved in setting up the SP and thus have a good understanding of the program. The senior civil servant is responsible for running the section of municipal administration that deals with the municipality's role within the SP. The three representatives were carefully selected for this analysis because they hold key positions in social policy formulation and administration, producing the kind of regimes of truth being scrutinized.

Statements examined were accessed in three ways. First, interviews with the respondents were conducted at City Hall and transcribed verbatim. The interviews took between 75 and 100 minutes each. The interviews were guided by the respondents' own descriptions and presentations of the program and the role of municipal authorities in relation to this. In this case too, interviews provide prompt descriptions of and access to notions and assumptions underpinning knowledge. Second, statements made by the councillors in a debate in the municipal council following an 
interpellation question were accessed on audiotape and transcribed verbatim. Five speeches and replies made by the policy makers were included. The debate involved a total of 10 councillors. However, statements made by other participants were not included in the material selected. Third, explicit quotations made by the councillors in local newspaper articles between the years 2008 and 2015 were collected. A total of 13 articles were included in the analysis. The articles contained a lot of material other than the statements made by the two policy makers that were not included in the study. Further details about the statements accessed and analysed are presented in article 4. As was noted with respect to article 3, the variety of statements includes, in this case, interviews, political debate and public presentation, which gives insight into various aspects of the knowledge articulated. The empirical material used was translated from Swedish into English by a professional translator to enable the presentation of excerpts in the articles. The translations were made with great carefulness and accuracy (cf. Nikander 2008).

\section{Four articles: procedures in analysis}

The four articles constituting the main body of the thesis are embedded within the analytics of governing and the theoretical framework introduced. However, this framework is not coherently made explicit in the different articles; moreover, each of the four articles constitute studies that stand on their own. In this section, a description is given of how the aim, theory and methods employed in the different articles are aligned; the distinct procedures involved in analysis are outlined and the way in which they are all encompassed by the analytics of governing is highlighted.

The first article investigates how Swedish research on 'sport as a means of responding to social problems' in the case of crime prevention can be understood in relation to international research. With its focus on the research questions posed in the literature on sport and crime prevention, the article is explorative, tracing objectives and perspectives in Swedish research that are disregarded or unexplored and identifying fruitful approaches for further research. In this specific article, the strategy of interpretation is 
inductive in the sense that no explicit theoretical argument drives the analysis; nor are the aim and questions posed theoretically generated. The literature review is described as a qualitative content analysis aimed at category development. The procedures used in analysis contained four subsequent steps. First, the literature was read thoroughly and the aims, theoretical framework and central findings in the literature examined were systematically identified. Second, the literature was analysed based on how the research questions were constructed and what the key results were. Third, certain patterns and regularities were observed in the articulations of research question and the key results identified. These patterns in the content served as the basis for the construction of categories. These categories made visible the central research approaches and the central findings in the literature. Fourth, characteristics in the Swedish literature were elaborated in light of the international research. These procedures are accounted for in the article. Notably, the merits of the article were in specifying the precise perspectives, aims and research questions to be investigated in the thesis. Accordingly, the article stands on its own in taking an explorative and inductive approach - and as a precondition for the perspectives promoted in the aim and questions of this thesis.

The second article aims to interrogate the knowledge about sport as a means of crime prevention generated in research. The ambition is to examine the discursive premises underpinning it and consider how this knowledge has been made possible. In addition, some discursive effects formed in relation to this are discussed. The discourse produced in the scientific literature is then examined with respect to how strategies of social change through the means of sport are explained. In contrast to the previous article, this article focuses on the premises enabling a certain kind of knowledge and on the discursive effects that may be produced. In targeting the discursive premises and effects with respect to the regimes of truth produced in the scientific discourse, the scope of the article most clearly aligns with the general aim, questions, theoretical framework and analytics promoted. Within the frames of a constructionist epistemology, the analysis takes an open-minded approach to the modes of prevention and discourses underpinning it. The analytical 
procedure for examining the manifest statements and developing abstract conceptions about the discourses and implicit underpinnings was conducted in three steps. First, the literature selected was read and systematically compiled with respect to the aim (including research questions), theoretical framework and findings. Based on patterns and regularities in the kind of research questions articulated, themes in the content could be clarified. Second, two main categories were constructed, into which the various themes in the literature examined were sorted. Prevention rationales of aversion were distinguished from rationales of social change. The two initial steps could be viewed as analytically descriptive, whereas the third step revolves more around an analytical discussion aimed at exploring how (through what discursive premises) these rationales have been enabled. Third, two discourses underpinning and shaping the content were identified. Individuality and transferability were identified as the rationales giving structure to the disparate and ambiguous content that constituted 'sport as a means of responding to social problems' with respect to crime prevention. The analytical moves from thematization and categorization to abstract conceptualization and reflective discussion align with the constructionist approach and are developed further in the article.

The third and the fourth articles then investigate the Sport Program discourse presented previously. Article 3 aims to examine how governing is conducted and exercised and how certain citizen subjects are formed and enabled for inclusion within the SP. With a focus on statements made by the social entrepreneur manager and affiliated coaches, the analysis seeks to interpret the rationales of governing in terms of problematization, technologies and subjectification: how they are enabled, how they operate, how they make certain effects possible. The analytical procedure was carried out in two steps. First, the articulations examined were sorted into three main themes. In accordance with the analytics of governing presented above, statements were identified as concerning problems, responding technologies and subject enactments. Thus, the themes mentioned were theoretically derived. Second, the statements sorted into each category were interpreted based on the toolbox described 
above, which is constituent of the analytics of governing. For example, the significance of risk was observed in the statements examined with respect to problem representations. Inspired by theoretical conceptualizations of risk in relation to agency, described above, rationales of risk intertwined with technologies of agency were noted as structuring the governmental rationality imbued in statements. Similarly, recognizing power as a productive force, the frames for interpretation helped to identify and sort out the different sequences in forming a desirable citizen subject provision of individual powers, promotion of freedom of choice and responsibility for consequences based on using the powers attained, and last, role-modelling of the powers provided and attained in shaping the includable citizen subject. In consistently adhering to the principle that problems and governing technologies (solutions) are constitutive of each other, representations of problems and the rationales underpinning governing technologies became clear. In this respect, the analysis follows the analytics of governing delineated above.

Article 4 aims to examine how a specific domain for intervention 'the community' - is formed for inclusion of youth citizen subjects within the SP. With its focus on statements made by the policy makers and the senior civil servant, the analysis seeks to trace the different strategies assumed to produce a sense of community. The analytical procedure contained three steps. First, based on an openminded initial reading of articulations, notions of 'the community' were identified as a response to tensions in society. In this sense, 'the community' was associated with inclusion, integration and social cohesion. This kind of response was enabled by the problematization that was focused on segregation as a cause of tensions, which in turn was believed to trigger social problems and social exclusion. Based on this observation, Rose's (1999) conceptualization of 'the community', described in chapter 3, was then used to interpret the statements. Second, three themes were discerned in the empirical material. The first two concern dimensions of how 'the community' could be formed. In one instance, it is formed as something distinct from state-centred public welfare; in another, it is formed as a space for moral and personal 
relations between authentic human beings. The third theme concerns the effect enabled by this particular representation of 'the community', namely, how the program was organizationally arranged. Third, the content in these themes was interpreted using the theoretical toolbox described above. For instance, the significance of moral and personal bonds as a characteristic feature of 'the community' was key to understanding how the SP was used as a strategy to overcome the line between statist public welfare and non-statist civil society and to provide social work with a human touch. Through such manoeuvres, the governmental rationality within 'sport as a means of responding to social problems' could be analysed and intriguing findings could be made - findings that aid our understanding of how micro practices of social work epitomize welfare state transformations.

In both articles, the examinations of statements follow the analytics of governing presented above. The various statements examined were dis-assembled, and themes, regularities and patterns were discerned and interpreted on the basis of the theoretical framework advanced. These formed re-assembled interpretations that highlighted abstracted concepts of problematizations, domains for intervention, governing technologies and subject enactments. In practice, the procedures of the analytics of governing in each of the studies had three common denominators. Thematization involves sorting the content, comprised by statements, treated as discourse according to the methodology and epistemology described. Interpretation involves dis-assembling and re-assembling statements based on the theoretical toolbox in search of the structuring rationales. Contextualization involves locating the rationales found in relation to lines of development in contemporary social policy.

\section{Discussion of methodology}

The methodological approach can be discussed and considered from a wide range of aspects. In this section four issues are brought forth. First, some thoughts on gathering empirical material are developed. Second, some reflections are conveyed regarding the theoretical framework and analytical approach of the study. Third, some concerns about how the knowledge produced in this study 
could be assessed are expressed. Fourth, concerns about research ethics are raised.

\section{Selection and collection of empirical material}

Two kinds of empirical material are investigated in this study. The material was described in previous sections, and the choice was justified based on the aim and questions of the thesis. In short, it has been acknowledged that the scientific discourse has a vital impact on the regimes of truth analysed and that the SP constitutes a typical case of a sport-based social and welfare intervention utilizing sport as an explicit means of responding to social problems, one that has emerged both in Sweden and elsewhere. However, some concerns about the material selected need to be sketched out.

First, articles 1 and 2 explicitly concern crime (and crime prevention), while articles 3 and 4 concern, along with crime, social exclusion and social problems in a broader sense. This could be considered from two angles. In one instance, crime is highlighted as a manageable example of a social problem. In the scientific discourse investigated, the focus on crime and crime prevention represents a necessary demarcation of social problems (and the solution attributed). Without this delineation, the empirical material would be too extensive to conduct this kind of review and investigation. In another instance, it is sport in 'sport as a means of responding to social problems' that is underscored in investigations. The focus is on the strategies for social change operating through sport. By focusing on sport, the constitution and representation of the social problems could be assessed. Hence, the slight variation in explicit forms of problems is only a minor concern. In addition, there is a certain point that social problems are not more specific in definition here. In the material examined, the explicit definitions of the problems targeted are very diffuse. The social problem could be viewed as crime but is given meaning in relation to segregation, social exclusion, failure in school and more. The meaning attributed to the problem in this context is the very object to be considered for analysis and scrutiny - and from the analytics of governing presented above, this can be done by paying attention to how the responding solution is promoted and performed. 
Second, limiting the analysis to the scientific discourse and the SP discourse has excluded an analysis of, for instance, national (or international) sport and social policy documentation. Such an analysis could arguably have benefited the analysis of the regimes of truth formed. However, since this policy area is under formation, focusing instead on the precise practices that enact and establish governing rationales provides more insight into the kind of knowledge about 'sport as a means of responding to social problems' that guides policy and practice. Other contexts and material are potential objects for future research. Regarding policy documentation in the case examined (the SP) in articles 3 and 4, there was insufficient documentation to provide empirical material for a fruitful analysis of the regimes of truth and practice promoted. In article 3, the documents accessed were examined with respect to official documentation and public presentations of the program. In article 4, documents produced in the political process, from municipal boards and the municipal council, were collected and initially analysed. However, the documents made up only a minor bulk of statements and made only a scarce contribution to the empirical material. A great deal was also excluded given the exclusive focus on the statements made by the designated policy makers and administrator.

Third, the SP was chosen as a single case of the regime of practice examined. Obviously, there are similar programs being conducted and potential cases in a wide range of forms around Sweden that could be categorized as examples of 'sport as a means of responding to social problems'. In setting up the study, other programs and practices were contacted; the plan was to include more cases in the studies. For example, institutional detention homes that carry out sport practices as a means of rehabilitation and prevention as well as grant applications for funding from the Swedish Sport Confederation based on social benefits from sport to voluntary sport clubs' programs. Contacts were established and the collection of empirical material was prepared. However, after an initial examination of the SP discourse material, a multitude of potential themes and findings were identified that needed further investigation and that would suffice for even more examinations 
than could be handled in one study. Based on this assessment, the other cases were put on hold. Hopefully, other practices and potential material will still be accessible for research in future. The SP was selected since it featured several of the most characteristic dimensions of the emerging regime of practice identified in the scientific discourse. This does not mean that the case chosen should be viewed as representative of all practices of this kind or serve as an object for generalization; instead, the case provides an opportunity to penetrate a specific practice and to study in detail some of the features known in the nexus of the sport and welfare provision.

Fourth, observations could provide other insights into the practices exercised. However, observations are a challenging method of collection, and the empirical material generated by such efforts would not likely make a worthwhile contribution. Instead, interviews give better access to knowledge that guides actions and practices; they give access to the respondents' self-reflections and their thoughts about their role in the intervention practices more directly and with greater precision. In targeting the governmental rationality imbued in and the regimes of truth that guide practice, the kind of knowledge articulated in statements constitutes a more thorough basis of study.

\section{Notes on the analytics of governing}

The theoretical perspective and analytics of governing conveyed in this study, described and developed in this and in previous chapters, have been discussed critically in the literature. A complete review of the range of themes, debates and discussions on the subject cannot be provided here. Scholars such as McNay (1994), McKee (2009), Walters (2012), Hörnqvist (2012), O’Farrell (2005) and Veyne (2010) go into detail on these issues. Beyond the methodological concerns noted, normative critiques about nihilism and anti-humanism (cf. Veyne 2010; Bové 1980) have been put forth in the debates but are not touched upon here. Four issues concerning methodological criticism with relevance for this particular study are discussed here, and an account is also given of how studies have addressed these issues. 
First, the governmentality approach has often been criticized for focusing on the discursive analysis of text in documents instead of on observations of material and concrete practices in the art of government. For this reason, explorations are viewed only to concern how governing is viewed and discussed but not how it is performed and conducted (McKee 2009; Stenson 2005). The previous section included reflections on excluding observations of governing practices from the material examined. The text-based empirical material provides access to the knowledges and truths articulated and the rationality imbued and was therefore preferred. Consequently, the study may lack input from an analysis of governing actions and the concrete exercise of power in practice; this could arguably have provided even further insight into the governmental rationality of 'sport as a means of responding to social problems' but would entail additional challenges and efforts. Nonetheless, statements analysed give access to respondents' reflections, self-understanding and views on problems and solutions with great precision, so this move was preferred. Supporting this stance, Miller and Rose (1990) argue for the importance of focusing on language while analysing government. They maintain that the means and ends constituting the political rationale can best be traced and analysed in discourse. They also argue that such an analysis takes seriously that it is investigation of the precise production of knowledge about objects and domains that provide with insights about how they are possibly made governable. Consequently, "the languages of description" (Rose 2000b, p. 322) are on the scope since that is where aspects of reality, problems, domains and subjects are made thinkable, animated and governable.

Second, studies of governmental rationality have been criticized for ascribing a certain rationality to a diverse set of practices where there really is no coherent rationality (Walters 2012). The point of an analytics of governing is to re-assemble knowledge to make visible the implicit rationality imbued. This means that the analysis does not take into account whether actors and agents expressing their views are themselves aware of this kind of rationality. Nor does the analysis concern the possible intentions behind statements. Rationalities are analytical constructs that the subject of enunciation 
may or may not be aware of (or intentional about). To say that there is no coherent rationality in practices would only mean that such a rationality has not yet been constructed.

Third, Villadsen and Dean (2012) warn of an analytical "state phobia" in studies on governmentality (not to be confused with the normative state phobia mentioned in chapter 7). With reference to, for instance, Rose and his discussion on 'the community' and civil society, they argue that scholars in the governmentality tradition have focused excessively on the dispersal of power and on how power is exercised by a diverse plurality of agencies, and ignored state-centred technologies - something that lacks support in Foucault's original lectures, Villadsen and Dean note. This kind of rejection of state power as a primary concern has been criticized from a range of perspectives (cf. McKee 2009) and is an important point of such critiques. This study is aimed at focusing not on the agencies exercising power but on the technologies through which power and governing are performed. The study recognizes that state-centred governing takes form through innovative assemblies of agencies and a variety of technologies. Indeed, it is the state and its municipal public agencies that find new forms for enacting social change and social inclusion by activating and assembling other agencies and facilitating the modes of interventions. In that sense, it is statist governing in reconfiguration that is included in the scope of investigation here. Arguably, the study specifically concerns the transformations and shifting rationalities in the Swedish welfare state. Although themes of de-statization are a notable feature of the developments in welfare provision, state power could not escape scrutiny in these analyses.

Fourth, empirical studies on advanced liberal governmental rationality most notably risk identifying only the exact characteristics of advanced liberal rule in their material (e.g. Mik-Meyer \& Villadsen 2013). Certainly, approaching sport practices with social objectives from the point of governmentality entails searching for the rationality of governing that is imbued. Scholars in this tradition have already noted features such as risk, agency, responsibilization and even community as key features of contemporary and advanced 
liberal social policy. However, analyses must not suffice in categorizing a certain kind of practice under the label of advanced liberalism, distinguished from welfarism (or any other demarcations of forms of power presented). Instead, the analyses in this study take these observations as a point of departure in interrogating how such themes and rationales are mobilized and enacted in a specific kind of social work and welfare provision. The study explores how social work and welfare provision are enabled and could be performed, how power and governing in terms of risk, agency, responsibilization and community are exercised through a specific regime of practice and what processes produce frames for both representing social problems and shaping includable citizen subjects.

\section{Reflections on the production of knowledge}

In line with the constructionist approach, the results and findings from this study could aid in understanding and problematizing what we consider knowledge and truth about 'sport as a means of responding to social problems'. The knowledge produced is specific to the empirical material examined; no pretence is made of drawing conclusions about other aspects of life and reality. A central point of recognition is that the analytics of governing does not offer an explanatory theory of power (cf. Rose 1999); instead, the knowledge produced may contribute concepts and ways of thinking to problematize certain aspects of welfare transformations and the role of social work. On a theoretically abstract level, such insights could aid in also understanding other developments in contemporary social policy.

Reflecting on the knowledge produced in this study also means concluding that the analyses and interpretations made are intelligible and reasonable based on the accounts of theoretical framework and the methodological considerations - not that the knowledge produced are reflections of and corresponding with an objective external reality (cf. Winther Jørgensen 2002). Supported by the theoretical framework and analytical approach outlined, the study has sought to trace some tendencies and rationales in contemporary welfare provision and governing. This does not mean that the tendencies and rationales outlined are the only themes in 
contemporary social policy; it means that these are tendencies and rationales that could be perceived and that the analysis exposes the kind of situations and activities they come forth and operate in. It is not argued that the tendencies and rationales demonstrated confirm a shift from welfarism to advanced liberalism; rather, the study considers how they operate and are contested within a certain regime of practice and truth.

The knowledge produced consists effectively of interpretations which moreover involve an interpreting subject (cf. Bacchi 2009). Accordingly, the researcher - the subject of the interpretation and articulation of the knowledge produced - is arguably subjected to surrounding regimes of truth (cf. Bacchi 2009); the researcher's subjectivity is the effect of a range of governing technologies and subjectification processes, which are not easy to sum up, let alone control. Moreover, because the knowledge produced takes shape as scientific knowledge, it contributes to such regimes of truth gaining status in society (cf. Foucault 1980). These issues call for a certain reflection on and awareness of the knowledge produced and how it should be assessed. From a constructionist point of view, this is intertwined with the methodological approaches presented questioning knowledge and truth (de-constructing and problematizing) are the very purpose of the methodology promoted.

So how could one assess whether the results and findings are intelligible within the frameworks and analytics presented and that the interpretations made are reasonable? A wide range of criteria for assessing quality in qualitative research have been developed. One common feature involves assessing credibility (e.g. Bryman 2004; Larsson, S. 2005; Patton 2015). With an account of the theoretical framework and its epistemological underpinnings - the methodological concerns of the analytics of governing and the analytical course of action taken as well as the detailed reports on the empirical material analysed - a clear case is made that the theory and methods are consistent with the aim and the questions posed; it then becomes possible to assess and guarantee the credibility of the studies in this thesis. The analysis and interpretations can be examined and assessed as intelligible and reasonable. 


\section{Ethics}

Because research and the production of scientific knowledge are recognized as a vital dimension of modern society, legitimate demands are raised that research should be conducted according to ethical principles (Gustafsson, Hermerén \& Petersson, B. 2006). Such codes of ethics are aimed at protecting groups and individuals involved in research (Oliver 2010); they are also aimed at protecting the wider population in society from potential harm as a result of research carried out (Gustafsson, Hermerén \& Petersson, B. 2006). This study was not subject to a formal ethical vetting. Research that could include sensitive information that is conducted without formal consent or that affects the participants physically or mentally needs to be approved. This study does not fall under those conditions. Nor has any risk of harming people involved as respondents been estimated, so such research does not need to be approved (Hermerén 2011). The study adheres to the Swedish Research Council's code of ethics about information, consent, confidentiality and usage (Swedish Research Council 2002). With respect to the empirical material comprised by the scientific literature, this is public material. With respect to the respondents involved in the SP, these guidelines need to be addressed. First, participating respondents were informed about the purpose of the study. Second, they gave their consent to participate after being fully informed about the purpose of the study, about principles of confidentiality and about that statements being used only for research purposes. The respondents were also informed about future publication channels. The respondents were informed that they could suspend their participation at any time. Third, the respondents were granted confidentiality. None of the respondents expressed concerns about confidentiality; instead, several respondents indicated that they did not mind if the name of the intervention, their own name or that of the municipality was spelled out. Still, confidentiality is granted. No names are given. Statements quoted from public material in newspaper articles and public presentations have been translated from Swedish to English and cannot be searched. The case was made confidential because the spotlight should be on the statements and the discourse - not the 
actors and agents articulating the statements. The focus is on the regime of truth - the discourse or structure of knowledge and thought - in which the articulating subjects are embedded and which enable the subjects' articulation of statements. Furthermore, the respondents have had no control over the frames of interpretation that have situated their statements; hence, it is not interesting to represent certain individuals as advocates of a certain kind of social policy (or shifting rationales of governing welfare) that they themselves are not conscious of. Accordingly, it is not important or interesting to engage in dialogue with these specific municipal councillors, the social entrepreneur manager or sport coaches; the study is rather in dialogue with the structure of power and knowledge that enable practices of governing social change (through 'sport as a means of responding to social problems') that also subject the specific respondents, their statements and subjectivity. In a way, this argument could be viewed as depriving the respondents of their agency. However, in that case, it would be in line with the theoretical approach not to focus on the agency or intentions of individuals, but rather on the discourse enabling subject positions - because, "the subject is not constitutive of meaning but the effect of discursively produced enunciative positions" (McNay 1994, p. 164). Fourth, the empirical material gathered is only being used in research. From a wider point of view, no potential harm to the broader population has been anticipated from the study or from the publication of results and findings; instead, the modest hope is that the study could benefit society and humanity by gaining new knowledge and refined perspectives on life, society and welfare. 


\section{RESULTS AND ANALYSIS: SUMMARY OF ARTICLES}

In this chapter, the findings and analyses in the articles are summarized. The main findings are highlighted and situated within the frameworks and background laid out in previous chapters. The findings provide a basis for the analytical discussion in the next chapter. This chapter thus only presents the findings; it does not synthesize or discuss them. The articles presented were submitted to and published in journals in the research fields of the sociology of sport and social work. The four articles presented build on each other in a sequence; they emphasize different aspects of the aim and questions presented in chapter 1 . Article 1 is explorative, mapping out the field of research and laying ground for the aim and questions investigated empirically in the later articles. The focus here is on the Swedish research literature. The findings suggest that a theoretically informed analysis is needed of sport as an explicit means for achieving social objectives, situated in relation to welfare state transformations. Article 2 reviews the international body of research with respect to the notions and assumptions that construct a scientific regime of truth about 'sport as a means of responding to social problems'. Article 3 refines the constructionist perspective by focusing on the governmental rationalities embedded in the SP. Special attention is given to pedagogical technologies that provide youths in the program with individual powers such as selfconfidence and self-esteem that they need to choose the right track in life. Article 4 continues the investigation of governmental rationalities within the program. The emphasis is on 'the community' as a space for solidarity inclusion and moral bonds as well as on how such a formation enables certain pedagogical technologies. It also investigates how 'the community' is distinguished from public welfare and professional social work.

\section{Article 1}

Ekholm, D. (2013). 'Research on Sport as a Means of Crime Prevention in a Swedish Welfare Context: A Literature Review'. Scandinavian Sport Studies Forum 4: 91-120.

The article is based on an examination of the scientific discourse, produced in Sweden and internationally, on sport as a means of 
responding to social problems. It explores how Swedish research on 'sport as a means of responding to social problems' in the case of crime prevention could be understood in relation to international research on the matter. The article seeks to specify characteristics in the Swedish body of research by asking what research questions and content are examined as well as how such questions and content are analysed. In this sense, the approach is explorative in mapping out the field of research and seeks to highlight some potential strands in need of further research. From this exploration, the main aim and research questions posed in the thesis are articulated and then investigated empirically in the three subsequent articles.

Through an inductive process of content analysis and category development, three types of research questions are distinguished. It was found that both Swedish and international research has focused on empirically driven, descriptive, evaluative approaches. Such research has sought to chart whether sport works, how sport works or under what conditions sport could work as a means of responding to social problems or promoting social objectives in relation to crime prevention. In brief, it was noted that while there is little evidence for sport as a means of achieving social objectives, sport could potentially benefit integration and community development, diversion from delinquency and individual pro-social development. A range of conditions for and limitations in this potential utility are listed in the article. From the exposition of content in the literature reviewed, a range of findings are highlighted that make visible specific characteristics of Swedish research.

First, the research seems to question the firm belief in sport's potential for achieving social objectives noted in policy making throughout Western society. The international literature suggests that there is nothing intrinsic to sport that makes sport suitable as a means of achieving social objectives. Furthermore, sport practices with such aims are difficult to evaluate properly because correlations between intervention practices and social objectives outcomes are complex and indirect, and the theory underlying sport practices for social objectives is most often poorly developed. This justifies further research on sport in relation to welfare provision and social 
objectives as a legitimate task. Second, empirically driven, descriptive and evaluative approaches both in Sweden and elsewhere subordinates more theoretically driven and constructionist approaches that examine the role of sport in society in relation to ideology or as a means of welfare provision. Based on this observation, such theoretically informed approaches situating sport in relation to welfare provision could provide with innovative perspectives, which would benefit the field of research. Third, Swedish research on sport in relation to social objectives of relevance to crime prevention most often focuses on the potential effects of sport practice participation. In contrast, international research has more often examined sport practices premised on social objectives. The distinction between premise and effect, presented in chapter 4, could be viewed as a central finding in this article, and constitutes a central analytical distinction for the general scope of the thesis. The Swedish research literature generally disregards this distinction. This could well be explained not by shortcomings in research approaches but by the fact that it is not a common feature in such practices - which see social objectives and solving social problems as the main premise for practice and utilize sport as a tool for achieving the objectives - either in institutionalized sports or in welfare provision. Accordingly, Swedish research has focused on sport performed in traditional clubs and associations.

The article includes a discussion of the tradition of broad target interventions in the Swedish welfare model. When sport is considered a means of providing welfare, this raises some questions: How is sport used to foster individuals in the Swedish welfare agenda today? How are changes in the Swedish welfare state mirrored in sport practices today? What ideological and political discourses related to welfare policy underlie the idea of sport as a means of achieving social objectives? The article concludes by stressing that further research is needed on Swedish conditions for sport practices based on the premise of social objectives. Such research would accordingly need to acknowledge the distinction between premise and effect. Furthermore, as a complement to the evaluative and descriptive research presented, more theoretically driven and constructionist perspectives focused on sport practices in 
relation to ideology and welfare could be advanced. From such a standpoint, the underlying assumptions, distinctions and research positions that constitute the conceptions and knowledge about 'sport as a means of responding to social problems' could be problematized and critically scrutinized. Such an approach could relate sport and social objectives to welfare state transformations and critically assess the emerging regimes of practice and the regimes of truth supporting it. Some research prospects identified from the analysis and findings were presented in their contours, intertwined with other perspectives on the field of research, in chapter 4.

\section{Article 2}

Ekholm, D. (2013). 'Sport and Crime Prevention: Individuality and Transferability in Research'. Journal of Sport for Development 1(2): 67-78.

This article is based on an exploration of the body of scientific discourse presented in the previous chapter. It draws upon the appeal for constructionist approaches in examining 'sport as a means of responding to social problems' highlighted in article 1. Such an approach is adopted, with the aim being to examine the scientific knowledge produced and scrutinize the underlying assumptions and notions - the discursive premises - that make possible the articulation of 'sport as a means of responding to social problems' in the case of crime prevention. In this endeavour, the study seeks to make explicit the implicit strains that are embedded in the kind of scientific knowledge produced.

Based on the identification of standard research questions (presented in article 1) that consider whether sport works, how it works and under what conditions sport could work as a means of responding to social problems, some initial findings are presented. First, concerning whether sport works as a means of responding to social problems such as crime, it was made apparent that there is a lack of clear evidence on the relationship between sport and social objectives, that there is nothing inherent in sport that makes it suitable for promoting social objectives in this regard and that 
possible correlations are complex, indirect and difficult to confirm. Second, with respect to how sport could possibly mediate the relation between sport and social objectives with respect to crime, two modes of response were identified. The averting mode deals with diversion and deterrence from social deviance and delinquent behaviour. The other mode, the social change mode, has a greater impact on research - and on the scope of this thesis. Social change involves both the development of individual skills and powers focused on 'the self and the development of personal relations within 'the community'. In the first instance, participation involves pro-social development such as empowerment that fosters individual activity and responsibility and leads to greater selfconfidence, self-esteem and self-control. These skills and competences of 'the self could also be understood in terms of the learning of life skills, that is, competences and skills that are transferable to other spheres in life. In the second instance, sport may promote social change through personal and social relations, leading to subjects obtaining forms of social capital, which could be related to community building and development. Third, in relation to what conditions sport could work under to promote social objectives, it is made clear that the emphasis should be on education in non-violence and on the importance of self-control and a sense of responsibility for oneself and for others. There needs to be a deemphasis of competitive elements, with stress thus on noncompetitive components such as personal and social relations with other youths and adults. Sport practices should also include a minimum of formal rules, to be adhered to individually or in smaller groups, and an emphasis on internal and individual motivation. Sport practices should also have a rational development plan with clearly developed and theorized means and ends. At the same time, the literature reviewed highlights several limitations to the potential utility of sport. For instance, sport cannot reduce poverty, unemployment or other structural causes of social problems such as crime; sport organizations are better able to provide sport than social services or welfare; sport reaches only limited strata of target groups; sport leads to exclusion because of the great emphasis on competition; sport legitimizes violence and rule-breaking; skills and competences attained in sport are not necessarily transferable to, or 
needed, in other social spheres. Crucially, focusing social change on individual conduct in terms of pro-social development and empowerment may even obscure structural understandings about the problems targeted through sport-based interventions.

A focus on the development of personal and social relations, empowerment, pro-social development and moral education constitute the primary ways of describing such social change. In this analysis, it is argued that these dimensions of social change only become meaningful concepts and rationales when they are underpinned by notions and assumptions about individuality and transferability. These two notions arguably create order in the otherwise disparate field of research on sport's potential for promoting social objectives and change and for responding to social problems such as crime. With respect to individuality, development of personal and social relations, empowerment, pro-social development and moral education all take the individual citizen subject's actions, behaviours and subjectivity as the subject of change. Moral and ethical dimensions of social change are stressed in the literature reviewed. Elements of moral education are seen as being fundamental in attaining competences with a social utility. Such education would focus on moral self-reflection, activity and responsibility of individuals and seek to instil a certain moral subjectivity in the individuals targeted; the technology would seek to impose certain values on the subjects and produce a certain kind of subjectivity. One of the key ideas about social change here is that individuals are supposed to attain powers with which they could enhance their ability to avert social problems. This is described as empowerment of life skills, which introduces the notion of transferability. Presumably, competences and skills, modes of actions, behaviours and subjectivity attained and produced within the sport setting could be transferred to other spheres of life - and hence constitute life skills necessary for playing the game of life. Such a notion of transferability presupposes that competences and subjectivities developed through sport participation are cherished in other spheres of society and that they can assist in helping youths to refrain from social deviancy and other such problems. It is notions like these that comprise the scientific regime of truth. 
Consequently, the analysis suggests that it is not possible to grasp 'sport as a means of responding to social problems' without taking into consideration the notions of individuality and transferability. Underpinning such a regime of truth, these assumptions and notions constitute a productive force that enacts a certain discursive effect. Solutions articulated in response to such problems in terms of social change that are focused on individual conduct represent problems (of delinquency and crime) as individual problems of morality. In this respect, sport is affirmed in some instances within the scientific discourse as a means of social change based on notions of individuality and transferability, producing a regime of truth that represents social problems as problems of individual and moral subjectivity and conduct, or rather the lack thereof.

\section{Article 3}

Ekholm, D. (in press). 'Sport-Based Risk Management: Shaping Motivated, Responsible and Self-Governing Citizen Subjects'. European Journal for Sport and Society.

This article is based on examinations of statements made by the social entrepreneur manager of the Sport Program and the affiliated sport coaches. The article proceeds to investigate sport practices with the explicit premise of promoting social objectives and providing responses to social problems in the direction set out above. In accordance with this direction, the investigation takes a constructionist perspective and focuses on the governmental rationalities entailed in the intervention. Two questions concerning the technologies and subjectification processes within the program are emphasised. First, the article investigates how governing technologies (and techniques) are described as operating within the program. Second, it considers how desirable citizen subjects are represented and enabled for social inclusion through the program. In order to address these questions, attention is given to the kind of problematizations that underpin and enable the specific governing rationale promoted.

From a constructionist perspective - the analytics of governing presented above - statements were analysed with a focus on the 
rationalities embedded in descriptions of problems and solutions. The analysis suggests that there is a discrepancy between the explicit articulation of the problem and an implicit representation of the problem in statements. Explicitly, problems of crime and social exclusion are explained by structural segregation; moreover, such segregation causes social problems specifically in the urban area targeted by the intervention, 'the place'. 'The place' is thought to be "off the map" (Coach 2) and to have a peripheral relation to the rest of the city; it is considered to be populated by immigrants at great risk of failure in school, unemployment, poverty, crime and exclusion; it is noted that the inhabitant population lacks social and economic resources to avoid social problems. Such segregation is attributed to 'the place' producing a spatialized domain, where problems are made visible and interventions may be put to work. Segregation is assumed to result in a risk of increasingly advanced social exclusion, from failing in school to being unemployed to doing bad things and becoming a criminal. Yet it is the lack of selfesteem, self-confidence and other powers of 'the self that is highlighted in promoting a response; it is the competences and agency of individual subjects that are to be subject to change and are made governable. This is possible because problems are articulated in terms of risk. When understood as risk, it is possible to make problems avoidable - the individual is given an opportunity and chance to navigate away from risk and problems.

According to the descriptions analysed, society is suffused with risks (specifically attributed to 'the place'), and these risks are taken for granted. Accordingly, subjects must learn to navigate among risks and problems, so they are equipped with powers of 'the self that are presumably needed to navigate and avoid them. Such risk rationality enables governing to focus on motivational powers, freedom of choice and "choosing the right track" (Coach 1), as well as shaping and modelling of the powers provided. When empowered with selfesteem and self-confidence, the subjects are urged to use these powers in seizing opportunities and making active choices. Accordingly, welfare and inclusion in terms of navigating and avoiding risk are represented as a matter of choice. In this sense, the 
problem is implied and represented as being a lack of personal powers (of 'the self') and of moral activation.

Empowerment strategies or technologies of agency align with a politics of activation. Such politics revolve around the assumption that subjects in 'the place' are passivized and in need of activation (or else misguided in their activities and choices). The governing rationale in play here concerns changing the subjects' subjectivities; they are "coach[ed], educate[d] and guide[d]" (Articles of Association) to change "their ways of thinking" (Coach 1) and to take responsibility for their actions. In this sense, subjects are urged to be free and to make active choices, navigating away from the risk and social problems that are still recognized (and accepted). The targeted subjects are enacted to embrace freedom of choice, to approach opportunities as rational and calculative agents pursuing their own interests while accepting responsibility for gaining welfare and inclusion. Accordingly, the powers of freedom need to be shaped in a certain way. Here, role models play a central part. Role models, that is the manager and coaches themselves, are portrayed as humane, authentic and anti-authoritarian, able to reach out to the youths in 'the place'. In this sense, it is implicitly beneficial that the coaches are not trained social workers or pedagogy professionals; instead, they are influential based on their personal authenticity as well as their common history and shared experiences, and because they have proved that they themselves can navigate among risks and have succeeded in choosing the right track. Most explicitly, they are noted to have a "degree from the university of the streets" (Public PowerPoint Presentation). They present themselves as entrepreneurs providing avoidance opportunities, and if the subject youths do as the role models do, they too will have the opportunities to navigate successfully and evade social problems. The subjects then become enacted as able (and enabled) to take care of themselves and gain mobility opportunities, welfare and inclusion. From this, it is implied that the SP can help subjects help themselves to manage their own risks by providing the powers that are necessary and by shaping the subjects' subjectivities in a desirable direction. 
In brief, participation in the program is presented as providing subjects with motivational powers of self-esteem and selfconfidence. Subjects are encouraged to use these powers in making active and free choices to navigate and avoid risks of social problems and more advanced exclusion. Shaping these powers is facilitated by role models, who themselves have already chosen the right track and proved successful navigation. Such governmental rationality is enabled by representing the youths in 'the place' as lacking the power and character to control their future and welfare: they are passivized and thus in need of activation. A problematization that is focused on risk introduces individual avoidance as an opportunity, appealing to entrepreneurial skills in choosing the right track - this is obviously intertwined in the empowerment strategies and technologies of agency promoted. Additionally, there is an obvious inconsistency in explaining the causes of social problems beyond the individual, in the structures of society, while attributing potential solutions to individual action. By introducing the technologies of agency and rationalities of risk as being intertwined, the problem is displaced from 'the social' domain to 'the self of individual subjects. In a range of ways, the individual subject is problematized and shaped as a domain made ready for governing. The conduct of individual subjects is rigorously engineered with envisaged outcomes by addressing their powers of freedom through the promoted techniques of coaching, educating and guiding. In contrast to welfare-statist social engineering, the rationale of the SP is rather an advanced liberal engineering engineering the powers of freedom to produce responsibilized, selfgoverning citizen subjects.

\section{Article 4}

Ekholm, D. (forthcoming). 'Responding to Social Problems: Mobilizing the Sport-Based Community'. Submitted manuscript.

This article is based on examinations of statements about the SP made by the policy makers and senior civil servant who initiated the intervention. Like the previous article, this one proceeds to investigate sport practices with the explicit premise of promoting 
social objectives and providing responses to social problems in the direction outlined previously. This is done from a constructionist perspective with a focus on governmental rationalities embedded in the program. The article takes as its point of departure an observation gleaned from the empirical material: the policy makers articulate that social problems of crime and exclusion are assumed to be caused by segregation, which gives rise to tensions in society; and because, sport participation is assumed to facilitate and even foster a sense of social cohesion, integration and community, which is vital in overcoming such tensions, sport is promoted as a response. With special attention given to the role of 'the community' in the context of Swedish welfare state transformations, the article investigates how 'the community' is formed as a space for social inclusion and in that sense as a response to the assumed tensions in society.

A constructionist framework focused on governmental rationality provides the analytics of governing that has guided this investigation. The emphasis is on the technologies of community that is, the strategies employed in forming a domain for solidarity and inclusion. Three dimensions made manifest in the analysis illustrate how 'the community' is formed and what kind of institutional arrangements that are enabled. The first dimension concerns relations between public welfare and civil society. The way the SP is presented in statements entails a distinction between public welfare and civil society. Public welfare and social work are associated in statements with political power and described (and problematized) as bureaucratic and insufficient - such actors are unable to reach out to the youths in need of social change. Because public welfare - described with words like "structure" and "system" (Municipal Councillor 2) - suffers, for instance, from the limited number of work hours that professionals can devote to it, they are unable to reach out to the youths at risk of social exclusion. In contrast, civil society, sport clubs and the social entrepreneur are associated with ideals of voluntarism, idealism, personal relations and moral bonds. The relation between these kinds of providers of welfare is also specified such that public welfare and municipal authorities must not administer the SP and civil involvement. 
Welfarism and state-centred interventions are assumed to have smothered civil engagement previously. In this way, civil society is made distinct from public welfare. The second dimension concerns the personal and moral relations within the program that constitutes community. The social entrepreneur manager and associated coaches are viewed as sharing experiences and a common identity with the youths at risk of exclusion and involvement in crime and are thus assumed to have a better chance of reaching out. Voluntarism and idealism outside the bureaucratic system of public welfare provide a human touch and authenticity in the presumably genuine, natural personal relations within the SP (which it is assumed are impossible to attain through professional public welfare and social work interventions). Within civil society, leadership traits such as entrepreneurialism and authenticity (as opposed to and in reaction to professional skills) are guaranteed to have space to flourish. Moreover, personal traits are highlighted, as the manager is described as being "irreplaceable" (Municipal Councillor 2). This means that his potential as a welfare provider does not come from professional skills attainable in education. It is assumed his efforts are tied to his unique individual traits, personality and experiences and could not be carried out by other professional staff. Consequently, it is apparently not important whether the manager operates the program in a voluntary setting (civil society) or as a market-based social entrepreneur. What is crucial, here, is that the manager is not an employed official or subsumed in the public welfare system. Being employed, it is implied, would confine his personal traits and limit his action capabilities. Instead, he needs to operate so that his human and unconstrained entrepreneurship can be utilized, on the basis of 'the community'. Accordingly, the SP is conceived of as a non-political space of personal and social relations dis-associated from professional social engineering. The two dimensions presented are key to integrating values of civil society into the publicly initiated welfare intervention that is the SP. To form a domain for including youths at risk of exclusion, the values of civil society need to be integrated in the intervention so that the sport clubs and the entrepreneur are mobilized in this intervention. This is where sport is so important: sport is assumed to be an equivalent of civil society and embody such values. In practice, the 
social entrepreneur, sport clubs and market-based corporations are all mobilized in the program in a partnership model, and the dividing line between distinct agencies (such as public welfare, civil society and market-based agencies) may be transcended. The third dimension concerns the institutional partnership arrangements. According to statements, the social entrepreneur is enacted as a gateway both to civil society and to market-based corporations. For instance, his entrepreneurial traits provide access to sponsorships. As a result, market-based agencies are associated in statements with a sense of morality and communal involvement. It is assumed that corporations have a moral motivation to take part and act upon their social and communal responsibility. However, they need assistance in channelling their contributions, which could be provided by the entrepreneur. Through this representation, marketbased agencies are included in 'the community' and qualify as partners in the SP. Such inclusion is facilitated by the entrepreneurial drive, by meeting people and reaching out to different groups (something that public welfare is described as being incapable of). In this way, innovative funding for welfare provision and social work programs like the SP can be provided. It is also noted in statements as being a consequence of deep cuts in public spending. The sport-based social and welfare intervention is thus presented as a response to austerity and retrenchment.

This set-up involves a redistribution of responsibility for responding to social problems. Because of austerity, municipal administrators do not respond to the risk of exclusion and to tensions in society through public welfare or social work; instead, civil society and market-based agencies are mobilized. This involves a diffusion of the delineation between the distinct agencies - they become enrolled and enmeshed in a more complex web of welfare provision and governing technologies. The role of municipal governing agencies becomes not to perform public social work, but rather to activate and mobilize partnerships with distinct agencies. The SP and 'the community' are produced as a non-political space for inclusion, presumably free from governing, power relations and subjectification (which is implied in public welfare and social work). The emphasis is on voluntarism and personal relations and bonds 
instead of social engineering. It is portrayed as a rejuvenation of an old sense of community (or gemeinschaft, to use another term) in reaction to the shortcomings of modernist social engineering and welfarism. Within the SP, a governing rationale emerges that is enabled precisely by authenticity in personal relations, moral bonds, common identity and shared experiences providing a human touch: role model identification. The conduct of youths can be shaped by their identification with and following in the steps of authentic role models within the SP. This governing rationale is based on the idea that mutual moral obligations between individuals who share identity and experiences would bind them together, fostering a sense of communal solidarity and moral cohesion. Governing through role model identification based on 'the community' as the premier rationale entails a de-professionalization of social work interventions - and moreover a break with welfarist notions of public social work. Policy making and administration take on a subsidiary role in activating and supporting civil society in response to social problems; outreach draws on a selective identification of targeted populations at risk. Such principles illustrate mutations in the traditionally upheld Swedish social-democratic welfare regime, where universal outreach is a core ambition. The formation of 'the community' with respect to the SP illustrates how personal bonds, shared experiences and common identity are central rationales for solidarity and inclusion - in many aspects, in contrast to welfarist ideals of a wider base for inclusion and solidarity beyond personal bonds. The statements analysed account for one instance out of a multitude, where seemingly minor mutations in governing rationales epitomize welfare state transformations. This may indicate how social work and welfare provision are performed and enabled beyond the institutionalized arenas of social-democratic welfarism. 


\section{ANALYTICAL DISCUSSION}

This chapter is intended to immerse the analysis of the empirical investigations presented in chapter 6 and to synthesize these analyses, reconnecting them with the theoretical and contextual frameworks presented in chapters 2, 3 and 4 as well as with the aim and general questions of this thesis introduced in chapter 1. In line, the research questions considered in chapter 5 guide the analytical discussion and reflections. This chapter, like the thesis as a whole, demonstrates how sport is constructed and made intelligible as a means of responding to social problems because the concept is associated with and is assumed to accommodate technologies of agency, forming moral subjectivity, as well as technologies of community, producing personal and moral relations. It demonstrates how promotion of 'sport as a means of responding to social problems' forms a governmental rationality and conception of social change, which rather than social reform or targeting society as a whole stresses activation and responsibilization of individual subjects, development of moral community and localized at-risk interventions. The study demonstrates how, by formalizing expectations of sport (by assessing such practices on the premises of social objectives), tendencies of a shifting balance in governmental rationality are inscribed in contemporary social policy. This illustrates some mutations and tendencies in the rationales of governing and welfare provision that epitomize welfare state transformations. It moreover raises some concerns about the significance of governing from the social point of view, which is vital in conceptualizing social problems and social work.

The chapter comprises two sections. First, the recurring patterns in the knowledge articulated about 'sport as a means of responding to social problems' are seen as forming a certain regime of truth. This kind of truth imbues specific forms of governmental rationality, that is, ways of conceiving of the means and ends of social change and how change is assumed to occur. Second, re-assembling the governmental rationality continues by focusing on mutations in 'the social' kind of domain, presented earlier, as a key point of recognition for Swedish - and social-democratic - welfare. This discussion reflects the tendency to locate social change in particular 
domains beyond 'the social' and explores the significance of this in understanding social problems and social work.

\section{Re-assembling the rationality of social change}

The aim of this study, to examine how rationales of social change are formed within the specific regime of practice, has been approached by analysing the variety of statements in the two distinct sets of empirical material. In this endeavour, it has been determined that the knowledge articulated in the two sets of material share some key features that constitute a common regime of truth. In this section, the ways of thinking about and articulating social change in terms of governing that are embedded in the regime of truth are reassembled and made visible. In demonstrating such a rationality, this enables the development of a refined understanding of how social change is associated with the regime of practice.

This section consists of six subsections. First, the regime of truth is outlined. Second, it is displayed how sport is signified (and fixed in discourse) as an equivalent of agency and community. Third, three particular domains are presented which are identified as targets of intervention and made governable in the knowledge articulated 'the self, 'the community' and 'the place'. These are the targets and domains in which social change is considered possible. Fourth, the formation of activated, responsibilized citizen subjects is explored in relation to the domains animated. Fifth, the argument is made that the regime of truth delineated constitute a politics of activation that highlights the ethical responsibility of individuals and communities, a way of reasoning that is embedded in a specific critique of welfarist governmental rationality. Sixth, a discussion is provided of how this way of governing ascribes a specific role to the agencies of public welfare provision.

\section{A regime of truth: 'Sport as a means of responding to social problems'}

In the examinations of the two sets of empirical material presented in the previous chapter, knowledge about 'sport as a means of responding to social problems' forms a more or less coherent regime of truth. Although there are obvious differences between the different sets of material - as was already noted - this discussion 
pinpoints a range of common facets that structure the knowledge and provide the regime of truth with a certain consistency. With respect to the scientific discourse (presented in articles 1 and 2), a multitude of perspectives on the potential for social objectives ascribed to sport are presented. This kind of knowledge has highlighted in what situations, under what terms and conditions and through what intermediates sport may be intelligible and reasonable as a means of providing welfare (and, accordingly, as a means of responding to social problems and promoting social change). The discourse also brings to the fore limitations and problems regarding the kind of potential ascribed to sport. In short, a multifaceted imagery of sport's potential for social objectives is delineated in the scientific discourse. With respect to the statements analysed that are made specifically in relation to the SP (presented in articles 3 and 4), a more one-sided, and unreserved picture is drawn of the potential of sport. Still, some common patterns and regularities could be noted in both the scientific discourse and the statements made by the various representatives of the SP. The recurring patterns concern different facets of how sport is expected to contribute to individual development and socialization as well as to interpersonal relations, relations between welfare-providing actors and to building a sense of community. To some degree, even the sport-evangelist notions and widespread beliefs in sport accounted for in chapter 4 could be recognized as being similar to key dimensions of the statements analysed.

With respect to individual development and socialization, some salient aspects are highlighted in article 2 on the scientific discourse. The potential of sport is described in terms of pro-social development and empowerment (specifically regarding self-esteem and selfconfidence) as well as attainment of life skills (capacities that are transferable from sport settings to other social spheres). Similar expectations can be recognized in article 3 with respect to the articulations of the sport coaches and the social entrepreneur manager. There, it is proclaimed that sport leads to attainment of motivational powers used for choosing the right track in life. These skills and competences - powers - are described as improved selfesteem and self-confidence. Similarly, such themes are touched 
upon in article 4, which has a different scope. This is expanded on in the scientific discourse with respect to community building, facilitating relations between people and between different actors in society. In article 2, it is emphasized that sport is assumed to provide opportunities for building social capital, which in turn is presumed to strengthen relations in local neighbourhoods and the community. These facets recur quite frequently in article 4, where policy makers and the municipal civil servant who initiated the SP express the advantages and gains expected from the intervention. They consider the formation of social cohesion on ground of 'the community', most clearly, as the overarching response to segregation and the tensions in society that cause risk and social problems. Crucially, they feel 'the community' of personal relations and moral bonds, which involve a variety of welfare-providing agencies, could be mobilized by initiating sport practices. Community building is also an important aspect in article 3 . Here, it is stated that personal relations and reciprocity between the youths and the coaches are necessary conditions for reaching out and for achieving the kind of social change that is sought after.

The facets outlined above will be further elaborated on in the following subsections with respect to the significance of sport, the domains made governable, dimensions of ethical activation and the role of public welfare. The aspects in focus here recur in both sets of material. However, what establishes this kind of knowledge as a regime of truth is not that it is articulated in multiple contexts, by a variety of agencies and from a multitude of perspectives; rather, it is because it underpins and enables a specific form of action and practice (the established regime of practice). After various features of individual and community development are explored in more detail in the subsequent subsections, relevant examples are provided from the empirical investigations. Although the regime of truth outlined appears to be established and uncontested, it is important to note that this specific fixity, which makes the knowledge both intelligible and reasonable, is the result and effect of ideological and discursive struggles in which other potential responses to social problems or other potential connotations of 'sport' have been overcome or downplayed. 


\section{Fixing the discourse and knowledge of 'sport'}

In the previous chapter and in articles 3 and 4, the technologies of agency and community have been explored at length. These have been identified as being fundamental to the governmental rationality that is formed in truth and practice. The scientific discourse suggests that there is not really a specific meaning of 'sport' nor does sport have inherent or essential qualities that make such practices especially suitable for achieving welfare objectives. It all depends on how practices are performed. Consequently, one may well wonder what qualities might really signify sport and make sport intelligible as a means of responding to social problems. While, ultimately, it has no fixed meaning, sport could be presented as an omnipotent tool for achieving social policy objectives in more or less any distinct historical or political context (as has been the case), with only slight variations in the momentary fixity of meaning ascribed to it. However, with respect to this specific examination and to the transforming conditions of Swedish welfare and social work, a specific meaning of sport is fixed.

In the empirical investigations, two kind of governing technologies steering social change and the production of includable subject citizens have been associated with sport. In this sense, sport becomes the equivalent of agency and community. Consequently, agency and community should be viewed as operating through sport as the means of responding to social problems. Agency and community are the imperatives of social policy recognized and analysed in this specific empirical case: agency and community as means of responding to social problems. The technologies of agency and community are assemblies of knowledges and techniques that points to 'the self' and 'the community' as locations where social change is possible and that consequently could be targeted by governing interventions. Here, the notions of individual agency and moral community, as vital instruments of social change, that are associated with sport constitute the discursive premises needed for the formation of 'sport as a means of responding to social problems'. Alongside the geographical territorialization of 'the place', the technologies and domains of agency of 'the self' and the formation (and agency) of 'the community' will be explored in the next subsection. 
To summarize, and to put it in simple terms, sport is signified as a means of responding to social problems not because there is an essential meaning of sport or because established experience proves its potential, but rather because sport practices and activities are associated in the discourse with individual activity and a certain kind of agency as well as with an active civil society and moral (and personal) community. In that sense, the physical kind of activity subsumed by sport is positioned in the discourse as a metaphor for civil and moral activity (and activation).

\section{Governable domains: 'the self', 'the community' and 'the place'}

With respect to the technologies of agency and community that are significant to sport when conceived of as a means of responding to social problems, three particular domains are constructed as targets of sport-based social and welfare interventions and for governing social change. These domains are the abstract spaces or discursive formations in which a certain kind of problematization is interlinked with the responding governing technology. The domains are in this sense enacted and animated within the regime of truth about 'sport as a means of responding to social problems', and they illustrate a fragmentation of society as a whole, which is central for the governmental rationality outlined. In different ways, 'the self, 'the community' and 'the place' have been made distinct, problematized and represented as governable terrains. In this subsection, some examples of the various technologies identified in the empirical investigations are sketched out and related to the problematizations noted. Based on a recap of the technologies and problematizations, the contours of these domains are outlined. To conclude, the questions of how the governmental rationality is enabled, how it operates and what effects are made possible by it are considered.

First, the technologies of agency are a recurring feature of the empirical investigations in referring to various techniques of governing and to activation of, or imposition of, social change on 'the self. The pedagogical tactics for promoting social change assigned to this technology have been labelled empowerment, prosocial development, development of self-esteem, self-confidence and self-control, and learning of life skills. In each respect, the 
tactics concern changing the conduct of individual youths, their actions, behaviour and ways of thinking (their mentality and subjectivity). One key facet discerned is that they revolve around learning responsibility. In this sense, providing moral subjectivity is the method for regulating the freedom of subjects without restricting their freedom; they are taught how to make responsible choices and be accountable for social change. The competences and powers that are on offer are designed to make it possible for them to navigate away from problems - to take care and be responsible for, as well as be the guarantor of, their own security and welfare.

Based on article 2 and the scientifically produced knowledge, an illustrative example of sport in social work could be highlighted. Lawson (2005, p. 158) notes that the purpose of the sport-based social work, he has observed, "lies in liberating and empowering people [and] this empowerment oriented freedom [means] freedom to choose, starting with what to do, play and create". This kind of potential recurs in the scientific statements examined and certainly aligns with the statements articulated by the sport coaches and the social entrepreneur manager that are explored in article 3. The knowledge produced in that setting, presented in article 3 , focuses on how sport may contribute motivational powers of self-esteem and self-confidence - something that is presumably lacking in the targeted youths - so that they themselves could learn to navigate in and adapt to a society full of risks, choose the right track and succeed in taking responsibility for their own lives and welfare. When equipped with such powers, as the sport coaches and the social entrepreneur manager describe, sport participation may offer subjects "other ways of thinking [and] make them feel that there are different tracks to choose" (Coach 1) as well as "get a sense of selfesteem and decide that crime is not for them" (the manager in a newspaper article). Here, 'choosing' and 'deciding' indicate that the governmental rationality is, above all, about learning to be active and responsible. This is especially evident with respect to acquiring and using life skills. By promoting life skills as a vital competence attainable in sport, life outside sports could metaphorically be described as a game: the game of life. Perhaps this is most clearly explicated in the scientific discourse by Williams et al. (2002, p. 41), 
who make the case that "sport are life skills [which] help our adolescent clients to better understand, and play, the game of life". The notion of life skills illustrates with a certain precision how governing targets the conduct and mentality of 'the self with the aim of producing elements of life itself.

The strategies of social change that are promoted are aimed at producing - and are seen to have the potential to produce - certain assemblies of skills, competences and powers (in other words, actions, behaviours and subjectivities), and that means, effectively, to produce a certain way of life. Even, to enact life outside sport as a game becomes a way of making these specific powers feasible. Shaping a certain kind of citizen subject through empowerment techniques and technologies of agency entails a specific form of technologization or even engineering. Shaping subjects prepared with motivational powers - who are self-aware, aware of their freedom, their opportunities (as well as obligations) and responsibilities to choose the right track and take advantage of the possibilities by navigating among and escaping risks and problems should be understood as a form of citizen subject engineering. In this sense, 'the self constitutes the discursive formation in which problematizations of individuals' actions, behaviours and ways of thinking are recognized and become a matter of social change. 'The self is outlined in various statements as the target and scope of sport-based governing interventions. The technology deployed, which is highly sophisticated, incorporates elements of moral selfreflection (featured as a condition of success in the scientific discourse), which means learning to conceive of oneself as a moral subject, as governable and as a domain in which to carry out morality formation.

Second, the governing technologies aimed at shaping personal relations and fostering a sense of moral community are termed technologies of community. 'The community' is the domain in which personal relations and relations between different actors and agencies are formed in moral gemeinschaft. This involves direct personal relations between individuals, that is, the youths' relations with other youths but also their relations with coaches or possibly 
educational and social workers; the partnerships between different agencies such as public welfare and social work agencies; civil society and voluntary associations; and even market-based entrepreneurs. In the first instance, the sport-based community is founded on individuals' personal and reciprocal relations and moral responsibility for each other. They presumably identify with each other and share common interests. Genuine and authentic relations in sport between youths and role-modelling coaches are highlighted in the discourse. Through sport practices, role models can reach out to youths, in contrast to professional conductors of welfare and social work, who are not part of 'the community'. The role models become animated as conductors of social work and mediators between inclusion and the targeted youths of exclusion (cf. Philp 1979); still, they are conductors who are inscribed potential mainly to reach out to those who potentially share experiences and identity.

In the second instance, public-private partnerships are also described with an emphasis on human relations, reciprocity and moral responsibility for each other. The main point here is that the human and moral kind of community that is animated is different from the professionalized and politicized social domain of instrumental and impersonal relations that presumably constitute the basis of public welfare efforts. The multiplicity of actors individuals and agencies - are assumed to be incorporated into a diverse space of morality and reciprocity, that is, 'the community'. Just like 'the self, 'the community' is represented as a response to problematizations that emphasize a lack. In the empirical material, a lack of morality and community, along with segregation, is viewed as causing tensions and conflicts that give rise to a risk of exclusion and social problems. Presumably, sport practices and participation are viewed as ideal institutions for enabling community-based solidarity and inclusion. This is at least in part because the sport setting provides opportunities for the social entrepreneur to establish a platform for reaching out to the targeted youths and to "civil society or associations, non-profit organizations" (Municipal Councillor 2) and "other institutions and companies" (senior civil servant), as noted in article 4 , that presumably want to be part of the 
community and share responsibility for responding to social problems.

Technologies of the community are a recurring feature of the empirical material investigated. To illustrate, a few examples are given. In the scientific discourse, as explored in article 2, Donnelly et al. (2007, p. 27) argue that the ways in which social relations are organized "[impact] the ethical and moral behaviour learned through sport [and affect] the values and ethics promoted in the sport and the moral character instilled in children and youth who participate". That excerpt links the moral character of 'the self to social and personal relations as well as to the moral community that incorporates the human individual. Crabbe (2000, p. 390) also maintains that, with respect to the sport-based intervention he followed, it "is about community development [in terms of] developing relationships with people on the basis of trust and mutual understanding". In article 3 , this theme is elaborated on with respect to the social entrepreneur manager's presentation of the intervention. He notes that the affiliated coaches have "a deep understanding of the targeted population and often come from that group... [and they] are credible role models" (Public PowerPoint Presentation). By being part of 'the community' and sharing a common identity and experiences, this kind of conductor of social work could be described as credible and as a potential facilitator of social change. In an excerpt from article 4, one of the municipal councillors expounds on how "more is needed" (Municipal Councillor 2) than professional welfare services to reach the youths identified as being at risk. In contrast to professionalism, the councillor describes the coaches of the program to "have their own background [...] extremely important in this meeting [and] they have an understanding of the problems in another [experiencebased] way" (Municipal Councillor 2). Thus, they have no specific professional skills, but they have experiences and an identity that make them part of 'the community', and this competence and qualification is what is sought after in the conductors of social work.

One especially interesting point to reflect upon is how 'the community', and 'the self for that matter, is animated as natural and 
non-political domains exempted from political steering in terms of authoritarian bureaucracy and professional hierarchies. These domains - humans themselves as well as their voluntary and civil forms of associations - are considered especially suitable for forming solidarity, inclusion and community specifically because they comprise authentic humans and moral relations (and not politicized authorities). At the same time, it is these domains - and most certainly for that particular reason - that is pointed out as possible to inculcate with tactics of social change. The notion of where social change may be located is discussed further in the next section with respect to the particularization of 'the social'.

Third, a few words about 'the place' are needed. The technologies of agency and community are constitutive of 'the self and 'the community'. These domains are animated, demarcated and made governable. In the last two articles, a discursive formation takes the shape of a geographical territorialization: 'the place'. This domain is formed to host a certain kind of problematizations attributed to the specific urban area and is accordingly made ready for the set of technologies that are promoted as being suitable for this distinct place. Because 'the place' is not given full attention in the articles, some aspects need to be clarified here. 'The place' is constructed as a targeted domain in two instances: first, it is animated as being dangerous, filled with risks and problems; second, the territory is populated by deviant people at risk of social exclusion and problems who are incapable of managing their lives, security and welfare.

In the first instance, a range of risks and problems are specifically located in the particular territorialization and demarcation of the city. 'The place' contains risks and problems against which technologies of agency and community can be inserted. In this case, the sport-based intervention specifically targets the demarcated territory and in that performative effort animates 'the place'. Most explicitly, this is illustrated in article 3 , since 'the place' is attributed a peripheral location, "off the map, so to speak" (Coach 2) in statements analysed. One basic premise of the SP intervention is that sport clubs residing in 'the place' are in need of extra support. In statements made by the policy makers, though not sufficiently 
addressed in the articles, 'the place' is described as an area of exclusion in relation to a nearby area of inclusion, which is located just on the other side of the expressway. The area of inclusion is characterized by homogenous ethnicity (Swedish), a high standard of living, parental involvement and well-managed sport clubs; in relation, 'the place' is described as lacking all this. For example, sport clubs in 'the place' suffer from poor support from immigrant parental activity; this is repeatedly explained to cause poor integration in Swedish sport club culture. Without expounding on empirical observations that have not been presented in sufficient detail, it is important to shed light on the formation of subjects in order to grasp how the people who are described as inhabiting 'the place' are constructed in statements, how they are made deviants and represented as targets of social and welfare interventions.

In the second instance, the construction of 'the place' means precisely that the territory is populated by people who constitute specific problems themselves. Article 3 concerns how the representation of 'the place' creates a division between different groups of people. On the one hand, there are people who are considered to have adapted well to society and who are capable of managing their own risk. They inhabit the area of inclusion. On the other hand, there are those who are not well adapted and are even incapable of managing risk and providing welfare for themselves and therefore are in need of support and interventions. They inhabit 'the place'. They have poor resources and insufficient opportunities to control their own lives, which are exposed and subject to social problems and hazards - they are, in Rose's (2000b, p. 331) words, "those who are outside this nexus of activity: the underclass, the marginalized, the truly disadvantaged", the "excluded subpopulations [that have] refused the bonds of civility and selfresponsibility"; they are "non-citizens, failed citizens, anti-citizens", they consist of "those who are unable or unwilling to enterprise their lives or manage their own risk, incapable of exercising responsible self-government, either attached to no moral community or to a community of anti-morality". An explicit description is given in article 3 of how these youths are assumed to lack social and economic resources, making them vulnerable to risk 
and exclusion. They are also identified as immigrants who suffer from unemployment and exclusion. In the article, it is noted how the solution in response to this is more self-esteem, self-confidence and powers in order to choose the right track. They are represented as passive, incapacitated by the welfare and security provided for them to face the risks and problems inherent in 'the place'; or, if not passive, they are misguided in their activity, leading to crime or other delinquent activities associated in these statements with life in 'the place'. In this sense, the representations resemble the problematizations attributed to youths observed by Ohlson and Swärd (1999), that they are violent and destructive as well as lack the norms and competences needed to be conscientious - and because their leisure and freedom must be subject to interventions.

One specific feature of how the excluded, targeted population is signified and constituted concerns how it is assumed they are reached through community role models linked to 'the place'. Conduct may be shaped and inclusion granted specifically through learning in terms of role model identification. The targeted group of youths subject to the intervention, it is implied, cannot be reached by professional welfare interventions and traditional social work, nor is it assumed that they can be reached by traditional Swedish voluntary associations. In this sense, they are animated as being unknown to professional social workers and public welfare administrators given that the population targeted as being at risk does not share a common history, experiences or identity with professionals and administrators. Moreover, they lack an understanding of Swedish voluntary sport organizations and therefore cannot arrange their leisure activities according to the established formula of Swedish sport. The youths targeted are constructed as different, deviant and unknown; their actions, behaviours and ways of thinking could not be sufficiently assessed by professionals, but their characteristics and conduct could be recognized and understood by the community role models and by their peers, who share an identity and history. Presumably, the population targeted as being at risk is tuned according to a different rationale and cannot be reached by 'the social' kind of welfare. They can only be provided welfare and inclusion through extraordinary 
efforts conducted by people with certain traits who exist in the same community - that is, the coaches and the social entrepreneur manager: the role models. It is through them as conductors of social change, and in the specific "spatio-ethical zone", that inclusion in 'the community' can be provided (cf. Rose 2000b). The youths become subject to a certain kind of community work rather than the professional form of social work (of social-democratic welfarism); accordingly, they may not automatically be offered a substantial social kind of inclusion and solidarity that operates on the wider population (beyond the personal bonds of those included in a moral and familiar community), but rather inclusion in the precise personal relations and moral bonds of 'the community'. 'The place' and the population are selected and made distinct from other places and populations. They are assessed as deviant and displaced from the rest of society. In this way, 'the place' and its population (like 'the self and 'the community') are demarcated from society as a whole and from governing, from the social point of view. By demarcating the deviant and excluded, the normal and included, who are reached and known by social agencies, can be made thinkable.

To summarize, the governmental rationality in 'sport as a means of responding to social problems' acknowledges three particular domains as sites for social change. The rationality makes visible how these domains are demarcated from society as a whole. It is in these sites that the technologies aimed at bringing about social change are made intelligible and reasonable. This line of reasoning has distinguished three particular domains, which are nonetheless somewhat interlinked. 'The self is constituted as a moral subject that is able to take care of itself but also able to take part in being responsible for others within the community. 'The community' is constituted by genuine and authentic personal relations and moral bonds and is located primarily in the specific territory outlined; it has a geographical residence. Finally, 'the place' is populated by a collective of selves who lack of powers needed in the active society. The particularization of governable domains and the kind of governmental rationality that frames it are part of a politics of activation. In demarcating these domains, they are also made distant 
from state-centred (or municipal) intervention authorities, limiting the assumed outreach of direct political power.

\section{Formation of the activated and responsibilized citizen subject}

In the previous subsection, some common threads were drawn about the particular domains constructed and the technologies utilized to govern social change. Crucially, the concern here is pedagogical techniques of activation; it is through pedagogy governing of social change may be conducted; attainment of the skills, competences, and capabilities described, the attainment of the resources identified in the studies - all are various descriptions of powers that are presumably learned by participating in sport practices designated by the premises of social objectives. This clearly illustrates the importance of pedagogy, the shaping and guiding of citizen subjects and their subjectivity, in bringing about social change in sport-based interventions. In this respect, the end product of governing technologies, and of pedagogical dimensions of social work, needs to be delineated (cf. Cruikshank 1999; Donzelot 1979; Villadsen 2004). After all, the citizen subjects shaped in the regime of practice examined is one of the main concerns in this thesis. Several aspects of the kind of citizen subjects formed have been touched upon already. Not least, the summary of findings in the articles and this discussion have concerned the formation of selfgoverning subjects equipped with powers and capacities to navigate among and away from the risks that society decrees and to accept responsibility for their situation in life. They are urged to take care of themselves, embrace freedom of choice, choose the right track and not be a burden to society. In addition, subjects should learn how to think of themselves as the locus of social change, to comprehend their own selves as the domain in which social change is possible. They should learn how to reflect on themselves as the target of social change so that they can govern change through active, responsible choices - they are motivated to re-enact themselves as managers and entrepreneurs. The rationales of pedagogy and learning in relation to formation of subjectivity and development of skills and competences, stresses that the intervention is aimed at future conduct and ways of action, to regulate events in an uncertain future. In this sense, even 'the future' 
is animated as a governable domain and as a target for governing intervention (cf. Petersson, K. et al. 2007). Moreover, shaping a moral subject also means being part of the particular collectivity that is 'the community', being involved in direct personal and moral relations. Being a moral subject also involves responsibility for not being a burden to society as a whole, not being in need of support. Interestingly, this would imply formation of a citizen subject that is autonomous in relation to 'the social', yet at the same time included and participating in as well as dependent on 'the community'.

\section{Ethical activation and the critique of welfarism}

A central dimension for situating the technologies highlighted earlier in this analysis and discussion and which are assumed to operate through sport and as a means of responding to social problems by setting social change to work is how this rationality is built on an advanced critique of welfarism and governing from the social point of view. Welfarism has been presented as the governing rationale of the welfare state, especially with respect to the traditional Swedish welfare model. Here, the concept of risk may provide a fruitful avenue for understanding this critique, which has enabled this particular take on 'sport as a means of responding to social problems'. In the statements examined in the two final articles, it is implied that youths suffering exposure to the risk of social exclusion and a life of crime and drugs should not passively rely on protection provided by the welfare state. In contrast to the welfarist rationale, where risk is made invisible in the daily lives of citizen subjects by being pooled and spread across the whole social collective as well as state-centred reduction schemes, the technologies of agency and community (in the way they are constituted in the statements examined) are built on making visible the risk of problems and exclusion in the daily lives of youths (they are constructed as being at risk). Through highlighting that society, and particularly 'the place' is dangerous and risky, the subjects are alerted and made aware of their vulnerable situation. They can thus also be made conscious of and reflect on themselves as the locus of change as well as their responsibility for steering change and avoiding risk and problems. Accordingly, 'the community' is animated, most specifically in article 4 , as a space where risks can be contained and 
dealt with. Risk does not necessarily need to be spread across society as whole, but it could advantageously be placed and managed within the demarcated group of individuals who share a background, identity and experiences.

The critique of welfarism, elaborated on in chapter 3, stresses the passivation of human morality in welfare provision. Consequently, the human domains that are 'the self' and 'the community' presumably need to be morally re-activated, so that they are able to contain and manage their own risk and problems. This (re-) location of risk to 'the self' and 'the community' illustrates the kind of politics of activation that have been presented before as a response to an overly passivizing welfarist social policy regime. Thus far, the problematizations accounted for in the analysis examined in this chapter have concretely concerned the conduct of individuals, their lack of certain powers and certain conditions in society. This is the outcome of the empirical investigations presented in the articles. Henceforth, the perspective will shift (or develop) to embrace the more abstract problematization of welfarist governmental rationality (epitomized by the concrete problematizations, governing technologies in response to social problems and the demarcated domains made governable). In general, four aspects of the critique against welfarist governmental rationality are recognized in the empirical material investigated and in the regime of truth outlined. The facets concerned here may be recognized from earlier, in relation to the gradual shift in the rationales of welfare provision described.

First, an economic critique is put forth. In article 4, sport is claimed to be a potential way of providing welfare and interventions in times of austerity. The financial scope for public spending and social efforts is shrinking for the municipality, according to statements articulated by one of the councillors. Putting public-private partnerships to work - via sport practices led by the autonomous social entrepreneur - provides an organizational setting that could cut public costs and even pave the way for sponsorships and innovative private funding. In this respect, it is also important to note that this involves spreading responsibility from state-centred 
agencies to civil society and market-based agencies. Economic downsizing and limited public spending regimes seem to be key political and institutional premises for the emerging regime of practice that uses 'sport as a means of responding to social problems' - at least, in this case. In this context, the role of public welfare becomes one of activating other agencies in public-private partnerships. This, in turn, necessitates an institutional framework in which purchasers are separated from providers. With these institutional premises, sport could potentially enter the arena of welfare provision and social work. This should be considered very much a material critique, with the problematization and dismantling of public spending, one that is central to welfarism.

Second, there is a critique of client mentality. The technologies of agency operating through sport practices are supposed to empower citizen subjects with the resources and capacities (powers of 'the self') that are needed for them to be substantially included and actively and responsibly participate in society and exercise social rights. In article 3, the sequences in forming activated, responsibilized citizen subjects are demonstrated. Subjects are empowered and motivated, encouraged to be active in making active choices and accepting accountability for consequences. This technology is a pedagogy of moral instalment: agency and responsibility - morality - are formed and incorporated in subjects. The tactics could be interpreted as re-installing presumably genuine and authentic human competence (which was presumably lost under welfarist social planning) in order to provide security and welfare for such subjects, so that they avoid social problems, in other words. This is done through the active participation of the subjects themselves (cf. Cruikshank 1999). Here, the response to problematizations of passivation is activation schemes. This kind of problematization emerges as a key discursive premise which underpins the technologies of agency imbued in the governmental rationality of 'sport as a means of responding to social problems'. Highlighted in article 3, the technologies of agency and the empowerment schemes that make up this kind of citizen subject activation were also explored earlier in this discussion. 
Third, there is a critique of welfarist authoritarian social engineering. The critique against welfarism, imbued in the way 'sport as a means of responding to social problems' is described, underlines the bureaucratic and authoritarian sides of government. Role models become central figures in representing the authentic human relations promoted in their human way of conducting social and pedagogical interventions. For instance, in article 3, the role models' genuine experiences of exclusion and social problems enable youths to identify with them. In turn, this may provide non-hierarchical outreach to the youths at risk - since they have the same background and identity, which provide mutual understanding and reciprocal relations. In article 4 as well, these merits are acknowledged and valued by the policy makers. In their statements, the policy makers emphasize the limitations in the outreach of professional and authoritarian interventions. In that sense, using sport practices, with community-based influential role models, is a more attractive alternative to paternalist social engineering. The practices are designed and led by authentic people (adding a human touch), not on the basis of professional expertise and skills but lived experiences and personal traits tied to identity. In this way, a problematization of 'the social' kind of professional intervention that operates beyond the personal and moral bonds and relations is demonstrated. The kind of welfare provision founded on individual agency and responsibility and which may be formed in reciprocal personal and moral relations and in community, could be conceived of as an alternative to state power and governing from above, engineering people's lives (cf. Hirdman 2000). This kind of critique of welfarist governmental rationality underpins the discourse produced in relation to the SP.

Fourth, a critique that civil society was suspended under welfarism are issued. The mobilization of private agencies and civil society associations through sport in providing welfare could be viewed as a reaction to the state-centred provision of welfarist professional bureaucracy. In article 4, statements are made suggesting that the expansion of welfare state agencies undermined or even ruined civil society structures, which presumably used to be a vital part of providing for youths' needs in Sweden. Interestingly, the popular 
and social movement associated with sport here represents civil society and is dissociated from the welfarist rationale of statist welfare provision. In article 3, too, statements note the potential for non-state agencies to be reinvigorated and become a vital force in welfare provision. Outside state welfare provision, there are a multitude of agencies that have presumably been suspended by the social-democratic welfare state, but which can now be mobilized. It is presumed that in the entrepreneurial sector and in civil society, there is space for a more autonomous form of managerialism. The critique of state-centred provision views public welfare as incompetent at containing and channelling the engagement of autonomous people, something that would presumably vitalize welfare provision (cf. Villadsen 2007). This critique aligns with the particularization of society as a whole and the demarcation of 'the community'. In that sense, such a problematization and critique are a central discursive premise for the technologies of community that are significant to sport in this regime of truth.

The activation of 'the self and 'the community' described previously and the critique examined above could be understood in ethical (or moral) terms. The politics of activation seeks to resurrect the moral fabric and re-install the moral agency of individuals and communities that were supposedly deprived of them under welfarism, and sport used as a tool to attain social objectives provides such an opportunity. In this way, activation politics illustrates re-distribution of the responsibility for guaranteeing welfare from the state to individuals and communities, inducing them to be active risk takers (cf. Lessenich 2011). It is technologies of a double responsibilization: of 'the self and of 'the community'. In this sense, the critique relies on a problematization of statecentred government or even a normative "state phobia" (Villadsen \& Dean 2012: 401). Non-state agencies are mobilized in a decentred partnership, established to avoid direct state (municipal) governing. Moreover, activation of 'the self' and 'the community', as described in the analysis and discussion above, resembles much of what was introduced in relation to neo-philanthropy in chapter 3. Most notably, in article 3, governing aims to provide youths with resources to help themselves and persuade them to free themselves 
from exposure and exclusion by means of changing themselves, their ways of thinking about themselves and the problems they may face. In this sense, problems are represented in discourse as "spiritual rather than material" (cf. Villadsen 2007); the spiritual dimensions of problems are identified for potential change. Material dimensions are not denied - indeed, they are considered to cause the segregation underpinning problems and exclusion. Yet they are not determined to be a target for social change strategies with respect to 'sport as a means of responding to social problems'. Rather, the spiritual and mental dimensions of 'the self - that is, the subjectivity and the ways of thinking about problems, about one's own freedom and about one's own responsibility for managing risk and providing welfare - are articulated as potentially subject to social change. This kind of discourse aligns with the empowerment rationales and pedagogy of pro-social development that are nascent in the scientific discourse, which are presented in article 2. Moreover, the governing of social change is designed to establish moral bonds between youths at risk and role-modelling coaches based on mutual understanding, morals and identity - subjects could reach out for help and support, which is provided to them by conductors with, presumably, a similar cultural identity and moral understanding. Certainly, this facet of community is most profoundly displayed in the analyses presented in article 4; it also seems to be a recurring notion in the scientific discourse presented in article 2. Similarly, Villadsen (2007, p. 314) describes philanthropy, with one of the key tactics in sport-based interventions being to "establish a moral community [...] where a set of collective moral standards and community obligations knitted individuals together". This form of demarcation of society as a whole spotlight 'the community' as a morally active space made ready for insertion of social change.

\section{An activating and facilitating role for public welfare}

Responding to, dealing with or even solving social problems through the forms of governing outlined in this section, with their focus on ethical activation of individual agency and of community, mean that public welfare institutions are ascribed a specific position. Rather than conducting professionalized interventions under their 
own auspices, the welfare state and municipal agencies assume the position of initiating, selecting, activating, mobilizing and supporting the social and welfare intervention. Public welfare assumes the position of identifying which individuals (selves) or groups of individuals (communities) and what areas (places) are in need of governing interventions and social change. In the case of the SP, examined in articles 3 and 4, the municipal agency providing welfare selected - and animated - a target group construed as being at risk of social problems and exclusion and localized in a demarcated territory (the area of exclusion called 'the place'). Public welfare, in this sense, is supportive of private agencies in providing for security and welfare. The supportive role of public agencies (state and municipal government) has long been well established in relation to sport practices and sport policy (cf. Norberg 2011), but has become part of the more formalized and explicit expectations on sport to provide with social objectives imported from sport policy into the field of social policy. The more residual principles of selectivity and subsidiarity are, incidentally, most often associated with other (liberal and conservative) welfare regimes than the Swedish and social-democratic one.

Under the heading of 'social work after the social', in chapter 3, three tendencies of transforming social work are clarified (cf. Clarke 1996), all of which are explored in the analyses and discussion. First, welfare interventions and social work are fragmented and performed in a range of different forms - in this case, by means of sport practices, a kind of activity that has not previously had a clear function in welfare provision or social work or as part of the social services. Second, the examinations illustrate how a wide range of agencies have become involved in welfare provision and social work as well as how the technologies that are used become decreasingly formalized and de-professionalized. This kind of decline in the status of professional skills and welfarist professional social work has been outlined in the literature (cf. Pollack 2010). The development, moreover, aligns with the growth of a sport-based social problems industry that includes philanthropists and private agencies to counter social problems (cf. Hartmann \& Kwauk 2011; Pitter \& Andrews 1997). Third, the more informal ways of carrying 
out welfare interventions create spaces for social entrepreneurs and non-professional managers conducting interventions as providers, while public welfare agencies are positioned as purchasers initiating, activating and funding efforts. Connections between entrepreneurial logics and sport practices were previously identified (cf. Cohen \& Peachey 2015; Linde 2013).

The position ascribed to public welfare in discourse about 'sport as a means of responding to social problems' involves initiation, activation and selection; it resembles the fragmentation and reorientation of social work and welfare provision noted by other scholars. Judging from this repositioning, it would be easy to think that involving sport in welfare provision means less government involvement and less power exercised in engineering the conduct of young citizen subjects. This study, however, shows that governing technologies are performed by agencies other than the state: these are the technologies of agency and community, which are most obviously strategies of power performed by a diverse range of agencies seeking to respond to social problems by shaping the conduct of citizen subjects. As a result, state-centred agencies in municipal and public welfare govern by means of initiation, activation and selection, but at a distance from the subjects of intervention. Given the shift in and mutations of the rationales of social work and welfare in more general terms, the next section further explores how using 'sport as a means of responding to social problems' raises questions about the meaning and significance of 'the social' in the context of post-welfarist social work with respect to the empirical investigations carried out.

\section{Making 'the social' particular}

In this section, questions about the meaning and significance of 'the social' with respect to social work are addressed, and a central point of departure in this effort is the particularization of intervention outreach focused on the three distinct domains. First, some reflections are provided on how sport could possibly be constructed (and communicated) as an intelligible and reasonable means of responding to social problems. This is not despite the fact that the potential of social change is limited to these three particular and 
demarcated domains or even that it could be viewed as an individual solution to structural problems, but rather because the intervention outreach is limited to the particular and seemingly non-political domains of society as a whole. Second, a discussion is provided of how the regime of practice delineated could be understood in relation to welfarism and governing from the social point of view. This discussion mainly concerns how such practices may be conceived of as social work beyond the frames and institutions of social-democratic welfarism.

\section{A rationality of social change beyond 'the social'}

In the statements examined and assessed in the articles, sport is represented as an intelligible and reasonable measure against social problems mainly when the problems are represented as problems of individual conduct or ethics. The kind of social work that can be performed with sport practices as a vehicle is somewhat limited to governing individual actions, behaviours and ways of thinking conduct - and to establishing interpersonal relations and partnerships between welfare-providing agencies (through which conduct can be governed). But while sport is constructed as a particular and individual response to problems that are explicitly explained in statements as caused by structural factors and social conditions, this does not necessarily mean that this representation is inconsistent or dissonant. Instead, this may be precisely because sport limits the targets and potential outreach of social change to the particular domains of 'the self, 'the community' and 'the place' and thus constitutes a social policy measure that could not possibly impose change on 'the social' domain or on society as a whole, that it becomes possible to communicate successfully within the frames of the contemporary social policy paradigm.

The core idea of promoting a solution that does not actually target the underlying causes of social problems may instead be one of the key features of sport as a means of social objectives: managing risk not preventing problems. Accordingly, the intervention examined in articles 3 and 4 is described as targeting risk management and reducing predicted and calculated harm rather than the causes of problems (potentially segregation, poverty and the presence of drugs 
in certain milieus). Perhaps these could be complementary strategies; however, the narrations about the Sport Program by political administrators, the social entrepreneur and affiliated coaches distinctly emphasize risk management and consequently not the presumed causes of problems. Risk may be considered an inevitable social fact but is still individually avoidable or manageable. In this sense, risk management could be interpreted as a strategy for reducing calculated harm by inducing individuals to avoid or assume responsibility for avoiding it, while still accepting the factual conditions of society. So when sport is conceptualized as a means of responding to social problems, it is not despite the fact that the intervention does not target 'the social' kind of change, but rather precisely because of this. It may simply be that, because sport cannot inscribe social reform, it becomes feasible with a conception of a fixed society. In contemporary society, perhaps such notions of sport and social change have a fashionable role to play. As a particular measure, 'sport as a means of responding to social problems' illustrates that, in the discourse, society as a whole is exempt from problematization; instead, particular deviances can be pointed out and remedied within the frames of the established social order: it is not society that should be reformed; it is the citizen subject that should reform or adapt. Consequently, the kind of change imbued in the governmental rationality of 'sport as means of responding to social problems' is built on the notion that major and more profound social reforms are neither conceivable nor desired.

In this sense (and in this case), 'sport as a means of responding to social problems' could potentially be interpreted as a sort of manifestation of the death of 'the social' or of a post-welfarist mutation of 'the social': fragmented and particularized. This kind of notion, where society is historically and politically fixed, in contrast to contingent, and thus not subject to social reform or renegotiation, is part of a certain - post-political (cf. Mouffe 2005) frame for interpretation. From such a perspective, only particular domains can be separated from (and fragment) society as a whole and be made the subject of social change. If social order is fixed which it seems to be in the statements examined - then it is up to individuals and communities to subjugate and adapt to this order 
and learn how to actively and responsibly manage the risks and social problems that come with this order of society. Taking a specific social order for granted and detaching 'the social' from reform and social change would also be considered a discursive premise for intelligibly articulating 'sport as a means of responding to social problems'. When profound social reform is not on the agenda, particular targets would fit the paradigm well.

\section{Questioning 'the social' of social problems and social work}

In chapter 3, it was concluded that governing from the social point of view is not an inevitable horizon for our thought, but that shifting balances in governmental rationality involve rather a postwelfarist conception of 'the social' (cf. Rose 1996b; Dean 2010). Even if positioning the particular domains of 'the self, 'the community' and 'the place' as the locations of social change does not necessarily mean a death of 'the social' but rather a gradual mutation of this domain, still it raises questions about how social problems, social work and social policy may and ought to be understood. The emerging sport-based regime of practice delineated above illustrates a kind of social policy and governmental rationality that place relatively less weight on reforming society as a whole. If this is a recurring theme in contemporary social policy, the transforming welfare state confronts challenges in assessing the role and importance of professional skills in social work and assessing what problems are social and therefore with legitimate needs of public and professional interventions. In line, some clarification is required as to what kind of agencies and authorities that should organize and lead social change.

The form of intervention outlined in this study primarily targets the governing of individuals' conduct and subjectivity; it involves a variety of welfare-providing agencies; it is conducted by coaches and a manager on the basis of personal traits (and not professional skills); they are nurtured by ideas in philanthropy and community work. In a variety of ways, this illustrates a somewhat different institutionalized welfare provision than those traditionally set up within the frames of the social-democratic regime. Questioning transformations in the institutions of the welfare state and the 
organization of social policy and social work must not be limited to the forms established within these traditions and the selfunderstanding of the social-democratic regime. New institutions are emerging; they are redrawing the map for social work and establishing new nodes. The analyses and discussions in this study contribute some refined questions that may continue the discussion about the institutions of social work beyond governing from 'the social' point of view and beyond the social-democratic regime of welfare. How could social work be performed and exercised in the contemporary welfare state? How are the institutions of social work constituted? What are the techniques and technologies used to promote social change? What are really the ends of social work interventions? What subjects are recognized as candidates for social work interventions? What ideals of citizenship, inclusion and solidarity does social work promote? What ideals should be promoted? And what indeed is an institution of social work but a container and conductor of a set of governing technologies aimed at producing a certain kind of includable citizen subject?

The advent of 'sport as a means of responding to social problems' moreover raises question of what sport could be in contemporary society. What explicit and formal expectations can reasonably be placed on sport practices? Is it reasonable to treat sport practices as a tool for achieving social objectives and welfare provision? What demands on professional guidance and rational action plans and curricula for social objectives is it fair and reasonable to expect from sport practices? Do formalized demands and expectations that also involve voluntary sport associations risk undermining the autonomy of clubs and associations? What are the consequences for voluntary sport associations when public funding is increasingly conditioned on expectations of contributing to the achievement of social objectives? 


\section{REFLECTIONS}

This last chapter of the thesis provides a summary and concluding reflections in order to trace the critical underpinnings of the study and elucidate the contributions made. This is done in three sections. First, practical, discursive and subjectification concerns about 'sport as a means of responding to social problems' are raised on the basis of the critical perspective underpinning this study. Second, the main contributions of this thesis to governmentality studies, the sociology of sport and studies on welfare provision and social work are outlined. Third, the chapter concludes with some final remarks.

\section{Re-assessing the critical perspective}

The critical perspective presented here has contributed approaches for highlighting the contingency of truth and practice, investigating the conditions of possibility that hold the kind of knowledge and truth together that have enabled the emergence of this regime of practice. It has provided tools for demonstrating the underlying historical and political premises; it has helped to outline how governing is assumed to operate by means of sport for welfare provision; it has offered frames for assessing, diagnosing and demonstrating the effects of power produced with respect to problem representations, frames for interpretation and enactments of and procedures for shaping desirable citizen subjects. In this line of thought, the ambition of this critical perspective has not been to provide insights that would emancipate citizen subjects from power, governing or subjugation, outline improved technologies of governing, determine whether this kind of regime of practice is good or bad, or assess the development potential of sport. As a result, this summary discussion does not end in programmatic declarations about 'sport as a means of responding to social problems'; nonetheless, the discussion will provide reflections on some findings that policy makers, welfare-providing agencies, sport advocates or the public in general would need to confront in assessing the potential of the regime of practice that is emerging and in allocating public resources to sport-based interventions. Three forms of critical concerns are mostly raised here: practical, discursive and subjectification concerns. 
First, the empirical examinations and discussions have touched upon some practical matters in using sport as a tool for welfare provision. This reflection does not go into detail on, nor restate, the limitations set forth in articles 1 and 2 - an account of a number of limitations is provided there, and reference was also previously made to sport as a generator of social problems with respect to the scientific discourse. Sport seems to have a limited potential to solve more profound and structural social problems (which may give rise to the particular problems touched upon in this thesis) (cf. Coakley 2011a; Coalter 2015); however, it may be assessed as one of many measures that together may contribute in combatting social problems while targeting the kind of domains identified in this thesis (cf. Collins \& Kay 2014). Consequently, the targets of sportbased interventions must be clearly defined and achievable. Moreover, the kind of agencies involved in sport practices and incorporated in welfare programs seldom seem to have resources or competences to meet the conditions required for designing and managing successful social change interventions. They are dependent upon voluntary efforts (and that is, indeed, described as one of their major assets) and therefore often lack skilled or trained leaders/educators who are capable of designing and following rational curricula and development plans that involve non-sport components focused on education and social relations. Indeed, sport practices and social services are generally not equivalent. Furthermore, although pro-social skills may be attained in the sport setting, there seems to be limited transferability to other spheres of life. All these dimensions of concern have been considered in the scientific discourse presented in articles 1 and 2, and there is a vast array of empirical accounts on these limitations in the literature (e.g. Coalter 2007a; Collins \& Kay 2014; Kelly 2011; Morgan 2013).

Second, discursive concerns need to be addressed. Recognizing that sport practices have a limited scope in inscribing social change means not only that there are practical limitations but also that, when promoted as a solution, such discourse animates social problems and represents them in specific ways. Such knowledge and discourse tend to diminish the complexity and diversity of social problems and in this case tend to be reduced to issues of individual 
agency and responsibility in choosing the right track. Consequently, dreams of social mobility, opportunities and emancipation that have low potential to be substantiated are of little value (cf. Coakley 2002; Riess 1980). There is, most reasonably, a complexity that could not possibly be addressed by the particular and fragmented efforts that sport practices constitute. Moreover, the discourse produced may be stigmatizing while attributing social problems to domains that are specifically demarcated (and made particular), that is, individuals attributed as excluded or at risk, communities assessed as excluded and deviant as well as places animated to be alien and dangerous. Rather than supporting effectively selected and targeted interventions, this may contribute to reinforcing stereotypes of passive, norm-breaking, deviant populations of risk and exclusion. In producing frames for interpreting problems and solutions, animating them, locating potential change in particular domains ('the self, 'the community' and 'the place'), other impending interpretations are obscured or even made un-thinkable. For instance, 'the social' is a discursive formation with effects on social policy only insofar as it is recognized, prized as a target of interventions and acted upon. When obscured and fragmented, the notion of governing from the social point of view is made detached. In that sense, promoting 'sport as a means of responding to social problems' with respect to the governmental rationality traced in this study may undermine political rationalities attuned to profound social reform. This also means that welfare state retraction is legitimized and made reasonable. These facets of discursive concerns have previously been explored in social research on contemporary sport practices (e.g. Coakley 2002, 2011a, 2011b, 2015; Green, M. 2012; Hartmann \& Kwauk 2011; Morgan 2013; Silk $\&$ Andrews 2012). Moreover, this kind of discourse de-legitimizes the role of professionals in combatting social problems.

Third, the governmental rationality imbued within 'sport as a means of responding to social problems' centres on producing active, autonomous, responsible and self-governing citizen subjects empowered and enabled to grant themselves self-inclusion and selfmanagement of risk. Notably, this kind of subject would be an intended artefact, an engineered subjectification effect of power and 
governing. The kind of enactment where individuals exposed to situations of risk, social problems and exclusion - being deviant, norm-breaking or even involved in drugs or crime, or not - is represented as them being responsible for making a way for themselves into inclusion by means of "pull[ing] themselves up by their own bootstraps" (Lawson 2005, p. 146), even when the exposure they suffer has far more complex and structural causes. When inclusion, security and welfare rely on individual willingness to take initiatives, make good choices and assume responsibility for the consequences of choice, those who are successful are offered social inclusion, security and welfare. In this sense, inclusion (and welfare) becomes conditional and dependent upon individual responsibility. This theme is found frequently in reflections about advanced liberal governmentality (cf. Scoular \& O’Neill 2007; Webb 2006). Moreover, certain norms of masculinity and self-discipline have been considered in the examinations which may not be unproblematically assessed as a sound basis for gaining community inclusion.

The study provides a critical assessment of 'sport as a means of responding to social problems' and of a certain tendency in social policy. However, it is not a critique in dialogue with the precise representatives of the intervention examined (or even with the scholars articulating scientific discourse); rather, it considers the discourse, knowledge and regime of truth that operate through the statements examined and produce the subjectivities and subjects of articulation. Although positioned as subjects of articulation in the examinations, neither scientists nor SP representatives are explicitly advocates of a certain social policy agenda. The rationales of governing outlined in the study are analytically re-assembled and made visible. The examinations have concerned a variety of ways to think about governing the conduct of youths and their communities, how their actions, behaviours and subjectivities are shaped within a specific regime of practice. However, it is most interesting to consider how the respondents (with respect to the SP) and their statements are produced - for instance, the social entrepreneur manager and coaches (and even policy makers) are, so to speak, not only the governors; they are governed, and their subjectivities and 
conduct are also the effects of power. The subjects of articulation are also subjected to the power-knowledge complex, encompassed and entangled within a certain social policy discourse. In addition to scrutinizing the regime of practice, the study likewise illustrates how the variety of agencies and authorities all encompass a specific kind of problematization and advocate specific kinds of responding measures (by means of governing the conduct of youths at risk). The statements produced and analysed are, indeed, one of the most notable discursive and subjectification effects of power; they are formed in accordance with the advanced liberal diagram of social policy and the politics of ethical activation. The subjects of articulation should not be treated here primarily as autonomous and intentional subjects who independently create political rationalities; they express and are the expressions of a dominant regime of truth that permeates the subjectivities, problem representations and rationales of governing. Power operates by means of making subjects encompass these frames of interpretation and making them re-produce discourse. This kind of subtle power establishes knowledges and makes them accepted; it makes ways of thinking about social problems, social work and even our own subjectivity naturalized and uncontested.

\section{Contributions to the field of research}

The study provides some insights and perspectives on 'sport as a means of responding to social problems'. In this section, some key added values are presented. These features are highlighted in relation to the governmentality perspective, to the sociology of sport and to studies on social work and welfare state transformations more broadly.

First, three issues could be stressed in relation to studies on governmental rationality. This study shows how the specific significance and fixity of sport in relation to welfare provision are an effect of various technologies and rationalities of governing attributed to it; sport becomes constituted as a container, generator and activator of a certain force of social policy that emphasizes individual agency and moral community. With respect to the relation between problems, domains and technologies, this study 
provides a theorization and refined conceptualization of how the domain could be assessed. This is vital in relation to the fragmentation of 'the social' and of society as a whole into particular domains ('the self, 'the community' and 'the place') and in assessing the mutating rationales of the contemporary welfare state. The study also makes a methodological contribution in providing a thorough demonstration and reflections on how an analytics of governing could be designed, prepared and conducted.

Second, in relation to the sociology of sport, the study gives a critical assessment of sport's role in society in general and specifically as a means of responding to social problems. In this sense, the approach challenges the great sport myth (cf. Coakley 2015) and provides theoretically informed empirical research that may aid policy makers and welfare-providing agencies in assessing sport in relation to social objectives. Moreover, the study contributes to the formation of a Swedish research field on sport as an explicit means of welfare provision. By describing the context of the regime of practice that emerges, by illustrating how such practices are actually arranged, by making concepts more precise and by scrutinizing the knowledge underpinning these practices, the thesis outlines some frames for approaching 'sport as a means of responding to social problems'. For instance, examinations presented in article 1 have identified a central distinction between social goods as premise or effect, an analytical distinction that helps in sorting out and understanding a range of sport-based practices as tools for social welfare and separates them analytically from voluntary and competitive club and association sport. Furthermore, the thesis displays the kinds of pedagogical rationales of social change embedded in sport practices for social objectives, spotlighting how youths are shaped as active, responsible and selfgoverning citizen subjects and how they are influenced on the basis of personal bonds and community.

Third, in relation to studies on social work and welfare state transformations, this thesis outlines sport practices as a phenomenon of social policy, contextualizes this kind of practice theoretically, demonstrates how advanced liberal governmentality is 
formed in practice and raises questions about the constitution of social work in contemporary society. This is not the first study to analyse sport in relation to welfare provision; however, in a Swedish context it provides an innovative approach in focusing on the rationales of power intertwined in the utilization and promotion of sport in this regard. From this angle, the politics of social work is also approached and viewed in light of shifting standards of social policy. The thesis contributes a refined understanding of how innovative and unconventional forms of welfare and social work are significant practices in contemporary society. The study clearly places the analysis of the regimes of practice and truth in a theoretical framework and thus in relation to shifting governmental rationalities of welfare and governing. This makes it possible to ponder similarities with other social policy areas and to use examples from the case of sport in reflecting upon the more general situation in contemporary social policy. For instance, themes such as privatization of risk, motivational technologies and mobilization of civil society could be recognized from social insurance policy (e.g. Seing 2014), workfare rationales in labour market policy (e.g. Larsson, J.K. 2015; Vesterberg 2016), tendencies of family dependence in care giving (e.g. Ulmanen 2015) and the increase in diaconal social work (e.g. Gärde 2015) in Sweden. The diagrams of power and politics of ethical activation sketched out are hardly unique to the regimes of practice and truth examined in the thesis; rather, they constitute a standard example of contemporary social policy and welfare arrangements.

Advanced liberal forms of welfare and governing have been thoroughly studied both empirically and theoretically before (cf. Dean 2010; Rose 1999). The point of this study is not to conclude that the governmental rationality imbued resembles tendencies known in the literature or from other examples, but rather to demonstrate and provide empirical accounts of how such a governmental rationality is formed within 'sport as a means of responding to social problems', how such rationales enact and perform micro-practices as well as regulate articulations and thinking in everyday social life in sport and welfare practices, how sport may be introduced as a designated venue for social policy. The 
study notes how rationales of responsibilization, empowerment, privatization of risk, formation of a sense of community and morality, and mobilization of public-private partnerships are assembled in the shape of sport for social objectives. In this sense, and in relation to re-assembling the governmental rationality comprised by, for instance, the particularized domains, the examinations and discussions in the thesis illustrate a variety of minor mutations in the rationales of welfare, security, inclusion and governing, and show how the welfare state is shifting its meaning of social change, fine-tuning its means and instruments and recalibrating its targets and objectives, which ultimately epitomize these welfare state transformations. Crucially, this does not mean that the analyses and discussions elucidate the demise of 'the social' or of welfarism as such; rather, they trace and demonstrate a variety of tendencies and rationales in contemporary social policy that reasonably co-exist with or may contribute to a transmutation of welfare state governing and welfare provision.

Finally, the reasoning in the investigations and discussions has prompted the problematization of a range of points of departure that are often unreflected on in thinking about social work practice and about how social problems may be countered. In this study, the meanings of, faith in and expectations of, sport for social objectives have been scrutinized in a variety of ways. The contingency of knowledge has been put in the limelight, made recognized and assessable. In that respect, the study constitutes a concrete contribution to agencies and authorities that conduct sport-based social interventions or are planning to do so. Moreover, the study problematizes even our own conceptions of social work and what welfare-oriented interventions could consist of, what their targets might be and how social change may be enacted and inscribed. Thus, the study raises questions that are significant for the institutions of social work research and for social work practice. Still, more research is needed on the position of sport in social policy. For instance, more attention needs to be given to the precise pedagogical processes and kinds of socialization imbued. The introduction of sport-based interventions in other fields of social policy and social work in relation to, for instance, migration and 
inclusion needs further scrutiny. In addition, research on sport as a tool explicitly made for social policy would benefit from a wider variety of theoretically informed perspectives.

\section{Final remarks}

Starting from the observation that sport has an emerging role as an innovative and unorthodox tool in social policy, welfare provision and social work, the study has sought to survey the conditions and assessments of social work in contemporary society. The study set out to investigate and problematize how the discourse on 'sport as a means of responding to social problems' was constructed and to analyse how rationales of social change were formed by means of this regime of practice. Accordingly, the scope of examination was the regime of practice, the truth underpinning it and, most importantly, the governmental rationality imbued. Specific attention has been given to how sport is premised and conditioned as a 'means of responding to social problems', how such practices are assumed to operate, how they are intertwined with and productive of problem representations, and how desirable citizen subjects are formed as an effect of the regimes of practice and truth.

The study demonstrates how sport is conceptualized and fixed in discourse as a means of promoting social objectives and responding to social problems when associated with technologies of agency (activating individual agency) and technologies of community (establishing moral bonds and genuine personal relations). This conceptualization aligns with a governmental rationality in which social change signifies mental activation and the responsibilization of individual subjects as well as the formation of a moral community tied to specific areas that are at risk of exclusion, rather than reform that targets society as a whole. Using the example of 'sport as a means of responding to social problems' in the scientific discourse and in relation to a sport-based intervention, the study illustrates how minor mutations in the rationales of governing and welfare provision merge into and epitomize welfare state transformations. The study gives a range of empirical accounts demonstrating how emerging tendencies and rationales of welfare and governing are expressed in statements and could be assessed in relation to the 
specific role of sport. In addition, the study provides some reflections on the meaning of governing from the social point of view and the significance of social problems, social work and social policy in relation to the shifting governmental rationality of the welfare state and which shape conditions for social work today and in future. 


\section{REFERENCES}

Agergaard, S. \& Michelsen la Cour, A. (2012). 'Governing Integration through Sports. A Case Study of Civil Society Involvement in Welfare Policy'. Nordic Journal of Migration Research 2(1): 26-34.

Agergaard, S., Michelsen la Cour, A. \& Treumer Gregersen, M. (2015). 'Politicisation of Migrant Leisure: A Public and Civil Intervention Involving Organised Sport'. Leisure Studies 35(2): 200214.

Anderson, E. (2010). Sport, Theory and Social Problems: A Critical Introduction. Abingdon: Routledge.

Andersson, T. (2002). 'Idrotten mellan skötsamhet och huliganism'. In: Lindroth, J. \& Norberg, J.R. (eds.) Ett idrottssekel. Riksidrottsförbundet 1903-2003 (281-298). Stockholm: Informationsförlaget.

Armstrong, G. (1998). Football Hooligans: Knowing the Score. Leamington Spa: Berg.

Bacchi, C. (1999). Women, Policy and Politics: The Construction of Policy Problems. London: SAGE.

Bacchi, C. (2009). Analysing Policy: What's the Problem Represented to Be? Frenchs Forest: Pearson.

Bacchi, C. (2012). 'Why Study Problematization? Making Politics Visible', Open Journal of Political Science 2(1): 1-8.

Banda, D. (2011). 'Sport in Action: Young People, Sex Education and HIV/AIDS in Zambia'. In: Houlihan B. \& Green, M. (eds.) Routledge Handbook of Sports Development (323-336). London: Routledge.

Barry, A., Osborne, T. \& Rose, N. (1996). 'Introduction'. In. Barry, A., Osborne, T. \& Rose, N. (eds.) Foucault and Political Reason: Liberalism, Neo-Liberalism and Rationalities of Government (1-17). Chicago: University of Chicago Press. 
Baudrillard, J. (1983). In the Shadow of the Silent Majorities... or the End of the Social' and Other Essays. New York: Semiotext(e).

Bech Dyrberg, T., Dreyer Hansen, A. \& Torfing, J. (2001). 'Metodiske reflektioner'. In: Bech Dyrberg, T., Dreyer Hansen, A. \& Torfing, J. (eds.) Diskursteorien på arbejde (319-338). Fredriksberg: Roskilde Universitetsforlag.

Bergh, A. (2009). Den kapitalistiska välfärdsstaten. Stockholm: Norstedts.

Berglund, S-A. (2000). Social pedagogik. I goda möten skapas goda skäl. Lund: Studentlitteratur.

Bergsgard, N.A. \& Norberg, J.R. (2010). 'Sport Policy and Politics: The Scandinavian Way'. Sport in Society 13(4): 567-582.

Besley, T. (2010). 'Governmentality of Youth: Managing Risky Subjects'. Policy Futures in Education 8(5): 528-547.

Best, J. (2013). Social Problems. New York: W. W. Norton \& Co.

Beutler, I. (2008). 'Sport Serving Development and Peace: Achieving the Goals of the United Nations through Sport'. Sport in Society (11)4: 359-369.

Black, D.R. (2010). 'The Ambiguities of Development: Implications for "Development through Sport". Sport in Society 13(1): 121-129.

Boréus, K. (1994). Högervåg: Nyliberalismen och kampen om språket $i$ offentlig debatt 1969-1989. Stockholm: Tiden.

Börjesson, M. \& Palmblad, E. (2003). I problembarnens tid. Förnuftets moraliska ordning. Stockholm: Carlssons.

Bové, P.A. (1980). 'The End of Humanism: Michel Foucault and the Power of Disciplines'. Humanities in Society 3: 23-40.

Brännberg, T. (1998). Bakom kulisserna: en socialpsykologisk studie av en förening. Floda: Zenon. 
Brante, T. (2010) 'Professional Fields and Truth Regimes: In Search of Alternative Approaches'. Comparative Sociology 9: 843-886.

Bröckling, U., Krasmann, S. \& Lemke, T. (2011). 'From Foucault's Lectures at the Collège de France to Studies of Governmentality: An Introduction'. In: Bröckling, U., Krasmann, S. \& Lemke, T. (eds.) Governmentality: Current Issues and Future Challenges (1-33). New York: Routledge.

Bryman, A. (2004). Social Research Methods, $2^{\text {nd }}$ edition. Oxford: Oxford University Press.

Bunar, N. \& Sernhede, O. (2013). Skolan och ojämlikhetens urbana geografi. Göteborg: Daidalos.

Burchell, G. (1991). 'Peculiar Interests: Civil Society and Governing “The System of Natural Liberty"'. In: Burchell, G., Gordon, C. \& Miller, P. (eds.) The Foucault Effect: Studies in Governmentality (119150). Chicago: University of Chicago Press.

Burchell, G. (1996). 'Liberal Government and Techniques of the Self. In: Barry, A., Osborne, T. \& Rose, N. (eds.) Foucault and Political Reason: Liberalism, Neo-Liberalism and Rationalities of Government (19-36). Chicago: University of Chicago Press.

Carlson, R. (2007). 'Etnicitet och kulturell mångfald inom föreningsidrotten - en analys av Handslagets första år'. Handslagsrapport 2007:3. Stockholm: Riksidrottsförbundet.

Castel, R. (1991). 'From Dangerousness to Risk'. In: Burchell, G., Gordon, C. \& Miller, P. (eds.) The Foucault Effect: Studies in Governmentality (281-298). Chicago: University of Chicago Press.

CIF (Swedish Research Council for Sport Science). (2014). 'Recept för rörelse - 10 berättelser med hög puls. Gatans lag fyller luckan'. Available at: http://centrumforidrottsforskning.se/wpcontent/uploads/2015/10/Gatans-lag-fyller-luckan.pdf [Accessed 10 May 2016]

Clarke, J. (1996). 'After Social Work?’ In: Parton, N. (ed.) Social Theory, Social Change and Social Work (36-60). London: Routledge. 
Coakley, J (2002). 'Using Sports to Control Deviance and Violence Among Youths: Let's Be Critical and Cautious'. In: Gatz, M; Messner, MA \& Ball-Rokeach, SJ (eds.), Paradoxes of Youth and Sport (13-30). Albany: State University of New York Press.

Coakley, J. (2011a). 'Youth Sports: What Counts as "Positive Development"'. Journal of Sport and Social Issues 35(3): 306-324.

Coakley, J. (2011b). 'Ideology Doesn't Just Happen: Sports and Neoliberalism'. Curitiba 1(1): 67-84.

Coakley, J. (2015). 'Assessing the Sociology of Sport: On Cultural Sensibilities and the Great Sport Myth'. International Review for the Sociology of Sport 50(4-5): 402-406.

Coalter, F. (2007a). 'Sport Clubs, Social Capital and Social Regeneration: "Ill-Defined Interventions with Hard to Follow Outcomes"?’ Sport in Society 10(4): 537-559.

Coalter, F. (2007b). A Wider Social Role for Sport: Who's Keeping the Score? London: Routledge.

Coalter, F. (2011a). 'Sport Development's Contribution to Social Policy Objectives: The Difficult Relationship between Politics and Evidence'. In: Houlihan B. \& Green, M. (eds.) Routledge Handbook of Sports Development (561-578). London: Routledge.

Coalter, F. (2011b). 'The Politics of Sport-for-development: Limited Focus Programmes and Broad Gague Problems'. International Review for the Sociology of Sport 45(3): 295-314.

Coalter, F. (2015). 'Sport-for-change: Some Thoughts from a Sceptic'. Social Inclusion (3)3: 19-23.

Cohen, A. \& Peachey, J.W. (2015). 'The Making of a Social Entrepreneur: From Participant to Cause Champion within a Sport-For-Development Context'. Sport Managements Review 18(1): 111-125. 
Collins, M. \& Haudenhuyse, R.P. (2015). 'Social Exclusion and Austerity Policies in England: The Role of Sports in a New Area of Social Polarisation and Inequality?'. Social Inclusion (3)3: 5-18.

Collins, M. \& Kay, T. (2014). Sport and Social Exclusion. London: Routledge.

Crabbe, T. (2000). 'A Sporting Chance?: Using Sport to Tackle Drug Use and Crime'. Drugs: Education, Prevention \& Policy 7(4): 381-391.

Crabbe, T. (2005). “'Getting to Know You”: Engagement and Relationship Building'. First Interim National Positive Futures Case Study Research Report. Available at: http://positivefuturesnorthliverpool.co.uk/media/1245/gettingto-know-you.pdf [Accessed 7 June 2016]

Crabbe, T. (2007). 'Reaching the "Hard to Reach": Engagement, Relationship Building and Social Control in Sport Based Social Inclusion Work'. International Journal of Sport Management and Marketing 2(1-2): 27-40.

Crawshaw, P. (2012). 'Governing at a Distance: Social Marketing and the (Bio) Politics of Responsibility'. Social Science \& Medicine 75: 200-207.

Cruickshank, J. (2012). 'The Role of Qualitative Interviews in Discourse Theory'. Critical Approaches to Discourse Analysis across Disciplines 6(1): 38-52.

Cruikshank, B. (1996). 'Revolutions Within: Self-Government and Self-Esteem'. In: Barry, A; Osborne, T. \& Rose, N. (eds.) Foucault and Political Reason: Liberalism, Neo-Liberalism and Rationalities of Government (231-251). Chicago: University of Chicago Press.

Cruikshank, B. (1999). The Will to Empower. New York: Cornell University Press.

Dahlstedt, M. (2008). 'The Politics of Activation: Technologies of Mobilizing "Multiethnic Suburbs" in Sweden'. Alternatives 33: 481504. 
Dahlstedt, M. (2009). Aktiveringens politik. Demokrati och medborgarskap för ett nytt millenium. Malmö: Liber.

Dean, M. (1998). 'Risk, Calculable and Incalculable'. Soziale Welt 49: 25-42.

Dean, M. (2010). Governmentality: Power and Rule in the Modern Society, $2^{\text {nd }}$ edition. London: SAGE.

Derrida, J. (2003) 'Structure, Sign and Play in the Discourses of the Human Sciences'. In: Delanty, G. \& Strydom, P. (eds.) Philosophies of Social Science: The Classic and Contemporary Readings (354-358). Maidenhead: Open University Press.

Donnelly, P., Darnell, S., Wells, S., \& Coakley, J. (2007). 'The Use of Sport to Foster Child and Youth Development and Education'. In: Sport for Development and Peace International Working Group (SDP IWG) Secretariat (ed.) Literature Reviews on Sport for Development and Peace (7-47). Toronto: University of Toronto.

Donzelot, J. (1979). The Policing of Families. London: The John Hopkins University Press.

Donzelot, J. (1988). 'The Promotion of the Social'. Economy and Society 17(3): 395-427.

Donzelot, J. (1991). 'The Mobilization of Society'. In: Burchell, G. Gordon, C. \& Miller, P. (eds.) The Foucault Effect: Studies in Governmentality (169-180). Chicago: University of Chicago Press.

Dreyfus, H.L. \& Rabinow, P. (1983). Beyond Structuralism and Hermeneutics, $2^{\text {nd }}$ edition. Chicago: University of Chicago Press.

Eichberg, H. \& Loland, S. (2010). Nordic Sports - from Social Movements via Emotional to Bodily Movement - and Back Again?' Sport in Society 13(4): 676-690.

Eitzen, D.S. (2012). Fair and Foul: Beyond the Myths and Paradoxes of Sport. Plymouth: Rowman \& Littlefield. 
Ellefsen Hansen, C. \& Törnros, E. (2015). 'En match mot segregationen - Aldrig mer offside' [Bachelor thesis]. Linköping: Linköping University.

Elvhage, G. \& Linde, S. (2012). 'Ungdomar och drive in-idrott - en utvärdering av organiserad spontanidrott 2009-2011'. Idrottslyftets externa utvärdering, Riksidrottsförbundet. Available at: http://www.rf.se/ImageVaultFiles/id_45088/cf_394/Drive_inidrott.PDF [Accessed 10 May 2016].

Endresen, I.M. \& Olweus, D. (2005). 'Participation in Power Sports and Antisocial Involvement in Preadolescent and Adolescent Boys'. Journal of Child Psychology and Psy-chiatry and Allied Disciplines 46(5): 468-478.

Eriksson, L (2004) 'Gemenskapen då och nu’. In: Eriksson, L., Hermansson, H-E. \& Münger, A-C. (eds.) Socialpedagogik och sambällsförståelse. Teori och praktik $i$ socialpedagogisk forskning (71-106). Stockholm: Brutus Östlings bokförlag Symposion.

Eriksson, L. \& Markström, A-M. (2000). Den svårfängade socialpedagogiken. Studentlitteratur: Lund.

Esping-Andersen, G. (1990). Three Worlds of Welfare Capitalism. Cambridge: Polity Press.

Esping-Andersen, G. (1999). Social Foundations of Postindustrial Economies. Oxford: Oxford University Press.

Ewald, F. (1991). 'Insurance and Risk'. In: Burchell, G., Gordon, C. \& Miller, P. (eds.) The Foucault Effect: Studies in Governmentality (197210). Chicago: University of Chicago Press.

Fahlén, J. (2015). 'The Corporal Dimensions of Sports-based interventions: Understanding the Role of Embedded Expectations and Embodied Knowledge in Sport Policy Implementation'. International Review for the Sociology of Sport.

Fahlén, J. \& Stenling, C. (2015). 'Sport Policy in Sweden'. International Journal of Sport Policy and Politics. 
Ferguson, I. \& Lavalette, M. (2013). 'Critical and Radical Social Work: An Introduction'. Critical and Radical Social Work 1(1): 3-14.

Foucault, M. (1979). Discipline and Punish: The Birth of the Prison. New York: Vintage Books.

Foucault, M. (1980). 'Truth and Power'. In: Gordon, C. (ed.) Power/Knowledge, Selected Interviews and Other Writings 1972-1977 (109-133). Harlow: Harvester Press Limited.

Foucault, M. (1982). 'The Subject and Power'. Critical Inquiry 8(4): $777-795$.

Foucault, M. (1991). 'Governmentality'. In: Burchell, G., Gordon, C. \& Miller, P. (eds.) The Foucault Effect: Studies in Governmentality (87104). Chicago: University of Chicago Press.

Foucault, M. (2004). 'Polemics, Politics, and Problematizations: An Interview with Michel Foucault'. In: Rabinow, P. (ed.) The Foucault Reader: An Introduction to Foucault's Thought (381-390). London: Penguin Books.

Foucault, M. (2009). Security, Territory, Population: Lectures at the Collège de France, 1977-78. Basingstoke: Palgrave Macmillan.

Foucault, M. (2010). The Birth of Biopolitics: Lectures at the Collège de France, 1978-79. New York: Picador.

Flyvbjerg, B. (1991). Rationalitet og magt. Bd 1, Det konkretes videnskab. København: Akademisk Forlag.

Fraser-Thomas, J., Côté, J. \& Deakin, J. (2005). 'Youth Sport Programs: An Avenue to Foster Positive Youth Development'. Physical Education and Sport Pedagogy 10(1): 19-40.

Gärde, J. (2015). 'Shrinking Religious Communities and Thriving Interreligious Social Work in Postsecular Sweden'. Journal of Religion \& Spirituality in Social Work: Social Thought 34 (1): 1-23. 
Garland, D. (2014). 'The Welfare State: A Fundamental Dimension of Modern Government'. European Journal of Sociology 55(3): 327364.

Gillis, J.R. (1984). Youth and History. Tradition and Change in European Age Relations, 1770-Present. New York: Academic Press.

Giulianotti, R. (2011). 'Sport, transnational peacemaking, and global civil society: Exploring the reflective discourses of "sport, development, and peace” project officials’. Journal of Sport \& Social Issues, 35(1): 50-71.

Gordon, C. (1987). 'The Soul of the Citizen: Max Weber and Michel Foucault on Rationality and Government'. In: Lash, S. \& Whimster, S. (eds.) Max Weber, Rationality and Modernity (293-316). London: Allen \& Unwin.

Gordon, C. (1991). 'Governmental Rationality: An Introduction'. In: Burchell, G., Gordon, C. \& Miller, P. (eds.) The Foucault Effect: Studies in Governmentality: With Two Lectures by and an Interview with Michel Foucault (1-51). Chicago: The University of Chicago Press.

Government Offices of Sweden (Regeringskansliet). (2015). ‘Ökat anslag till idrottsrörelsen i kommande vårproposition’, press release, 14 April 2015. Available at: http://www.regeringen.se/pressmeddelanden/2015/04/okatanslag-till-idrottsrorelsen-i-kommande-varproposition/ [Accessed10 May 2016].

Gray, P. (2009). 'The Political Economy of Risk and the New Governance of Youth Crime'. Punishment \& Society 11(4): 443-458.

Gredig, D. \& Marsh, J.C. (2010). 'Improving Intervention and Practice'. In: Shaw, I., Briar-Lawson, K., Orme, J. \& Ruckdeschel R. (eds.) The Sage Handbook of Social Work Research (64-82). Los Angeles: SAGE.

Green, D. (2007). 'Risk and Social Work Practice'. Australian Social Work 60(4): 395-409. 
Green, M. (2007). 'Governing under Advanced Liberalism: Sport Policy and the Social Investment State'. Policy Sciences 40: 55-71.

Green, M. (2012). 'Advanced Liberal Government, Sport Policy, and "Building the Active Citizen"”. In: Andrews, D.L. \& Silk, M.L. (eds.) Sport and Neoliberalism: Politics, Consumption, and Culture (3856). Philadelphia: Temple University Press.

Green, M. \& Houlihan, B. (2006). 'Governmentality, Modernization, and the "Disciplining" of National Sporting Organisations:

Athletics in Australia and the United Kingdom'. Sociology of Sport Journal 23: 47-71.

Groves, M., Griggs, G. \& Leflay, K. (2012). 'Hazing and Initiation Ceremonies in University Sport: Setting the Scene for Further Research in the United Kingdom'. Sport in Society 15(1): 117-131.

Gustafsson, B., Hermerén, G. \& Petersson, B. (2006). Good Research Practice - What Is It? Views, Guidelines and Examples. Stockholm: Vetenskapsrådet.

Haahr, J.H. (2004). 'Open Co-ordination as Advanced Liberal Government'. Journal of European Public Policy 11(2): 209-230.

Hallström, V. (2015). Samhällsentreprenörskap i teori och praktik: Exemplet Överenskommelsen mellan ideell sektor och en svensk kommun [PhLic thesis]. Linköping: Linköping University.

Hartman, L. (2011a). 'Inledning'. In: Hartman, L. (ed.) Konkurrensens konsekvenser. Vad händer med svensk välfärd? (9-31). Stockholm: SNS Förlag.

Hartman, L. (2011b). 'Slutsatser'. In: Hartman, L. (ed.) Konkurrensens konsekvenser. Vad händer med svensk välfärd? (258-276). Stockholm: SNS Förlag.

Hartmann, D. \& Depro, B. (2006). 'Rethinking Sports-Based Community Crime Prevention: A Preliminary Analysis of the Relationship between Midnight Basketball and Urban Crime Rates'. Journal of Sport and Social Issues 30(2): 180-196. 
Hartmann, D. \& Kwauk, C. (2011). 'Sport and Development: An Overview, Critique, and Reconstruction'. Journal of Sport and Social Issues 35(3): 284-305.

Haudenhuyse, R.P., Theebom, M. \& Coalter, F. (2012). 'The Potential of Sports-Based Interventions for Vulnerable Youth: Implications for Sport Coaches and Youth Workers'. Journal of Youth Studies 15(4): 437-454.

Heaward, A., Ryan, P.A. \& Suckling, S. (2008). 'Closing the Gap: Innovation and Sustainability in Addressing Ssocial Exclusion through Sport'. In: Berg, E., Barry, J., Saiala, P. \& Chandler, J. (eds.) Dilemmas of Identity, New Public Management, and Governance (3541). Luleå Research Report 2008:06. Luleå: Luleå University.

Heinemann, K. (2006). 'Sport and the Welfare State in Europe'. European Journal of Sport Science 5(4): 181-188.

Helsingborgs Dagblad. (2004). 'Olympiska spelen hittade hem', 14 August 2004. Available at:

http://hd.se/sport/2004/08/14/olympiska-spelen-hittade-hem/ [Accessed 25 October 2011].

Hermerén, G. (2011). God forskningssed. Stockholm: Vetenskapsrådet.

Hertzberg, F. (2007). 'Gymnasievalet och bilder av framtiden på en etniskt delad arbetsmarknad'. In: Dahlstedt, M., Hertzberg, F., Urban, S. \& Ålund, A. (eds.) Utbildning, arbete, medborgarskap (129158). Umeå: Boréa.

Hewitt, M. (1983). 'Bio-Politics and Social Policy: Foucault's Account on Welfare'. Theory, Culture and Society 2(1): 67-84.

Hirdman, Y. (2000). Att lägga livet tillrätta. Stockholm: Carlsson.

Holmberg, B. \& Liljegren, L. (1993). 'Idrott och socialt arbete'. Samordningskansliet för brottsförebyggande åtgärder, Stockholms stad.

Hörnqvist, M. (2012). En annan Foucault: Maketens problematik. Stockholm: Carlsson. 
Houlihan, B. (1997). Sport, Policy and Politics. London: Routledge.

Houlihan, B. (2011). 'The Influences on Sports Development. Introduction: The Constraints of History'. In: Houlihan, B. \& Green, M. (eds.) Routledge Handbook of Sports Development (5-8). London: Routledge.

Houlihan, B., Bloyce, D. \& Smith, A. (2009). 'Editorial: Developing a Research Agenda in Sport Policy'. International Journal of Sport Policy 1(1): 1-12.

Howarth, D. (2000). Discourse. Buckingham: Open University Press.

Hughes, G. (1998). Understanding Crime Prevention: Social Control, Risk and Late Modernity. Philadelphia: Open University Press.

Hylton, K. (2011). 'Sport and Social Integration'. In: Houlihan, B. \& Green, M. (eds.) Routledge Handbook of Sports Development (100-113). London: Routledge.

Johansson, H., Arvidsson, M. \& Johansson, S. (2015). 'Welfare Mix as a Contested Terrain: Political Positions on Government-Nonprofit Relations at National and Local Levels in a Social Democratic Welfare State'. Voluntas 26: 1601-1619.

Johansson, H., Nordfeldt, M. \& Johansson, S. (2015). 'Ideella organisationers roll i välfärdssamhället - röst och service'. In: Johansson, S., Dellgran, P. \& Höjer, S. (eds.) Människobehandlande organisationer. Villkor för ledning, styrning och professionellt välfärdsarbete (132-151). Stockholm: Natur \& Kultur.

Johansson, K. (2007). 'Välfärdsstaten som styrning'. In: Lövgren, S. \& Johansson, K. (eds.) Viljan att styra. Individ, sambälle och välfärdens styrningspraktiker (25-38). Lund: Studentlitteratur.

Johnsson, E. \& Svensson, K. (2005). 'Theory in Social Work: Some Reflections on Understanding and Explaining Interventions'. European Journal of Social Work 8(4): 419-433.

Kelly, L. (2011). “'Social Inclusion” through Sports-Based Interventions?’ Critical Social Policy 31(1): 126-150. 
Kelly, L. (2012). 'Sports-Based Interventions and the Local Governance of Youth Crime and Antisocial Behavior'. Journal of Sport and Social Issues 37(3): 261-283.

Kemshall, H. (2002). 'Effective Practice in Probation: An Example of "Advanced Liberal" Responsibilisation?" The Howard Journal 41 (1): 41-58.

Kidd, B. (2008). 'A New Social Movement: Sport for Development and Peace'. Sport in Society 11(4): 370-380.

Kilborn Arvérus, A. (2009). 'Idrott som metod i socialt arbete med barn i riskzonen för kriminalitet. En studie i en fotbollsförening' [Master thesis/Idrottsvetenskapliga rapporter 2009:24]. Göteborg: University of Gothenburg..

Kings, L. (2011). Till det lokalas försvar: civilsambället $i$ den urbana periferin. Lund: Arkiv.

Kolfjord, I. (2007). 'Från projekt till modell: Helamalmö - motion, integration och brottsförebyggande arbete'. Handslagsrapport 2007:11. Stockholm: Riksidrottsförbundet.

Larsson, J.K. (2015). Integrationen och arbetets marknad. Stockholm: Atlas.

Larsson, B., M. Letell \& H. Thörn. 2012. 'Transformations of the Swedish Welfare State: Social Engineering, Governance and Governmentality: An Introduction'. In: Larsson, B., Letell, M. \& Thörn, H. (eds.) Transformations of the Swedish Welfare State (3-22). New York: Palgrave MacMillan.

Larsson, S. (2005). 'On Quality of Qualitative Studies'. Nordisk Pedagogik 25: 16-35.

Lawson, H.A. (2005). 'Empowering People, Facilitating Community Development and Contributing to Sustainable Development: The Social Work of Sport, Exercise and Physical Education Programs'. Sport, Education and Society 10(1): 135-160. 
Lessenich, S. (2011). 'Constructing the Socialized Self: Mobilization and Control in the "Active Society". In: Bröckling, U., Krasmann, S. \& Lemke, T. (eds.) Governmentality. Current Issues and Future Challenges (304-319). New York: Routledge.

Levander, U. (2011). Utanförskap på entreprenad. Diskurser om sociala företag $i$ Sverige. Göteborg: Daidalos.

Linde, S. (2013). 'Konkurrerande logiker - en möjlighet för institutionella entreprenörer?' In: Linde, S. \& Svensson, K. (eds.) Förändringens entreprenörer och tröghetens agenter (109-126). Stockholm: Liber.

Lindroth, J. (1988). Från sportfanneri till massidrott. Stockholm: HLS Förlag.

Lindvall, J. (2004). The Politics of Purpose: Swedish Macroeconomic Policy after the Golden Age [PhD thesis]. Göteborg: University of Gothenburg.

Loseke, D.R. (2003). Thinking about Social Problems: An Introduction to Constructionist Perspectives. New Brunswick: Transaction publishers.

Luhmann, N. (1993). 'Deconstruction as Second-Order Observing'. New Literary History 24(4): 763- 782.

Lundström, T. \& Wijkström, F. (1997) The Nonprofit Sector in Sweden. Manchester: Manchester University Press.

Madsen, B. (2005). Socialpedagogik. Integration och inklusion i det moderna sambället. Lund: Studentlitteratur.

Markström, A-M. \& Münger, A-C. (2004). 'Socialpedagogiska institutioner för barn i tid och rum’. In: Eriksson, L., Hermansson, H-E. \& Münger, A-C. (eds.) Socialpedagogik och sambällsförståelse.

Teori och praktik i socialpedagogisk forskning (107-134). Stockholm: Brutus Östlings bokförlag Symposion.

Marshall, T.H. (1950). Citizenship and Social Class, and Other Essays. Cambridge: Cambridge University Press. 
McKee, K. (2009). 'Post-Foucauldian Governmentality: What Does It Offer Critical Social Policy Analysis?’ Critical Social Policy 29(3): 465-486.

McNay, L. (1994). Foucault: A Critical Introduction. Cambridge: Polity Press.

Meeuwisse, A. \& Swärd, H. (2007). 'Cross-National Comparisons of Social Work: A Question of Initial Assumptions and Levels of Analyses'. European Journal of Social Work (10)4: 481-496.

Messner, M.A. (1990). 'When Bodies are Weapons: Masculinity and Violence in Sport'. International Review for the Sociology of Sport 25(3): 203-220.

Messner, M.A. \& Sabo, D.F. (1994). Sex, Violence \& Power in Sports: Retbinking Masculinity. Freedom: Crossing Press.

Mik-Meyer, N. \& Villadsen, K. (2013). Power and Welfare: Understanding Citizens' Encounters with State Welfare. London: Routledge.

Miller, P. \& Rose, N. (1990). 'Governing Economic Life'. Economy and Society (19)1: 1-31.

Mørch, S. (1997). 'Individualisering och deindividualisering'. In: Isenberg, B. \& Oddner, F. (eds.) Seendets pendel. Festskrift till Johan Asplund (123-143). Stockholm: Brutus Östlings bokförlag Symposion.

Morgan, H. (2013). 'Sport Volunteering, Active Citizenship and Social Capital Enhancement: What Role in "Big Society"? International Journal of Sport Policy and Politics 5(3): 381-395.

Mouffe, C. (2005). On the Political. London: Routledge.

Muncie, J. (2006). 'Governing Young People: Coherence and Contradiction in Contemporary Youth Justice'. Critical Social Policy 26 (4): 770-793. 
Münger, A-C. (2000). Stadens barn på landet. Stockholms sommarlovskolonier och den moderna välfärden [PhD thesis]. Linköping: Linköping University.

New Moderates (Nya Moderaterna). (2010). 'Bryt mönster - se idrottens möjligheter. En rapport om ungdomar och integration, jämställdhet och brottsförebyggande'. Available at: http://moderatkultur.se/wp-content/uploads/2013/04/Brytm\%C3\%B6nstret_Idrottspolitik.pdf [Accessed 25 October 2011].

Nichols, G. (2007). Sport and Crime Reduction: The Role of Sports in Tackling Youth Crime. London: Routledge.

Nikander, P. (2008). Working with Transcripts and Translated Data. Qualitative Research in Psychology 5: 225-231.

Norberg, J.R. (2004). Idrottens väg till folkhemmet : studier i statlig idrottspolitik 1913-1970. Stockholm: SISU idrottsböcker.

Norberg, J.R. (2010). 'The Development of the Swedish Sport Movement between State, Market and Civil Society: Some Remarks'. In: Evers, A. \& Zimmer, A. (eds.) Third Sector Organizations Facing Turbulent Environments. Sports, Culture and Social Services in Five European Countries (183- 201). Baden Baden: Nomos.

Norberg J.R. (2011). 'A Contract Reconsidered? Changes in the Swedish State's Relation to the Sports Movement'. International Journal of Sport Policy and Politics 3: 311-325.

O’Farrell, C. (2005). Michel Foucault. London: SAGE.

Ohlsson, L.B. \& Swärd, H. (1999). Ungdom som sambällsproblem. Lund: Studentlitteratur.

Öhlund, T., Gundel, P.O. \& Klaus, M. (2009). 'Förortens sociala kapital - En utvärdering av Lugna gatan i Göteborg och Malmö’. Arvsfonden. Avaliable at:

http://www.arvsfonden.se/sites/default/files/article_reports/utv arderingsrapport_-_forortens_sociala_kapital.pdf [Accessed 10 May 2015]. 
Oliver, P. (2010). The Student's Guide to Research Ethics, $2^{\text {nd }}$ edition. Maidenhead: McGraw-Hill, Open University Press.

Olson, H-E. (1995). Staten och ungdomens fritid. Kontroll eller autonomi. Lund: Arkiv.

Olson, M., Fejes, A., Dahlstedt, M. \& Nicoll, K. (2015). 'Citizenship Discourses: Production and Curriculum'. British Journal of Sociology of Education 36(7): 1036-1053.

O’Malley, P. (1996). 'Risk and Responsibility'. In: Barry, A., Osborne, T. \& Rose, N. (eds). Foucault and Political Reason: Liberalism, Neo-Liberalism and Rationalities of Government (189-207). Chicago: University of Chicago Press.

Österlind, M. (2016). 'Sport Policy Evaluation and Governing Participation in Sport: Governmental Problematics of Democracy and Health'. International Journal of Sport Policy and Politics: 1-16.

Österlind, M. \& Fahlén, J. (2015). 'Reconsidering the Epistemology of the Swedish Sports Model through the Lens of Governmentality: Notes on the State-Civil Society Relationship, Government, Power and Social Change'. Idrott, Historia \& Sambälle. Svenska idrottshistoriska föreningens ärsskrift 2015: 148-170.

Österlind, M. \& Wright, J. (2014). 'If Sport's the Solution Then What's the Problem? The Social Significance of Sport in the Moral Governing of "Good" And "Healthy" Citizens in Sweden, 19221998'. Sport, Education and Society 19(8): 973-990.

Östnäs, A. (1990). 'Idrott och socialtjänst. Ett möte med förhinder'. Aktuell beteendevetenskaplig idrottsforskning, SVEBI:s årsbok 1990: 105121.

Östnäs, A. (1991). 'Idrotten i det sociala arbetet. Några reflektioner kring en tankeram'. Aktuell beteendevetenskaplig idrottsforskning, SVEBI:s årsbok 1991: 164-181.

Östnäs, A. (2005). 'Att utforma en kurs. Diskussion kring en idrottsrelaterad kurs inom socionomprogrammet på Högskolan i 
Kalmar'. Aktuell beteendevetenskaplig idrottsforskning, SVEBI:s årsbok 2005: 245-261.

Palmås, K. (2008). 'Socialt entreprenörskap: Ny sektor eller rebranding av ideellt arbete?' In: Lundström, A. \& Sundin, E. (eds.) Perspektiv på förnyelse och entreprenörskap i offentlig verksambet (245-257). Örebro: FSF.

Palmblad, E. (2007). 'Hur ska (problem)barn styras?' In: Lövgren, S. \& Johansson, K. (eds.) Viljan att styra. Individ, sambälle och välfärdens styrningspraktiker (39-60). Lund: Studentlitteratur.

Parton, N. (1996). 'Social Theory, Social Change and Social Work: An Introduction'. In: Parton, N. (ed.) Social Theory, Social Change and Social Work (4-18). London: Routledge.

Parton, N. \& Kirk, S. (2010). 'The Nature and Purposes of Social Work'. In: Shaw, I., Briar-Lawson, K., Orme, J. \& Ruckdeschel, R. (eds.) The Sage Handbook of Social Work Research. Los Angeles: SAGE.

Patriksson, G. (1973). Idrottens historia i sociologisk belysning. Stockholm: Utbildningsförlaget.

Patton, M.Q. (2015). Qualitative Research \& Evaluation Methods: Integrating Theory and Practice, $4^{\text {th }}$ edition. Thousand Oaks: SAGE.

Payne, M. (2014). Modern Social Work Theory, $4^{\text {th }}$ edition. Basingstoke: Palgrave Macmillan.

Petersson, K. (1990). Ungdom, livsvillker och makt. En studie av erfarenheternas rum $i$ det moderna $[\mathrm{PhD}$ thesis]. Linköping: Linköping University.

Petersson, K. (1997). 'Viljan att förekomma - om unga i den svenska profylaxens ordningsprojekt'. In: Dahlgren, L. \& Hultqvist, K. (eds.) Seendet och seendets villkor. En bok om barns och ungas välfärd (161-208). Stockholm: HLS Förlag.

Petersson, K. (2000). 'Mobilisering av gemenskapen. Om den socialpedagogiska offensiven i lokalmiljön'. In: Arnstberg, K-O \& 
Ramberg, I. (eds.) I stadens utkant. Perspektiv på förorter (86-118). Tumba: Mångkulturellt centrum.

Petersson, K., Olsson, U., Popkewitz, T.S. \& Hultqvist, K. (2007). 'Framtiden som styrning: en genealogisk betraktelse av det utbildningsbara subjektet och pedagogisk teknologi under det tidiga 2000-talet'. In: Lövgren, S. \& Johansson, K. (eds.) Viljan att styra. Individ, sambälle och välfärdens styrningspraktiker (239-268). Lund: Studentlitteratur.

Piggin, J., Jackson, S.J. \& Lewis, M. (2009). 'Knowledge, Power and Politics. Contesting "Evidence-based” National Sport Policy'. International Review for the Sociology of Sport 44(1): 87-101.

Philp, M. (1979). 'Notes on the Form of Knowledge in Social Work'. The Sociological Review 27(1): 83-111.

Pitter, R. \& Andrews, D.L. (1997). 'Serving America's Underserved Youth: Reflections on Sport and Recreation in an Emerging Social Problems Industry'. Quest 49(1): 85-99.

Pollack, S. (2010). 'Labelling Clients "Risky": Social Work and the Neo-Liberal Welfare State'. British Journal of Social Work 40(4): 1263-1278.

Potter, J. \& Wetherell, M. (1987). Discourse and Social Psychology: Beyond Attitudes and Behaviour. London: SAGE.

Preston, I. \& Szymanski, S. (2003). 'Cheating in Contests'. Oxford Review of Economic Policy 19(4): 612-624.

Raffnsøe, S., Gudmand-Høyer, M. \& Thaning, M.S. (2014). 'Foucault's Dispositive: The Perspicacity of Dispositive Analytics in Organizational Research'. Organization: 1-27.

Reisch, M. (2013). 'What is the Future of Social Work?' Critical and Radical Social Work 1(1): 67-85.

Richards, J., Kaufman, Z., Schulenkorf, N., Wolff, E., Gannett, K., Siefken, K. \& Rodriguez, G. (2013). 'Advancing the Evidence 
Base of Sport for Development: A New Open Access, PeerReviewed Journal'. Journal of Sport for Development 1(1): 1-13.

Riess, S.A. (1980). 'Sport and the American Dream'. Journal of Social History 14(2): 295-303.

Roe, D. (2015). 'Rings on the Water: An exploration of Sport Pedagogy in Juvenile Justice Settings' [Master thesis]. Stockholm: Stockholm University.

Rose, N. (1990). Governing the Soul: The Shaping of the Private Self. Florence: Routledge.

Rose, N. (1996a). 'Governing “Advanced” Liberal Democracies'. In: Barry, A., Osborne, T. \& Rose, N. (eds.) Foucault and Political Reason: Liberalism, Neo-Liberalism and Rationalities of Government (3764). Chicago: University of Chicago Press.

Rose, N. (1996b). 'The Death of the Social? Re-Figuring the Territory of Government'. Economy and Society 25(3): 327-356.

Rose, N. (1999). Powers of Freedom: Reframing Political Thought. Cambridge: Cambridge University Press.

Rose, N. (2000a). 'Community, Citizenship and the Third Way'. American Behavioral Scientist 43(9): 1395-1411.

Rose, N. (2000b). 'Government and Control'. British Journal of Criminology 40: 321-339.

Rose, N. \& Miller, P. (1992). 'Political Power beyond the State: Problematics of Government'. The British Journal of Sociology 43(2): 173-205.

Rubington, E. \& Weinberg, M.S. (2011). 'Social Problems and Sociology'. In: Rubington, E. \& Weinberg, M.S. (eds.) The Study of Social Problems, $7^{\text {th }}$ edition (3-14). New York: Oxford University Press.

Sahlin, I. (2000). Brottsprevention som begrepp och fenomen. Lund: Arkiv. 
Sallnäs, M. \& Wiklund, S. (2015). 'Konkurrensutsättning av individoch familjeomsorgen - om marknadssärdrag och statlig tillsyn'. In: Johansson, S., Dellgran, P. \& Höjer, S. (eds.) Människobehandlande organisationer. Villkor för ledning, styrning och professionellt välfärdsarbete (113-131). Stockholm: Natur \& Kultur.

Schelin, B. (1985). Den ojämlika idrotten: Om idrottsstratifiering, idrottspreferens och val av idrott [PhD thesis]. Lund: Lund University.

Scoular, J. \& O’Neill, M. (2007). 'Regulating Prostitution: Social Inclusion, Responsibilization and the Politics of Prostitution Reform'. British Journal of Criminology 47: 764-778.

SDP IWG (Sport for Development and Peace International Working Group). (2008). 'Harnessing the Power of Sport for Development and Peace: Recommendations to Governments. Final report for the UN Office on Sport for Development and Peace'. Available at: http://www.un.org/wcm/webdav/site/sport/shared/sport/pdfs /SDP\%20IWG/Final\%20SDP\%20IWG\%20Report.pdf [Accessed 10 May 2016].

Sefiha, O. (2012). 'Bad Sports: Explaining Sport Related Deviance'. Sociology Compass 6(12): 949-961.

Seing, I. (2014). Activating the Sick-Listed: Policy and Practice of Return to Work in Swedish Sickness Insurance and Working Life [PhD thesis]. Linköping: Linköping University.

Seippel, Ø., Ibsen, B. \& Norberg, J.R. (2010). 'Introduction: Sport in Scandinavian Societies'. Sport in Society 13(4): 563-566.

Sernhede, O. (2007). AlieNation is my Nation: Hiphop och unga mäns utanförskap i det nya Sverige. Stockholm: Ordfront.

Sernhede, O. (2008). 'Nyfattigdom, stigmatisering och socialpedagogik - Ungdomsarbetes villkor och den postkoloniala ordningen'. In: Molin, M., Gustavsson, A. \& Hermansson, H-E. (eds.). Meningsskapande och delaktighet. Om var tids socialpedagogik (4582). Göteborg: Daidalos. 
Severinsson, S. (2010). Unga i normalitetens gränsland. Undervisning och behandling $i$ särskilda undervisningsgrupper och hem för vård eller boende [PhD thesis]. Linköping: Linköping University.

Shaw I., Briar-Lawson, K., Orme, J. \& Ruckdeschel, R. (2010). 'Editorial Essay: Mapping Social Work Research: Pasts, Present and Futures'. In: Shaw, I., Briar-Lawson, K., Orme, J. \& Ruckdeschel, R. (eds.) The Sage Handbook of Social Work Research (120). Los Angeles: SAGE.

Sherry, E., Schulenkorf, N. \& Chalip, L. (2015). 'Managing Sport for Social Change: The State of Play'. Sport Management Review 18(1): 15.

Silk, M.L. \& Andrews, D.L. (2012). 'Sport and the Neoliberal Conjuncture: Complicating the Consensus'. In: Andrews, D.L. \& Silk, M.L. (eds.) Sport and Neoliberalism. Politics, Consumption, and Culture (1-22). Philadelphia: Temple University Press.

Sjöblom, Y. (2012). 'Ungdomsproblem och ungdomars problem'. In: Höjer, I., Sallnäs, M. \& Sjöblom, Y. (eds.) När sambället träder in - barn, föräldrar och social barnavård (119-148). Lund:

Studentlitteratur.

Smith, A. \& Waddington, I. (2004). 'Using "Sport in the Community Schemes" to Tackle Crime and Drug Use among Young People: Some Policy Issues and Problems'. European Physical Education Review 10(3): 279-298.

Soydan, H. (2012). 'Understanding Social Work in the History of Ideas'. Research on Social Work Practice 22(5): 468-480.

Spaaij, R. (2009). 'Sport as a Vehicle for Social Mobility and Regulation of Disadvantaged Urban Youth: Lessons from Rotterdam'. International Review for the Sociology of Sport 44(2-3): 247264.

Spaaij, R (2013). 'Changing People’s lives for the Better? Social Mobility through Sport-based Intervention Programmes: 
Opportunities and Constraints'. European Journal for Sport and Society 10(1): 53-73.

Spaaij, R. \& Jeanes, R. (2012). 'Education for social change? A Freirean critique of sport for development and peace'. Physical Education and Sport Pedagogy 18 (4): 442-457.

Spaaij, R., Oxford, S. \& Jeanes, R. (2016). 'Transforming communities through sport? Critical pedagogy and sport for development'. Sport, Education and Society 21(4): 570-587.

Sparr, A. (2015). 'Idrott, integration och medborgarskap. Om idrottsprojekt som integrationsskapande styrningsteknik' [Bachelor thesis]. Linköping: Linköping University.

Spector, M. \& Kitsuse, J.I. (1987). Constructing Social Problems. New York: Aldine de Gruyter.

Stenling, C. (2014a). 'Sport Programme Implementation as Translation and Organizational Identity Construction: The Implementation of Drive-In Sport in Swedish Sports as an Illustration'. International Journal of Sport Policy and Politics 6(1): 5569.

Stenling, C. (2014b). 'The Emergence of a New Logic? The Theorizing of a New Practice in the Highly Institutionalized Context of Swedish Voluntary Sport'. Sport Management Review 17(4): 507-519.

Stenling, C. (2015). The Drive for Change: Putting the Means and Ends of Sport at Stake in the Organizing of Swedish Voluntary Sport [PhD thesis]. Umeå: Umeå University.

Stenson, K. (2005). 'Sovereignty, Biopolitics and the Local Government of Crime in Britain'. Theoretical Criminology 9(3): 265287.

Sugden, J. \& Yiannakis, A. (1982). 'Sport and Juvenile Delinquency: A Theoretical Base'. Journal of Sport and Social Issues 6(1): 22-30. 
Sullivan, T.J. \& Thompson, K.S. (1994). Introduction to Social Problems, $3^{\text {rd }}$ edition. London: Macmillan.

Sunesson, S., Blomberg, S., Edebalk, P.G., Harrysson, L., Magnusson, J., Meuwisse, A., Petersson, J. \& Salonen, T. (1998). 'The Flight from Universalism'. European Journal of Social Work 1(1): 19-29.

Svedberg, L. \& Olsson L.E. (2010). 'Civil Society and Welfare Provision in Sweden: Is There Such a Thing?' In: Zimmer, A. \& Evers, A. (eds.) Third Sector Organizations Facing Turbulent Environments: Sport, Culture and Social Services in Five European Countries (225-251). Baden-Baden: Nomos.

Svedberg, L. \& Vamstad, J. (2006). 'Swedish Civil Society and the Provision of Welfare: Ideological Visions and Social Realities'. In: Matthies, A.L. (ed.) Nordic Civic Society Organizations and the Future of Welfare Services: A Model for Europe (233-254). Tema Nord 2006: 517. Copenhagen: Nordic Council of Ministers.

Svensson, P.G., Hancock, M.G. \& Hums, M.A. (2016). 'Examining the educative aims and practices of decision-makers in sport for development and peace organizations'. Sport, Education and Society 21(4): 495-512.

Swedish Research Council. (2002). 'Forskningsetiska principer inom humanistisk-samhällsvetenskaplig forskning'. Available at: http://www.codex.vr.se/texts/HSFR.pdf [Accessed 10 May 2016].

Thörn, H. \& Larsson, B. (2012). 'Conclusions: Re-Engineering the Swedish Welfare State'. In: Larsson, B., Letell, M. \& Thörn, H. (eds.) Transformations of the Swedish Welfare State (262-282). New York: Palgrave MacMillan.

Trägårdh, L. (1990). 'Swedish Model or Swedish Culture?' Critical Review 4(4): 569-590.

Trägårdh, L. (2013a). 'Det civila samhällets välfärdstjänster - Sverige i ett jämförande perspektiv'. In: Swärd, H., Edebalk, P-G. \& 
Wadensjö, E. (eds.) Vägar till välfärd - idéer, inspiratörer, kontroverser, perspektiv (300-308). Stockholm: Liber.

Trägårdh, L. (2013b). 'Statsindividualismen och civilsamhället'. In: Trägårdh, L. Selle, P. Skov Henriksen, L. \& Hallin, H. (eds.) Civilsambället klämt mellan stat och capital. Välfärd, maingfald, framtid (33-48). Stockholm: SNS Förlag.

Turunen, P. (2009). 'Nordic Community Work in Transition'. In: Hutchinson, G.S. (ed.) Community Work in the Nordic Countries New Trends (38-63). Oslo: Universitetsforlaget.

Ulmanen, P. (2015). Omsorgens pris $i$ àtstramningstid. Anbörigstöd för äldre ur ett könsperspektiv [PhD thesis]. Stockholm: Stockholm University.

UNODC (United Nations Office on Drugs and Crime). (2014). 'Message by Mr. Wilfried Lemke, Special Adviser to the SecretaryGeneral on the Sport for Development and Peace'. Available at: https://www.unodc.org/video/e-lectures/002\%20lemke.flv [Accessed 10 May 2016].

UNODCCP (United Nations Office for Drug Control and Crime Prevention). (2002). 'Sport: Using Sport for Drug Abuse Prevention'. Available at: http://www.unodc.org/pdf/youthnet/handbook_sport_english.p df [Accessed 10 May 2016].

Verdot, C. \& Shut, P.O. (2012). 'Sport and Social Inclusion: The Political Position vs. Practices'. European Journal for Sport and Society 9(3): 203-227.

Vesterberg, V. (2016). Ethnicizing Employability: Governing the Unemployed in Labour Market Projects in Sweden [PhD thesis]. Linköping: Linköping University.

Veyne, P. (2010). Foucault: His Thought, His Character. Cambridge: Polity Press.

Villadsen, K. (2004). Det sociale arbejdes genealogi. Om kampen for att gøre fattige og udstødte til frie mennesker. København: Hans Reitzels Forlag. 
Villadsen, K. (2007). 'The Emergence of "Neo-Philanthropy": A New Discursive Space in Welfare Policy?' Acta Sociologica 50(3): 309-323.

Villadsen, K. (2008). 'Doing without State and Civil Society as Universals: "Dispositifs" of Care Beyond the Classic Sector Divide.' Journal of Civil Society 4(3): 171-191.

Villadsen, K. (2009). 'The "Human" Touch: Voluntary Organizations as Rescuers of Social Policy'. Public Management Review 11(2): 217-234.

Villadsen, K. (2011a). 'Freedom as Self-Transgression: Transformations in the Governmentality of Social Work'. European Journal of Social Work 11(2): 93-104.

Villadsen, K. (2011b). 'Modern Welfare and "Good Old" Philanthropy. A Forgotten or a Troubling Trajectory?' Public Management Review 13(8): 1057-1075.

Villadsen, K. (2011c). 'Neo-Philanthropy'. Social Work and Society 9(2): 1-3.

Villadsen, K. \& Dean, M. (2012). 'State-Phobia, Civil Society, and a Certain Vitalism’. Constellations 19(3): 401-420.

Wagnsson, S. (2009). Föreningsidrott som socialisationsmiljö [PhD thesis]. Karlstad: Karlstad University.

Waldron J.J. \& Kowalski C. (2009). 'Crossing the Line: Rites of Passage, Team Aspects, and Ambiguity of Hazing'. Research Quarterly for Exercise and Sport 80(2): 291-302.

Walters, W. (2012). Governmentality: Critical Encounters. London: Routledge.

Webb, S.A. (2006). Social Work in a Risk Society: Social and Political Perspectives. New York: Palgrave MacMillan. 
Wicks A., Beedy, J.P., Spangler, K.J. \& Perkins, D.F. (2007). 'Intermediaries Supporting Sports-Based Youth Development Programs'. New Directions for Youth Development 115: 107-118.

Wijk, J. (2001) 'Idrott, ungdom och “dansbaneelände”: om den svenska idrottsrörelsens begynnande engagemang som ungdomsfostrare på 1940-talet'. Idrott, historia och sambälle 2001: 85111.

Wijkström, F. (2012). 'Hybrider i civilsamhället. När filantropiskan och ekonomiskan kom till byn'. In: Wijkström, F. (ed.) Civilsambället och sambällskontraktet. En antologi om vad som står på spel (93-122). Stockholm: European Civil Society Press.

Wiklund, S. (2011), 'Individ- och familjeomsorgens välfärdstjänster'. In: Hartman, L. (ed.) Konkurrensens konsekvenser. Vad händer med svensk välfärd? (111-145). Stockholm: SNS Förlag.

Williams, D.J., Strean, W.B. \& Bengoechea, E.G. (2002). 'Understanding Recreation and Sport as a Rehabilitative Tool within Juvenile Justice Programs'. Juvenile and Family Court Journal 53(2): 31-41.

Winman, T. \& Hermansson, H-E. (2008). 'Skola, social integration och pedagogik'. In: Molin, M., Gustavsson, A. \& Hermansson, HE. (eds.) Meningsskapande och delaktighet. Om vår tids socialpedagogik (251-262). Göteborg: Daidalos.

Winther Jørgensen, M. (2002). Reflexivitet og kritik. Socialkonstuktionistiske subjektpositioner. Fredriksberg: Roskilde Universitetsforlag.

Winther Jørgensen, M. \& Phillips, L. (2000). Diskursanalys som teori och metod. Lund: Studentlitteratur.

Wirén Åkesson, J. (2014). Idrottens akademisering: Idrottsvetenskaplig kunskap inom forskning, utbildning och arbetsmarknad [PhD thesis]. Malmö: Malmö University.

Young, K. (2002). 'From "Sports Violence" to "Sports Crime": Aspects of Violence, Law, and Gender in the Sports Process'. In: 
Gatz, M., Messner, M.A. \& Ball-Rokeach, S.J. (eds.) Paradoxes of Youth and Sport (207-224). Albany: State University of New York Press. 


\section{Articles}

The articles associated with this thesis have been removed for copyright reasons. For more details about these see:

http://urn.kb.se/resolve?urn=urn:nbn:se:liu:diva-130783 